\title{
Habitat use and population viability of the Red Kite (Milvus milvus) in Germany
}

\author{
Dissertation \\ for the award of the degree \\ "Doctor rerum naturalium" Dr. rer. nat. \\ Division of Mathematics and Natural Sciences \\ of the Georg-August-Universität Göttingen \\ within the doctoral program Biology \\ of the Georg-August University School of Science (GAUSS) \\ submitted by \\ Jakob Kaspar Katzenberger \\ from Schwalmstadt (j. Ziegenhain), Germany
}

Göttingen, 2021 
Thesis Committee:

Prof. Dr. Matthias Waltert, Conservation Biology/Workgroup on Endangered Species, JohannFriedrich-Blumenbach Institute of Zoology and Anthropology

Prof. Dr. Niko Balkenhol, Wildlife Sciences, Faculty of Forest Sciences and Forest Ecology

Dr. Eckhard Gottschalk, Conservation Biology/Workgroup on Endangered Species, Johann-FriedrichBlumenbach Institute of Zoology and Anthropology

\section{Members of the Examination Board:}

Reviewer: Prof. Dr. Matthias Waltert, Conservation Biology/Workgroup on Endangered Species, Johann-Friedrich-Blumenbach Institute of Zoology and Anthropology

Second Reviewer: Prof. Dr. Niko Balkenhol, Wildlife Sciences, Faculty of Forest Sciences and Forest Ecology

\section{Further Members of the Examination Board:}

Dr. Eckhard Gottschalk, Conservation Biology/Workgroup on Endangered Species, Johann-FriedrichBlumenbach Institute of Zoology and Anthropology

Prof. Dr. Johannes Kamp, Department of Conservation Biology

Prof. Dr. Andreas Schuldt, Forest Nature Conservation, Faculty of Forest Sciences and Forest Ecology

Prof. Dr. Christoph Leuschner, Plant Ecology and Ecosystems Research, Albrecht-von-Haller-Institute for Plant Sciences

Date of the oral examination: 29.03 .2021 


\section{Table of contents}

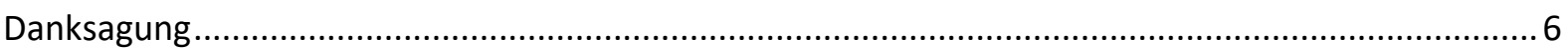

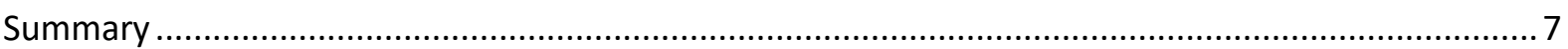

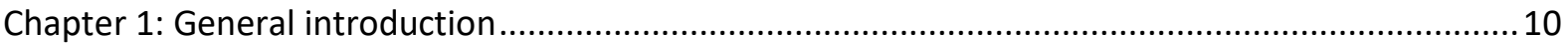

1.1 Rise and fall of the Red Kite in Europe and in Germany ..................................................... 10

1.2 The Red Kite: A sentinel for human impacts? ...................................................................... 11

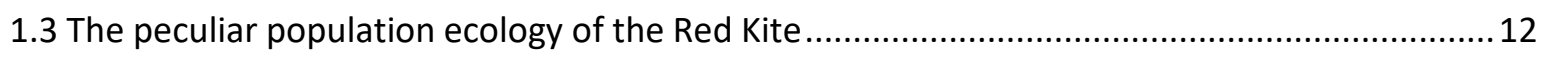

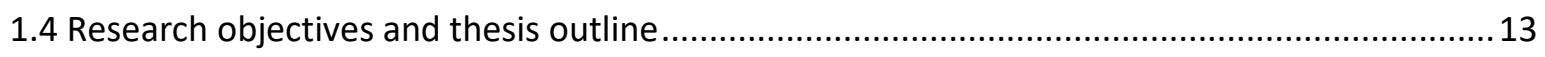

Chapter 2: An estimation of age-specific survival rates in the German Red Kite population from 1970-2015

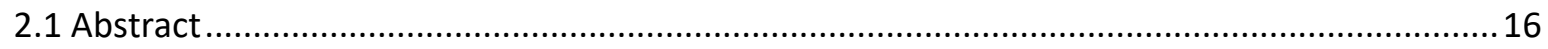

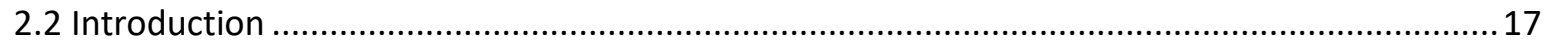

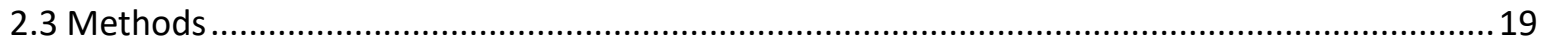

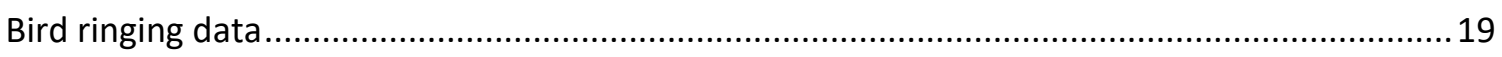

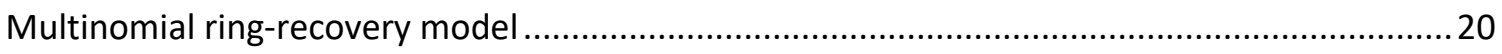

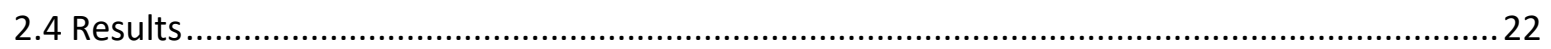

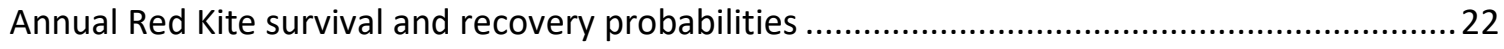

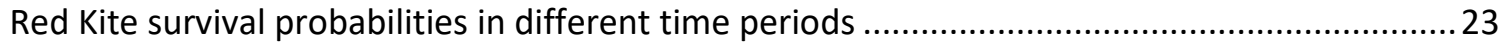

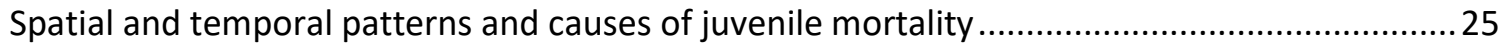

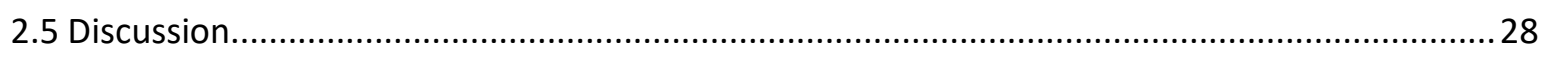

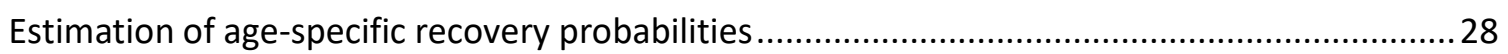

Survival probabilities over time in the German Red Kite population .........................................29

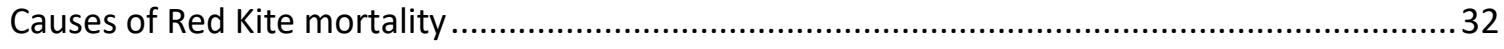

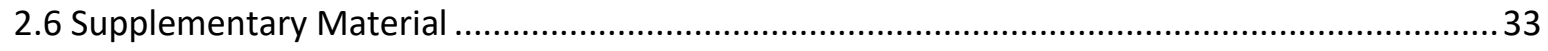

Chapter 3: A model of distribution and habitat suitability for the Red Kite in Germany .....................37

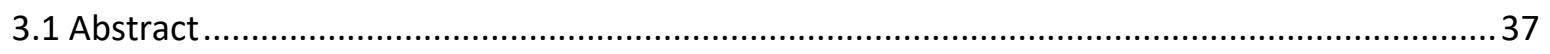

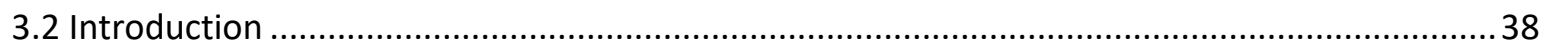


3.3 Methods.

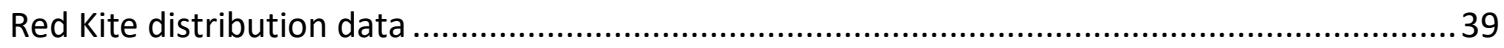

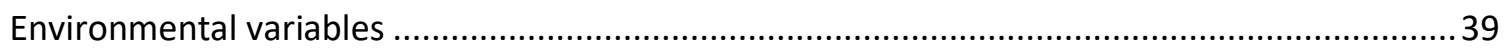

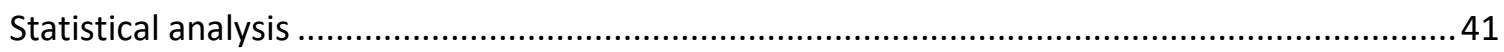

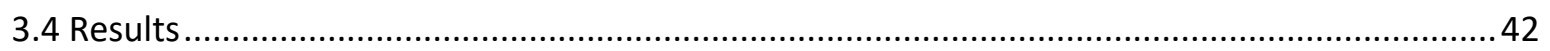

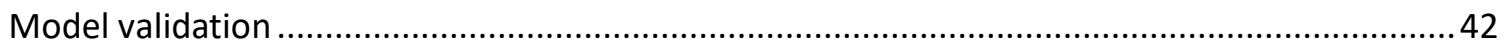

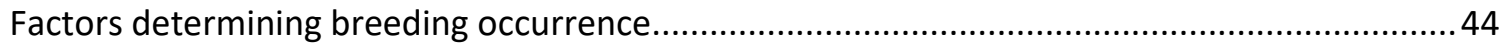

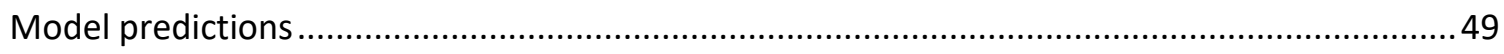

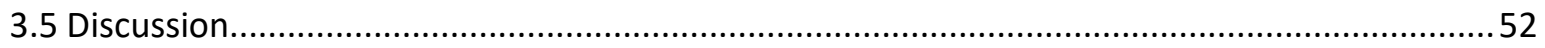

Chapter 4: A reconstruction of the long-term population dynamics for the Red Kite in Germany ......55

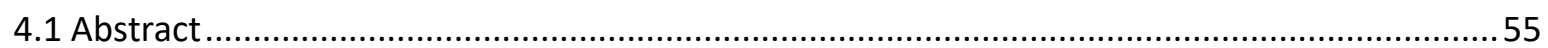

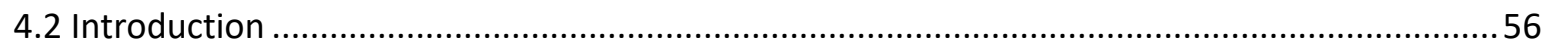

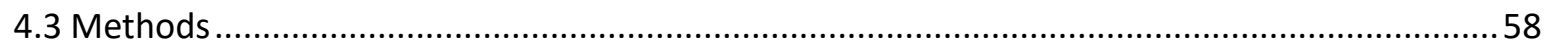

Estimating density-dependent age of first reproduction for the Red Kite ...................................58

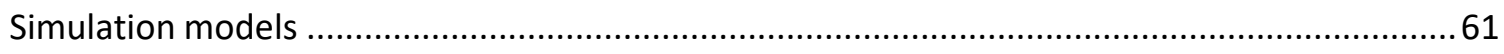

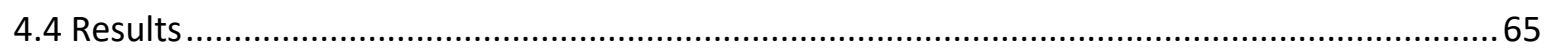

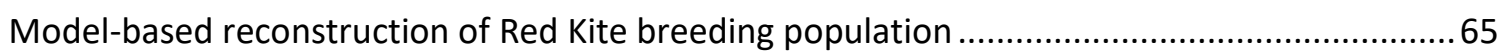

Population dynamics and density-dependent age of first reproduction....................................67

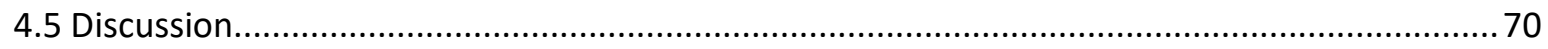

Density-dependent age of first reproduction ..................................................................... 70

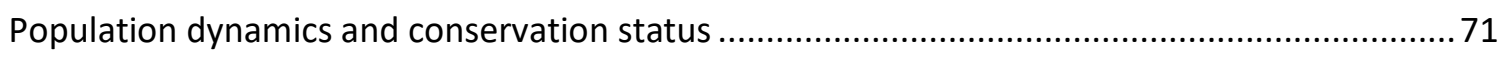

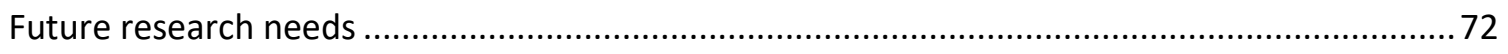

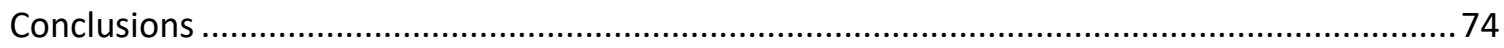

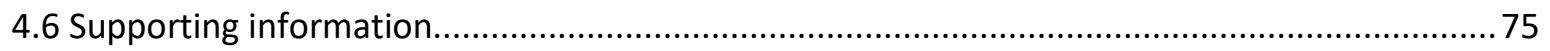

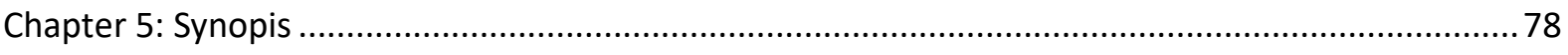

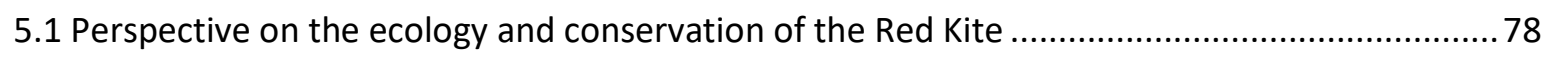

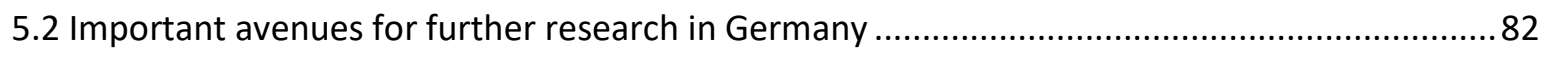

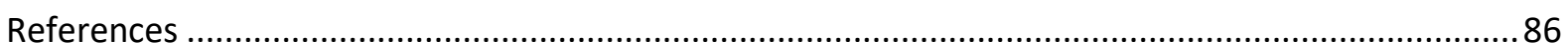


Declaration. 


\section{Danksagung}

Zunächst möchte ich mich für die durchgängige Unterstützung während der vergangenen vier Jahre bei meinen Betreuern Eckhard, Matthias und Niko bedanken. Nicht nur habt ihr meine Promotion fachlich betreut und hilfreiche Anregungen einfließen lassen, sondern auch darüber hinaus konnte ich immer auf eure Hilfe zählen und wir hatten ein sehr gutes und vertrauensvolles Verhältnis. Dafür danke ich euch von Herzen!

Ebenso möchte ich dem DDA und insbesondere Christoph dafür danken, dass er das Promotionsvorhaben im Zusammenhang mit meiner beruflichen Anstellung ermöglicht hat. Ohne deine kontinuierliche Unterstützung, Christoph, wäre dieses Ziel ebenfalls nicht erreichbar gewesen daher auch dir ein großes Dankeschön! Meinen aktuellen und ehemaligen Kolleginnen und Kollegen beim DDA danke ich für das tolle Miteinander und vielfältige inhaltliche Anregungen und Diskussionen, die meine Arbeit und meinen Horizont bereichern. Den Weggefährten und Weggefährtinnen der fachlichen Arbeit mit dem Rotmilan in den verschiedenen Projekten der vergangenen Jahre gilt ebenso ein großer Dank für eine gute Zusammenarbeit.

Als persönliche Stütze und Begleitung auf diesem langen Weg bist natürlich zuerst du zu nennen, Sarah. Danke, dass du stets an mich geglaubt hast, mich ermutigt hast und mir die Kraft gegeben hast dieses persönliche Projekt Schritt für Schritt und Tag für Tag umzusetzen. Danke einfach, dass du für mich da bist! Um den Antrieb und die Motivation über die Jahre hochzuhalten, waren mir meine Freunde und insbesondere Tom, Jannes, Jacques, Natalie und Marc, die ebenfalls ein solches Mammut-Vorhaben durchleb(t)en, immer eine große Hilfe. Danke für eure Freundschaft und die Unterstützung die ich daraus ziehen konnte! Meiner Familie und insbesondere meinen Eltern möchte ich dafür danken, dass Ihr mir meine Ausbildung, meinen Lebensweg und meine Freiheit ermöglicht habt. Ohne euch wäre ich nicht bis hierhin gekommen! 


\section{Summary}

The Red Kite (Milvus milvus) is a European near-endemic raptor species and due to its limited distribution and small global population size in the focus of national and international conservation efforts. Even within Europe, the distribution of the Red Kite is strongly restricted and the majority of the species' breeding and wintering populations, especially in Germany and Spain, showed declines over the last decades. In contrast, some reintroduced or formerly marginal Red Kite populations, especially in in the UK, Switzerland and Sweden, showed increasing populations in recent years. Red Kites are opportunistic scavengers in the agricultural landscape and the species has seen a changeful history of population increase and decline, strongly linked to human cultivation of farmlands and anthropogenic mortality. In comparison to other raptors and considering its intermediate size, the Red Kite is an extremely long-lived and highly social bird species - which strongly affects its demography and distribution. Although mortality of adult breeding individuals has by far the strongest impact on Red Kite population growth rates, demographic data and studies on age-specific survival rates are lacking - limiting the understanding of the species' population trends. Also, the impact of apparent strong philopatry on breeding occurrence and population development of Red Kites as well as the consequences of a propensity for delayed recruitment ('floating' behaviour) are currently not well understood.

The aim of this doctoral thesis is to synthesise data on Red Kite demography and distribution from Germany with current analytical methods, to increase the understanding of central demographic rates and to describe crucial influencing variables for the species' breeding occurrence. The results are expected to inform conservation and research on the Red Kite in Germany and to contribute to a scientific basis for evidence-based management in the future.

Chapter $\mathbf{2}$ addresses the lack of recent age-structured survival estimates for the Red Kite in Germany. Using a long-term dataset of nearly 30,000 Red Kites marked with metal rings and about 1500 dead recoveries of these individuals, we estimate age-specific survival probability over nearly 50 years in a major part of the German Red Kite population. With a multinomial ring-recovery model, we consider age-dependent recovery probability, based on separate datasets of birds marked as nestlings and as adults/immatures, and thereby estimate juvenile, subadult and adult survival probability over time. The results showed a substantial long-term decline in Red Kite juvenile survival of more than $40 \%$ from the 1970s until today. Furthermore, from years 1974-2014 adult survival probability showed a consistently decreasing trend (-0.26 \% p.a.). The recovery probability for dead Red Kites in the first year (as juveniles) was estimated as being two times lower than for birds that reach subadult/adult age classes, which could be related to differing causes or locations of death in the first year of life. 
The spatiotemporal patterns in juvenile Red Kite recoveries suggested an increase in mortality at the breeding grounds, but in $>60 \%$ of the cases the cause of death was unknown or not reported. To understand which factors are driving changes in survival of the Red Kite, age-dependent causes of mortality need further study. This work lays the foundation for further analyses of Red Kite population viability in this thesis and it allows to study annual variation in Red Kite survival and its potential drivers in the future.

Chapter 3 examines how environmental factors and local correlation patterns shape the breeding distribution of the Red Kite in Germany. Based on a national-scale population survey, with more than 6,000 breeding occurrences and high-resolution data on land use, habitat structure and climate variables, it decomposes environmental variability and spatial correlation and derives predictions of habitat suitability and probability of occurrence for the Red Kite in Germany. To account for spatial autocorrelation in the distribution data, a hierarchical model was used which corrects the model estimates using random effects ('Gaussian random fields'). The model results showed very good predictive accuracy (AUC $=0.89$ ) and explained $64.6 \%$ of the variability in the distribution data, of which more than half was attributable to the environmental variables. Local occurrence of the Red Kite was strongly influenced by agricultural use and habitat diversity, but also by human disturbance. A high proportion of grassland in the surroundings, but also arable fields paired with woody margins (groves, hedges etc.) strongly increased the probability of a Red Kite nest being present. In addition, the results showed a substantial negative effect of agricultural intensification on the occurrence of the Red Kite, measured by the density of livestock farming. Model predictions of habitat suitability confirmed the need of a spatially comprehensive approach for protection in Germany, while the actual distribution of the Red Kite in some areas also deviated substantially from the model predictions. The work underlines and extends previous evidence on important habitat characteristics for the Red Kite, which is necessary for well-targeted habitat improvements, but also opens new possibilities to identify essential habitats for effective spatial protection measures.

Chapter 4 investigates the total population dynamics of the Red Kite in Germany using an agestructured demographic model. Based on the survival estimates from chapter 2 and published data on reproduction, we reconstructed key features of the population development over nearly 40 years in different age classes, including also non-breeding ('floater') individuals. Because recruitment age is a key demographic factor and varies substantially across Red Kite populations, we also considered a simple density-dependent function for age of first reproduction based on the literature in different model scenarios. The simulations showed a drastic decrease of juvenile and non-breeding individuals in the Red Kite population over time - driven both by declining vital rates and a density-dependent shift towards a younger age of first breeding. 
This process was however not visible when judged by the size of the breeding population, which our model estimated to be of similar size today as in the 1980s. The total Red Kite population, including also non-breeding and juvenile individuals, was reduced to nearly $50 \%$ of its former size in our reconstruction. Comparing the different model scenarios with existing estimates of breeding population size in Germany suggested that age of first reproduction for the Red Kite most likely varies non-linearly with density. Such a general feedback mechanism has largely been overlooked in previous studies but should be considered for improving the robustness of demographic simulations. The model reconstruction also highlights that conservation assessments for long-lived bird species, with a propensity for floating behaviour, profit from further demographic data and modelling procedures to avoid overlooking potentially cryptic population declines. 


\section{Chapter 1: General introduction}

\subsection{Rise and fall of the Red Kite in Europe and in Germany}

The Red Kite (Milvus milvus) is a raptor species occurring in a highly restricted distribution nearly limited to the European continent, which is home to $>95 \%$ of the species' global population (BirdLife International 2019; Aebischer and Sergio 2020). As such a near-endemic species, the Red Kite is in the focus of international (esp. Annex I EU Birds Directive, Knott et al. 2009) and national protection efforts (e.g. Carter 2019; Deutsche Wildtier Stiftung 2020) to ensure the long-term conservation of the currently around 25,000-33,000 breeding pairs (BirdLife International 2019).

Within the European range of the Red Kite, the main breeding area extends from the Iberian Peninsula to central Europe, concentrated especially in Germany which harbours about $50 \%$ of all breeding pairs, but separated from further breeding occurrences in southern Italy, Sweden, the U.K. and eastern Europe (BirdLife International 2019). As the species is partially migratory, most individuals are found in the western parts of the range during winter, especially in Spain and southern France, but some individuals also winter in the central European breeding areas (Aebischer 2009; Karthäuser et al. 2019b).

The Red Kite forages opportunistically in open farmland habitats by scavenging dead prey remains as well as hunting small mammals or (juvenile) birds and it therefore prefers heterogeneous agricultural landscapes with a considerable proportion of grassland - where prey is both abundant and accessible (Knott et al. 2009). The Red Kite population has seen a changeful history over the last centuries, with population decline and increase tightly linked to human activities: Due to the preference for low vegetation and open habitats, the Red Kite most likely profited strongly from the anthropogenic transformation of the landscape in medieval times, where large areas of forest were cleared for farmland (Ortlieb 1989). During this time the Red Kite was most likely very common, living in close proximity to humans and scavenging even in large cities (Aebischer 2009; Carter 2019). However, in the $18^{\text {th }}$ century a wave of relentless human persecution against raptors began and hunting, poisoning and nest destruction drove the Red Kite to near extinction by the early $20^{\text {th }}$ century (Ortlieb 1989; Carter 2019). In the second part of the $20^{\text {th }}$ century, changing attitudes led to subsiding persecution and eventually legal protection of raptors under the EU Birds Directive in the late 1970s, which in turn helped the Red Kite population to recover substantially - especially in the core breeding area Germany but also elsewhere in Europe (Ortlieb 1989; Aebischer 2009). In the early 1990s however, this recovery came to an end in the most important breeding and wintering areas of the Red Kite in Spain, France and Germany, when again anthropogenic impacts from illegal persecution, poisoning, agricultural 
intensification and more recently also collision with wind turbines negatively affected these major populations (Aebischer 2009; BirdLife International 2019).

Today, the majority of the European Red Kite population is still under threat from human impacts, but continuing increases especially in the formerly marginal breeding populations of Switzerland and Sweden, as well as the reintroduced population in the U.K., apparently stabilised or even reversed the globally declining population trend of the Red Kite (BirdLife International 2020).

\subsection{The Red Kite: A sentinel for human impacts?}

Raptors are top predators, which prey on lower trophic groups in the food web and usually have large space requirements and home ranges - they are therefore generally treated as indicators of biodiversity and flagship species for conservation (Sergio et al. 2008). Although the role of top predators as indicators for biodiversity has been questioned, studies on raptors support the 'umbrella' function of these birds (Sergio et al. 2006; Roth and Weber 2007; Burgas et al. 2014; Senzaki et al. 2015). With its strong association to open farmland and agricultural landscapes, the Red Kite mainly depends on habitats where the decline of bird populations and biodiversity in general is particularly rapid and dramatic - both in Europe (Pe'er et al. 2014; PECBMS 2020) and in Germany (BfN 2017; Hallmann et al. 2017; Gerlach et al. 2019; Busch et al. 2020).

Because by far the largest proportion of the global Red Kite population breeds in Germany, the conservation of the species is an important aim on both national and federal levels, and the Red Kite is a national indicator species for agricultural habitats (Achtziger et al. 2004). Due to the dependence of breeding success and productivity on open farmland habitats, the species is thought to indicate changes in composition and use-intensity of agricultural landscapes (Nachtigall 2008). Agricultural intensification, especially loss of habitat diversity and increased pesticide application, affects the Red Kite negatively all over Europe (Knott et al. 2009). Non-target poisoning with chemical pest-control compounds and lead-poisoning are widespread threats for the Red Kite (Chollet et al. 2015; Molenaar et al. 2017; Ganz et al. 2018; Jacob et al. 2018; Badry et al. 2021) and the species could thus also be seen as a highly sensitive toxicological bioindicator (Carter and Grice 2000; Blanco and Bautista 2020).

Yet, the Red Kite is a highly adaptive scavenger which also feeds on human waste and which reacts positively to increased mowing-intensity in grasslands due to an increased availability of dead prey objects (Gottschalk et al. 2015; Bischofberger et al. 2019) - this has the potential for local conflicts between conservation measures for the Red Kite and other aspects of biodiversity (Joest 2018; Karthäuser et al. 2019a). Further, direct mortality of Red Kites from collisions, electrocution and illegal persecution severely affects the survival rates of the species and these threats most likely differ in 
intensity between central European breeding and Iberian wintering areas (Langgemach et al. 2010; Kolbe et al. 2019; Katzenberger et al. 2019a; Balmori 2019; Crespo-Luengo et al. 2020; Mateo-Tomás et al. 2020). Thus, at least for German Red Kite populations, major determinants of growth rate and the resulting population trends operate disjointly from the breeding habitats - which complicates the interpretation of Red Kite population development as an indicator for agricultural landscapes in the breeding areas. Rather than general population size, Red Kite feeding ecology, exposure to contaminants and ultimately reproduction and productivity likely show a closer link to biodiversity and intensity of use in the agricultural breeding habitats. Nevertheless, it is clear that the future population viability of the Red Kite in Europe is closely connected to man-made landscapes and their biodiversity as well as to anthropogenic causes of mortality - which calls for national and international cooperation and management to ensure the species' conservation (Bezzel 2010).

\subsection{The peculiar population ecology of the Red Kite}

Amidst the European raptor species, the Red Kite is of intermediate size - with a wingspan of 145-170 $\mathrm{cm}$ and a body weight of 860-1200 $\mathrm{g}$ for males and 950-1400 $\mathrm{g}$ for females (Aebischer 2009). Yet, the species is extremely long-lived, with individuals reaching ages $>30$ years in the wild and an estimated generation length of 11 years (BirdLife International 2019) - a value higher than $87 \%$ of all other Accipitridae raptors in the world and rivalling much larger species like some Aquila or Haliaeetus eagles or even Gyps vultures (Bird et al. 2020). This pronounced longevity explains in part why the population development of the Red Kite reacts highly sensitive to increased levels of mortality, especially of breeding adults (Tenan et al. 2012; Sergio et al. 2019a). This predisposition is so strong that proportionally (judged by elasticity analysis) the population growth rate of the Red Kite reacts 1020 times more strongly to variation in adult survival probability than to changes in fledgling productivity (Sergio et al. 2019a). Previous studies show that Red Kite survival varies with age and between different regions throughout Europe (Aebischer 2009; Newton et al. 2016; Sergio et al. 2019a). But, despite the crucial importance for a better understanding of Red Kite population dynamics, up-to-date survival rates for the species are mostly not available (Aebischer 2009; Bezzel 2010; Bairlein 2020).

The Red Kite is also a highly social bird, which congregates at roosting sites during the non-breeding season and dispersal as well as breeding occurrence of the species are strongly impacted by social factors (Aebischer 2009; Carter 2019). In Germany, the breeding distribution of the Red Kite shows strong spatial heterogeneity and correlation; likely at least in part due to social attraction, site fidelity and biogeographic history (Hothorn et al. 2011; Heuck et al. 2013). This means that local demography and population trends of the Red Kite are possibly not only affected by current changes in land use 
and other anthropogenic effects on the population vital rates but also by such changes in the past - a phenomenon also known as 'land-use legacies' (Foster et al. 2003; Perring et al. 2016). The degree as to how strongly land-use legacy or patterns of anthropogenic mortality in the past affect the current Red Kite population dynamics is however unknown.

Another aspect that likely relates to local habitat quality as well as to social factors is immigration and emigration between local breeding populations. These processes could be realised both by juvenile dispersal but also by older non-breeding individuals that have not yet acquired a mate and breeding territory - the so called 'floaters'. Floaters play a key role in better understanding and management of long-lived bird populations, which is especially well known for raptors (Penteriani et al. 2011). Yet, we currently lack understanding of the size of non-breeding Red Kite populations and the variation in age of first breeding, which can also markedly affect population development of raptors (Morandini et al. 2019). Because it is very time-consuming and a lot of effort to mark individuals in the field, we also currently do not know how much interplay and exchange really exists between neighbouring breeding populations of the Red Kite and if there are source-sink dynamics at play. Especially in relatively dense and interconnected breeding areas of the species, as in Germany, this could be highly relevant for local population trends.

\subsection{Research objectives and thesis outline}

Due to its European distribution and the strong association with human impacts, the Red Kite presents a unique opportunity to comprehensively study the ecology and population dynamics of a raptor species and the effects of conservation management on the continental scale. The major importance of the German breeding populations led to a large body of research on the species in the country, especially from eastern Germany which used to hold the world's highest Red Kite population densities (Nicolai and Kostrzewa 2001). Yet, much of that knowledge originates from the period of population recovery around the 1970s-1980s, is written in German language and hardly accessible to international readers. Data on the Red Kite is collected with great efforts by hundreds of volunteers in local bird ringing and monitoring initiatives and also in different federal or national research and conservation projects in Germany (Katzenberger et al. 2019b). However, there is still much potential to increase the cooperation between the different initiatives and to synthesise the existing data on larger spatial scales and thereby exponentiate the value for research and conservation. Also, the recent decade appears as the beginning of a new period for the Red Kite in Europe, with persistent as well as newly emerging threats but also substantial gains in formerly marginal breeding areas (BirdLife International 2020). Contributing timely, robust, and accessible research is therefore a major aspect 
of addressing the responsibility for the long-term conservation of the Red Kite in Germany and in Europe.

The aim of this doctoral thesis is to synthesise data on Red Kite demography and distribution from Germany by using current analytical methods. The core of this work consists of three scientific manuscripts which are concerned with habitat use and population biology of the Red Kite in Germany:

Chapter 2 addresses the lack of recent age-structured survival estimates for the Red Kite in Germany. It uses a long-term dataset of nearly 30,000 Red Kites marked with metal rings and the dead recoveries of these individuals to estimate juvenile, subadult and adult survival probability over nearly 50 years in a major part of the German Red Kite population. This work also lays an important foundation for further analyses of Red Kite population viability in this thesis and it allows to study annual variation in Red Kite survival and its potential drivers in the future.

Chapter 3 examines how environmental factors and local correlation patterns shape the breeding distribution of the Red Kite in Germany. Based on a national-scale population survey with more than 6,000 breeding occurrences and high-resolution data on land use, habitat structure and climate variables, it decomposes environmental variability and spatial correlation and derives predictions of habitat suitability and probability of occurrence for the Red Kite in Germany. The work underlines and extends previous evidence on important habitat characteristics for the Red Kite, which is necessary for well-targeted habitat improvements but also for effective spatial protection measures.

Chapter 4 investigates the total population dynamics of the Red Kite in Germany using an agestructured demographic model. Based on the survival estimates from chapter 2 and published data on reproduction, it reconstructs key features of the population development over nearly 40 years in different age classes, including also non-breeding individuals. The simulations highlight that age of first reproduction for the Red Kite most likely responds non-linearly to population density and that this general feedback mechanism should regularly be considered in demographic simulations. The results also illustrate a drastic decrease of juvenile and non-breeding individuals in the population over time, which is however not visible judging only by the size of the breeding population.

During the period of dissertation, I further contributed substantially to the following scientific articles on the Red Kite (articles in German, with English summary and captions):

Karthäuser, J., Katzenberger, J., \& Sudfeldt, C. (2019). Evaluation von Maßnahmen zur Verbesserung des Nahrungsangebotes für den Rotmilan Milvus milvus in intensiv genutzten Agrarlandschaften [Evaluation of agri-environmental schemes to enhance prey availability for the Red Kite Milvus milvus in intensively used agricultural landscapes]. Vogelwelt 139, 71-86. 
Brune, J., Krüger, O., Hippauf, E., Rösner, S., \& Katzenberger, J. (2019). Eine nichtinvasive Methode für Populationsstudien beim Rotmilan Milvus milvus: Molekulargenetische Individualerkennung anhand von Mauserfedern [Genetic fingerprinting from moult feathers: A non-invasive method for population studies with the Red Kite Milvus milvus]. Vogelwelt 139, 129-140.

Bischofberger, I., Kamrad, M. J., Wasmund, N., Sindl, L., Bayoh, R., Katzenberger, J., Laux, A., Müller, B., Horchler, B., Helms, F., Beining, F., Michels, P., Stricker, V., Krämer, M., \& Gottschalk, E. (2019). Werden junge Rotmilane Milvus milvus satt? - Nahrungsmengen und Nahrungszusammensetzung in drei Regionen Deutschlands [Enough food for the brood? Prey mass and prey composition in Red Kites Milvus milvus - video-recording in three regions in Germany]. Vogelwelt 139, 87-99. 


\section{Chapter 2: An estimation of age-specific survival rates in the German Red Kite population from 1970-2015}

Publication: Katzenberger, J., Gottschalk, E., Balkenhol, N. \& Waltert M. (2019): Long-term decline of juvenile survival in German Red Kites, Journal of Ornithology 160, 337-349, doi: 10.1007/s10336-018-1619-z

\subsection{Abstract}

The Red Kite (Milvus milvus) is a raptor species of conservation concern in Europe and especially in Germany, where about $50 \%$ of all breeding pairs are found. Agricultural intensification and deteriorating food availability, but also anthropogenic mortality by poisoning and collisions are major threats for the species throughout the strongly restricted distributional range. Despite the great influence of mortality on the population size of the long-lived Red Kite, information on current agespecific survival probabilities and their change over time is lacking. We analysed a long-term dataset of $>29,000$ Red Kites marked with metal rings and about 1500 recoveries of dead birds from 19702015 with a multinomial ring-recovery model. We model age-dependent recovery probability, based on separate datasets of birds marked as nestlings and as adults/immatures, and thereby estimate juvenile, subadult and adult survival probability over nearly 50 years in a major part of the German Red Kite population. The results show a substantial long-term decline in juvenile survival of more than $40 \%$ from the 1970 s until today. Furthermore, from years $1974-2014$ adult survival probability shows a consistently decreasing trend (-0.26 \% p.a.). We estimated recovery probability for dead Red Kites in the first year (as juveniles) being two times lower than for birds that reach subadult/adult age. Also, the recovery probabilities of all age classes showed a decreasing trend over time except for the last years. The spatial and temporal distribution of juvenile Red Kite recoveries suggests an increase in mortality at the breeding grounds, but in $>60 \%$ of the cases the cause of death is unknown. The agestructured differences in recovery probability potentially highlight differences in the most important causes of mortality, however further investigation of the cause of death in all ages classes is required to gain a more accurate picture. Our study provides valuable data towards a better understanding of Red Kite demography and ongoing changes in population size. 


\subsection{Introduction}

Studying demography is central to the conservation of animal populations, because effective management, aiming to improve population viability, depends on identifying which demographic parameters (e.g. survival, reproduction) are limiting population size (Newton et al. 2016). A widely used method to gain reliable estimates of survival in wild birds is marking of individuals with metal rings, to monitor the fate of individuals and infer from their life-time the survival probabilities of different age classes of a population (Baillie 2001).

The Red Kite (Milvus milvus) is a raptor species with a highly restricted distribution - it occurs almost exclusively in Europe and has a world population of only about 30,000 pairs (BirdLife International 2015). The main breeding grounds are in central Europe, with the stronghold Germany harbouring roughly $50 \%$ of all Red Kite breeding pairs (Gedeon et al. 2014; BirdLife International 2015). Because such a large proportion of the breeding population is based in Germany, the conservation of the species is an important aim on both national and federal levels, and the Red Kite is prioritised as an umbrella species for agricultural habitats (Achtziger et al. 2004). Population trends of the species differ within Europe, but declines in the core states Germany, France and Spain are only partly offset by increases in other countries within the last decades (Knott et al. 2009). Within Germany, the Red Kite is concentrated in the central and eastern parts of the country; but field surveys in the last 6-12 years showed that population size is gradually decreasing in these high-density areas, while apparently increasing in the south-west (Gedeon et al. 2014). Most of the German Red Kites migrate to France and the Iberian Peninsula in autumn, while only a small part of the breeding population overwinters in the country (Schönfeld 1984; Pfeiffer and Meyburg 2009).

Red Kites are known to be long-lived, with maximum ages for wild birds up to 30 years documented previously (Pfeiffer 2009; Bairlein et al. 2014). The life cycle of Red Kites can be partitioned into three stages: first year juveniles, second year subadults and all ages above two years as adults (Mammen et al. 2014). Previous studies show that Red Kite survival varies with age and between different regions throughout Europe (Aebischer 2009; Newton et al. 2016). The ring-recovery studies by Schönfeld (1984) and Pfeiffer (2009) investigated Red Kite survival in Germany with data from the 1960s-1970s, while a local study from 2000-2005 by Nachtigall (2008) additionally marked birds with wing tags for survival estimation. Approximation from these studies suggests that in Germany $>60 \%$ of the Red Kite juveniles survive the first year of life, while in the second year about $75 \%$ survive to reach the adult age class, where survival is then around $80 \%$ or more (Schönfeld 1984; Nachtigall 2008; Pfeiffer 2009). However, these survival estimates were gained using dated methods, ignoring imperfect detection (Kéry and Schaub 2012). 
If recovery probability differs according to age, but this is not considered during analysis, the resulting survival estimates either under- or overestimate true survival (depending on whether e.g. juveniles are more or less often recovered than older birds). Analyses of ringing data in Switzerland showed that dead juvenile Red Kites are found much less often than individuals which completed the first year of life (Aebischer 2009; Kéry and Schaub 2012).

The size of the German Red Kite population declined by 20-30\% since the early 1990s, however, over the past two decades it has fluctuated and remained relatively stable (Gedeon et al. 2014; Mammen 2016). A decrease in reproductive productivity is suspected as a main reason for the population decline in Germany (Mammen et al. 2014). The reduced productivity is attributed to agricultural intensification, which reduces foraging possibilities for the opportunistically scavenging Red Kite during the critical time of chick rearing in late spring (Nachtigall et al. 2010). The German reunification in 1989-1990, entailing profound changes in land-use and agriculture in eastern Germany, is perceived as a major turning point for the Red Kite population (George 1995; Mammen et al. 2014). Especially the loss of feeding habitats following unification of the two German states is often linked to the population decline in the 1990s (George 1995; Mammen et al. 2014).

In recent years, the species has also been identified as being under threat of collision with wind turbines, with the continuing expansion of onshore wind farm development possibly reaching demographically relevant levels of mortality for the Red Kite population (Bellebaum et al. 2013; Grünkorn et al. 2016; Busch et al. 2017). Other important causes of anthropogenic mortality threatening the survival of individuals are poisoning and direct persecution, both along the flyway and in the breeding grounds (Knott et al. 2009; Hirschfeld 2011). The use of rodenticides in agriculture especially threatens Red Kites by secondary poisoning (Berny and Gaillet 2008; Coeurdassier et al. 2012; Montaz et al. 2014; Molenaar et al. 2017). However, up-to-date population-level estimates of mortality for different age classes in the German breeding population are still lacking (Bezzel 2010).

Over the course of the last 50 years, great efforts by both professionals and volunteers have been undertaken in Germany to mark nearly 30,000 Red Kites in the nest with metal rings - allowing the study of individual survival histories and migratory behaviour after ring recovery (Schönfeld 1984; Pfeiffer 2009; Bairlein et al. 2014). Using current methods to draw on this wealth of existing long-term ringing data, the aim of this study was to estimate age-specific survival probabilities of the Red Kite population in Germany from 1970 until 2015. Reliable estimates of survival are one crucial parameter needed to inform the discussion about ongoing changes in population size. 


\subsection{Methods}

\section{Bird ringing data}

Data on the number of Red Kites fitted with metal rings in Germany and recoveries of dead birds were collated from the regional authorities Vogelwarte Hiddensee, Vogelwarte Helgoland and Vogelwarte Radolfzell. From 1970-2015 approximately 29,800 Red Kite juveniles (range per year: 140-1290, median: 690) were ringed in Germany, most individuals (>90 \%) were marked in eastern Germany with Vogelwarte Hiddensee rings. Ring recoveries from 1970-2015 provided data from 1470 marked Red Kites. The recoveries of dead birds were collected opportunistically, by gathering casualties with ring number and cause of death (if known) from reports by the general public. Most of the recovered birds ( $89 \%$ ) were marked with Hiddensee rings in eastern Germany, but among them were birds from the whole distributional range within Germany (Fig. S2.1, suppl. mat.). Of all 1470 recoveries, 1426 were birds marked as juveniles (1412 marked while still in the nest), of which 461 were recovered dead in the first year of life. Because it is much more difficult to capture and mark individuals once they have left the nest, the number of birds fitted with rings as adults or immatures represents only a small proportion of total marking effort. In this case around 900 adult/immature Red Kites were marked with Hiddensee or Helgoland rings from 1970-2015, of which 44 were recovered dead. Information on ringing effort was fully digitised in Hiddensee from 1977 onwards (pers. comm. U. Köppen), however the data presented in Schönfeld (1984) for the number of marked Red Kites in years 1970-1976 were used for reconstruction. Annual marking effort with rings from Vogelwarte Helgoland was available in detail from year 2000 onwards (pers. comm. O. Geiter). Since these data only represents a marginal amount of all Red Kites ringed in Germany, an approximation of the number of birds marked with Helgoland rings was used for years 1970-1999, according to summary statistics presented in Foken (2000). From a total of 2424 marked Red Kites (Foken 2000), we approximated an annual average of 44 ringed birds in years 1945-1999, with a percentage of immatures and adults of $12 \%$ (the average value from all three ringing authorities). This approximation was similar to the annual average of 38 birds marked with Helgoland rings thereafter (years 2000-2015). To assign the age of individuals since marking, the first of June (01.06.) was used as the start of a new year. If the exact age at marking was unknown (for all immatures and adults), ages represent the minimum age since marking. To assure that nestling mortality did not affect the analysis, we checked how many recoveries of juveniles were made in May-July close to the nest after being ringed in the same year. This amounted to 44 recoveries of which $80 \%$ were made after the year 2000 . Of these 44 recoveries, only $29 \%$ were made shortly after ringing (two weeks) and this only occurred in years 2005-2015. We are therefore certain that late nestling mortality did not substantially affect our analysis. 


\section{Multinomial ring-recovery model}

A Bayesian implementation of a ring-recovery model (Brownie et al. 1985) with Markov chain Monte Carlo sampling was used to estimate survival and recovery probabilities for the different Red Kite age classes following Kéry and Schaub (2012). If survival and recovery probability are age-dependent and individuals are only marked as juveniles, only adult survival is identifiable (Anderson et al. 1985). With a different number of age classes for survival and recovery probability and data on marked adults however, juvenile survival can be estimated (Kéry and Schaub 2012). We thus modelled the survival of the three age classes juveniles (1. year), subadults (2. year) and adults ( $>2$. year) separately, while recovery probability was distinguished between juveniles (1. year) and the two older age classes combined ( $>1$. year; Kéry and Schaub 2012). To show that with this model formulation all parameters are identifiable and can be estimated from ring-recovery data similar to our dataset, we include the results from simulations and the code to reproduce these as supplementary materials. All individuals marked at the same age and in the same year were treated as a release cohort. A non-informative prior (uniform distribution, interval 0-1) was used for all parameters. The likelihood was calculated from the number of birds recovered in each age class in each year - modelled as a multinomial trial, with index equal to cohort size and cell probabilities as a function of survival and recovery parameters (Tab. 2.1). All models were run in JAGS v. 4.2 .0 (Plummer 2003) via R v. 3.3.2 (R Core Team 2018) and package jagsUI v. 1.4.4 (Kellner 2016). The mixing of three chains was inspected visually and convergence was confirmed by Rhat values < 1.01 (Brooks and Gelman 1998; Kéry and Schaub 2012). To estimate annual survival probabilities from 1970-2015, independent survival for each year and age class was fitted for adult, subadult and juvenile survival, while recovery probabilities were modelled with a random year effect. The random year effect was specified on the logit scale as a normal distribution with mean zero and the between-year variance. For the latter, a uniform prior distribution between 0 and 5 was used for the standard deviation. To test if the mean annual survival probabilities of each age-class showed a trend over time, we used a precision-weighted linear regression. We implemented this with the metafor R package (Viechtbauer 2010), using the standard deviation of the posterior distribution as weights for the mean of the posterior distribution and report the slope estimate with a $95 \%$ confidence interval. To gain reliable estimates of survival for different time periods, allowing for age-specific recovery probabilities, we used a model with 5-year periods from 1970-2015 for survival and the same random time-effect formulation as before. To investigate if changes in survival probabilities over time are robust to the assumption that recovery probability differs with age, we fitted the same model estimating survival in the 5-year periods while assuming identical recovery probability for all age classes, again with recovery probability varying over time with a random year-effect. 
Tab. 2.1: Cell probabilities for multinomial trial used to estimate likelihood for parameters juvenile survival (sjuv), subadult survival (ssub), adult survival (sad), juvenile recovery (rjuv) and adult recovery probability (rad). Subscripts denote an index of time for each parameter, prod = product

\begin{tabular}{|c|c|c|c|c|c|}
\hline \multicolumn{6}{|c|}{ Recoveries marked as juveniles (with year $\mathrm{t}$ ) } \\
\hline Age & 1 & 2 & 3 & $\geq 4$ & $\begin{array}{l}\text { Never } \\
\text { recovered }\end{array}$ \\
\hline Probability & $\begin{array}{l}\left(1-\text { sjuvt }_{\mathrm{t}}\right)^{*} \\
\text { rjuvt }_{\mathrm{t}}\end{array}$ & $\begin{array}{l}\operatorname{sjuv}_{t}^{*}(1- \\
\left.\operatorname{ssub}_{t+1}\right) * \operatorname{rad}_{t+1}\end{array}$ & $\begin{array}{l}\operatorname{sjuv}_{\mathrm{t}}{ }^{*} \text { ssub }_{\mathrm{t}+1} * \\
\left(1-\mathrm{sad}_{\mathrm{t}+2}\right)^{*} \\
\operatorname{rad}_{\mathrm{t}+2}\end{array}$ & $\begin{array}{l}\operatorname{sjuv}_{t}{ }^{\text {ssub }_{t+1}} * \text { prod }\left(\text { sad }_{t+2: a g e-1}\right) * \\
\left(1-\text { sad }_{\text {age }}\right) * \text { rad }_{\text {age }}\end{array}$ & 1- rowsum \\
\hline \multicolumn{6}{|c|}{ Recoveries marked as adults (with year $\mathrm{t}$ ) } \\
\hline \multicolumn{2}{|c|}{ Age (since marking) } & 1 & $\geq 2$ & \multicolumn{2}{|c|}{ Never recovered } \\
\hline \multicolumn{2}{|l|}{ Probability } & $\left(1-\mathrm{sad}_{\mathrm{t}}\right) * \mathrm{rad}_{\mathrm{t}}$ & \multicolumn{2}{|c|}{$\operatorname{prod}($ sadt:age-1 $) *\left(1-\right.$ sad $\left._{\text {age }}\right) *$ rad $_{\text {age }}$} & \\
\hline
\end{tabular}




\subsection{Results}

\section{Annual Red Kite survival and recovery probabilities}

The estimated annual survival probabilities of all Red Kite age classes showed a substantial amount of variability between years, with the highest survival probabilities seen in the late 1970s and early 1980s (Fig. 2.1). Annual survival probabilities for most age classes could not be reliably estimated for the first and the last one or two years from the time-series (greyed-out in Fig. 2.1) and were thus not used for trend estimation. The adult survival estimates for years 1972-73 seem unrealistically low and should be treated cautiously. Survival of adult birds (in the third year and older) fluctuated between 0.79 and 0.85 until the mid-1980s, slightly decreased and remained stable around 0.79 until the year 1990, slowly increased up to 0.83 throughout the 1990 s and then declined steadily to values near 0.75 after the year 2000 (Fig. 2.1). Based on years 1972-2014 adult survival did not show a consistent trend (slope: $-0.17 \%, 95 \% \mathrm{Cl}:-0.37$ to $0.04 \%$ ). Excluding the unrealistic first two estimates (1972-73) for trend estimation however showed that from 1974-2014 adult survival declined annually by a mean of $0.26 \%$ (95\% Cl: -0.47 to $-0.05 \%$ ). Subadult birds in the second year of life varied strongly in their survival probabilities from year to year, with annual estimates spread around an average near 0.74 until the year 1995 and thereafter fluctuating around a lower average near 0.65 (Fig. 2.1). Subadult survival did not show a consistent trend from 1971-2013 (slope: $-0.26 \%, 95 \% \mathrm{Cl}$ : -0.54 to $0.02 \%$ ). Juvenile survival was relatively high (average 0.65) until the mid-1980s, declined to 0.51 after year 1984, briefly recovered, and then dropped further with the year 1990 close to 0.4 (Fig. 2.1).

Thereafter, survival of first year birds remained generally low - fluctuating around 40-50 \% survival probability, declining in the late 1990s and reaching a minimum of $26 \%$ in 2013. From years 19702014 juvenile survival showed a negative trend with an annual decrease by $0.66 \%$ (95 \% Cl: -0.94 to $-0.39 \%)$. Recovery probability for Red Kites older than one year (adults and subadults) continually declined from values near $12 \%$ in the early 1970 to a minimum near $5 \%$ in the year 1997, showing a slightly increasing trend again after the year 2005 (Fig. 2.1). Across all years, adult recovery probability was estimated with a mean of $7.2 \%$ (SE $0.8 \%$ ). The annual mean of juvenile recovery probability also declined markedly from 1970-1997, showing values approximately two times lower than adult recovery probability and similarly increased slightly after 2005 (Fig. 2.1). The mean of juvenile recovery for 1970-2015 was estimated at $3.7 \%$ (SE $0.5 \%$ ). 


\section{Red Kite survival probabilities in different time periods}

To reliably assess the temporal development of survival rates in the German population we estimated mean Red Kite survival over 5-year periods, together with the associated uncertainty and considering changing recovery probability. Mean survival probabilities were relatively high for all three age classes in 1970-1984, showing decreases over the following periods for all parameters but with differing magnitudes (Fig. 2.2). Adult survival probability dropped by 4.9 percentage points (pp) from $81.3 \%$ after 1984 , then increased up to $82 \%$ in the early 1990 s and then declined again below $80 \%$ after the year 2000. The uncertainty around the mean estimate increased over time and the $95 \%$ credible intervals (CI) from all periods overlapped (Fig. 2.2). Survival of subadult birds declined by $6.4 \mathrm{pp}$ from $77.5 \%$ after 1984, in the late 1990s it reached a minimum near $63 \%$ but subsequently increased again up to $70 \%$. As for adult survival, all periods overlapped in their $95 \% \mathrm{Cls}$ (Fig. 2.2). In contrast, a substantial decline in survival was seen for birds in the first year of life. Survival of juveniles in the 1970s was estimated at high levels, with mean values above $68 \%$ and lower $95 \%$ Cls near $58 \%$ (Fig. 2.2). Thereafter, during the 1980s, mean juvenile survival dropped in total by 24 percentage points and after 1984 showed no overlap of the upper $95 \% \mathrm{Cl}$ at $56.7 \%$ with the previous decade (Fig. 2.2). In the following period, after the German unification, mean juvenile survival decreased by another $13.9 \mathrm{pp}$ and thereafter remained at a minimum near $35 \%$ survival probability until 2009 (Fig. 2.2). The uncertainty around the mean estimate of juvenile survival also increased towards the end of the time series. In the last 5-year period until 2014, mean juvenile survival was estimated to increase up to 40 $\%$ (Fig. 2.2), but this suggestion of a positive trend contrasts with declines in juvenile survival after 2012 (Fig. 2.1). The increasing uncertainty and some differences between annual and periodic survival estimates towards the end of the time series indicated that not enough data were available to precisely estimate survival after the year 2010. Estimation of survival in the same 5-year periods with a model assuming identical recovery probability for all ages confirmed the long-term decrease of juvenile survival, but without separating recovery of first year birds in the model the onset of the decline was only seen later in the 1990s and with a smaller magnitude (decrease by 17 percentage points, Tab. S2.1, suppl. mat.). 

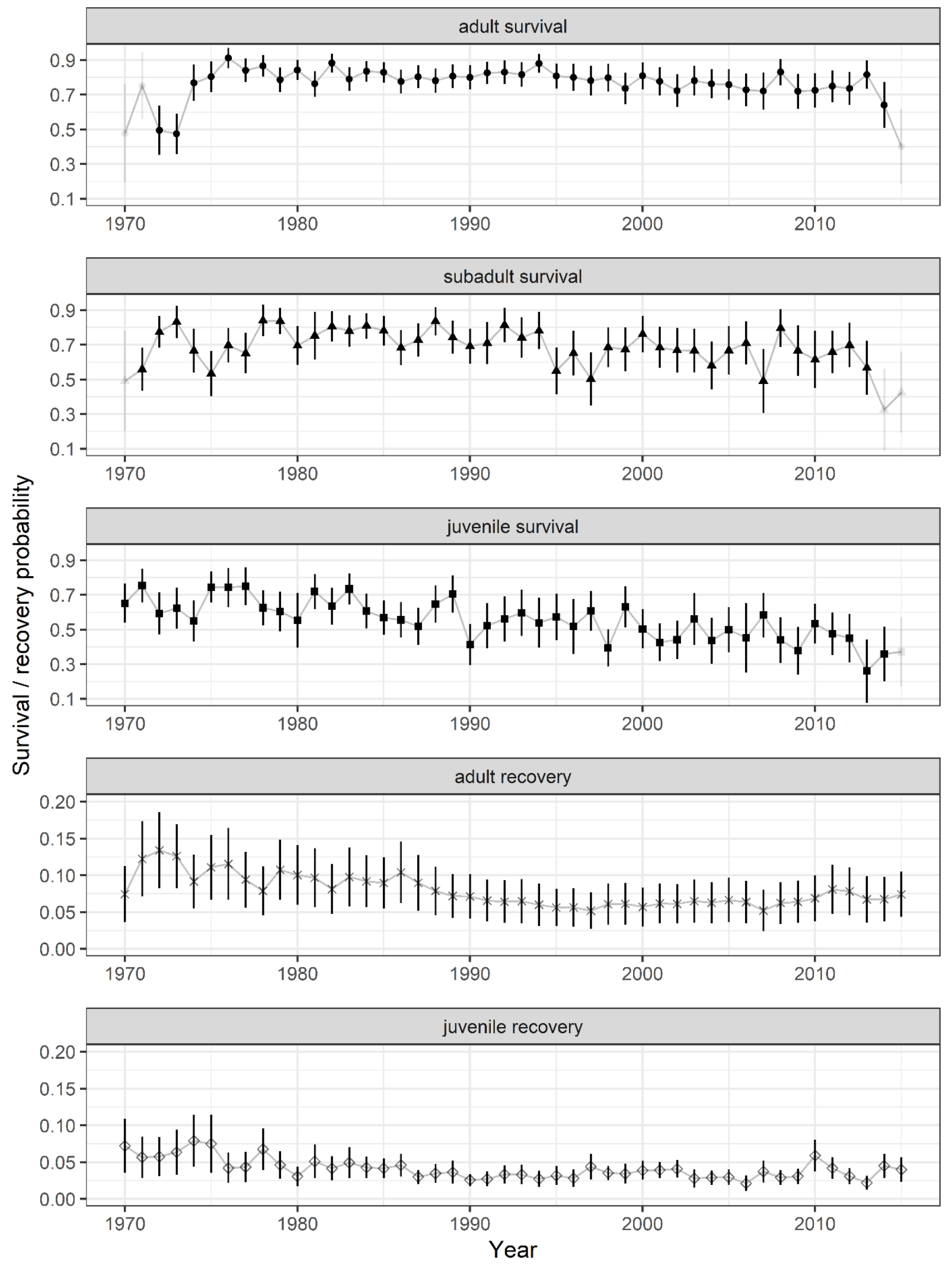

Fig. 2.1: Estimated annual survival probabilities for adult, subadult and juvenile Red Kites from 1970-2015. The survival estimates are conditional on estimates of recovery probability for juvenile birds and birds older than one year in the respective year. Error bars show \pm 1 standard deviation around the posterior mean - note the differing $y$-axes. Values coloured in light grey could not be estimated precisely and are only shown for the sake of completeness. The adult survival estimates for years 1972-73 seem unrealistically low and should be treated cautiously. 

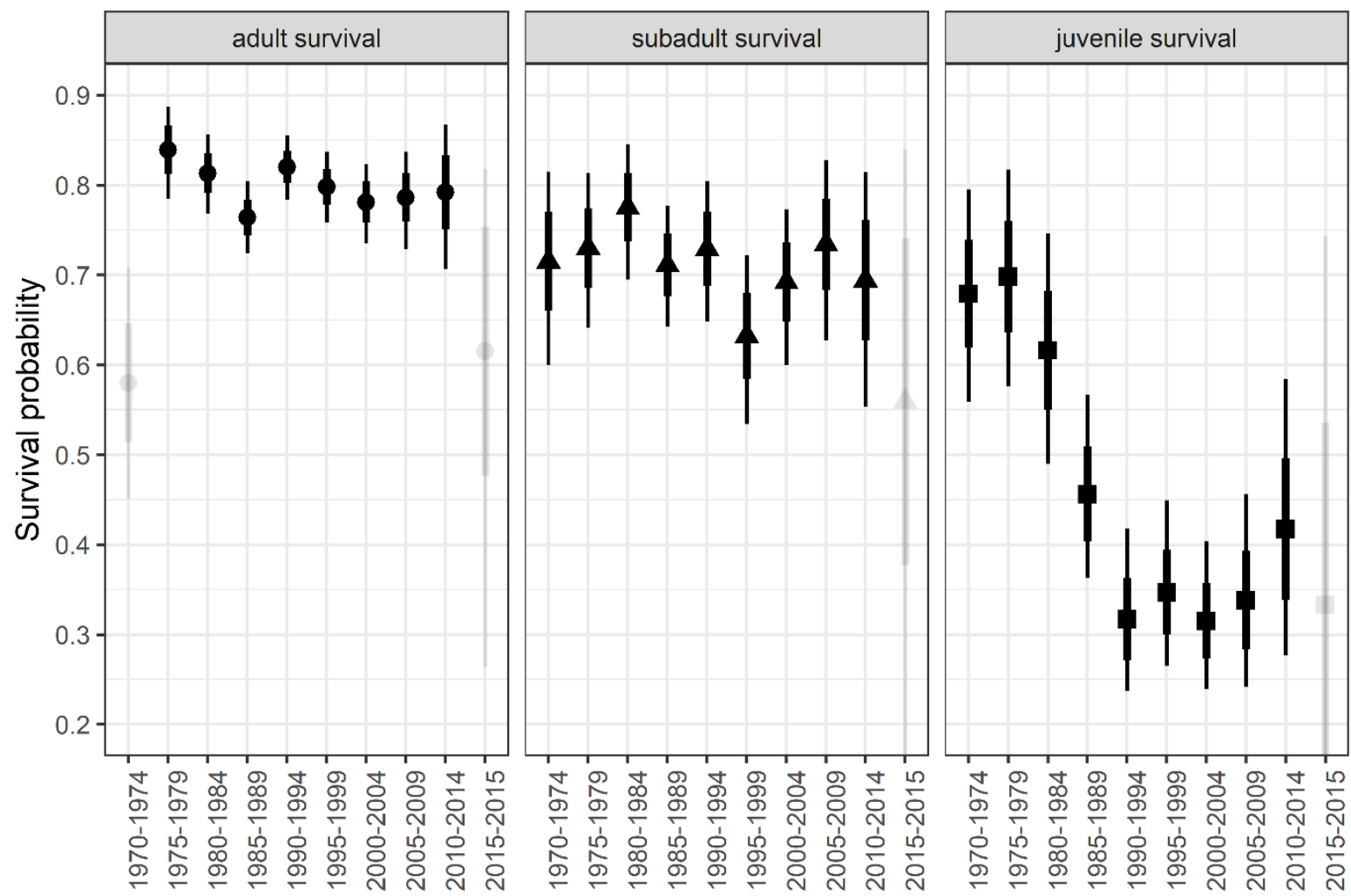

Time period

Fig. 2.2: Survival estimates of adult, subadult and juvenile Red Kites in 5-year periods from 1970-2015. The periodic survival estimates are conditional on annual estimates of recovery probability for juvenile birds and birds older than one year as shown in Fig. 2.1. Inner error bars show \pm 1 standard deviation around the posterior mean while outer error bars show a $95 \%$ credible interval. Values coloured in light grey could not be estimated precisely.

\section{Spatial and temporal patterns and causes of juvenile mortality}

The recovery dataset showed two Red Kites that reached a record age of 34 years, after being marked as nestlings in 1973 and 1978. Further analysis of the juvenile recoveries revealed that over time the proportion recovered dead near the location where they were marked strongly increased (Fig. 2.3-4). In years 1970-1985 a total of 112 birds ringed in Germany were recovered dead as juveniles, in 19862000 this amounted to 185 individuals and from 2001-2015 165 recoveries of juveniles were made. Between $34-51 \%$ of the recoveries of dead juveniles were made along the migratory route in France, Spain or Portugal during all time periods (Fig. 2.3), however over time more and more fatalities were reported less than $50 \mathrm{~km}$ away of ringing location in Germany (Fig. 2.4). Correspondingly, the distance of recovery to ringing location for dead juvenile Red Kites decreased significantly from 1970-2015 $\left(F_{1,408}=7.8, p=0.005 ;\right.$ Fig. S2.2, suppl. mat. $)$. The distribution of juvenile recoveries throughout the year showed a bimodal pattern in all time periods, with peaks in April and October (Fig. 2.5). In the last period, from 2001-2015, there was a clear increase in the recovery of juvenile fatalities in the fledging period at the end of the breeding season (late June, early July; Fig. 2.5). 
The cause of death reported for the ring recoveries of the juvenile Red Kites also changed over time, with mortality from collisions, poisioning and predation increasing (Fig. 2.6). For fatalities of first year birds within Germany (up to $50 \mathrm{~km}$ distance to the origin), predation showed an especially strong increase in reporting in the period 2001-2015 (Fig. 2.6B). However, in $60 \%$ of the cases or more the cause of death for the juvenile birds was unknown or not reported - showing only limited explanatory power to reliably assess causes of mortality.

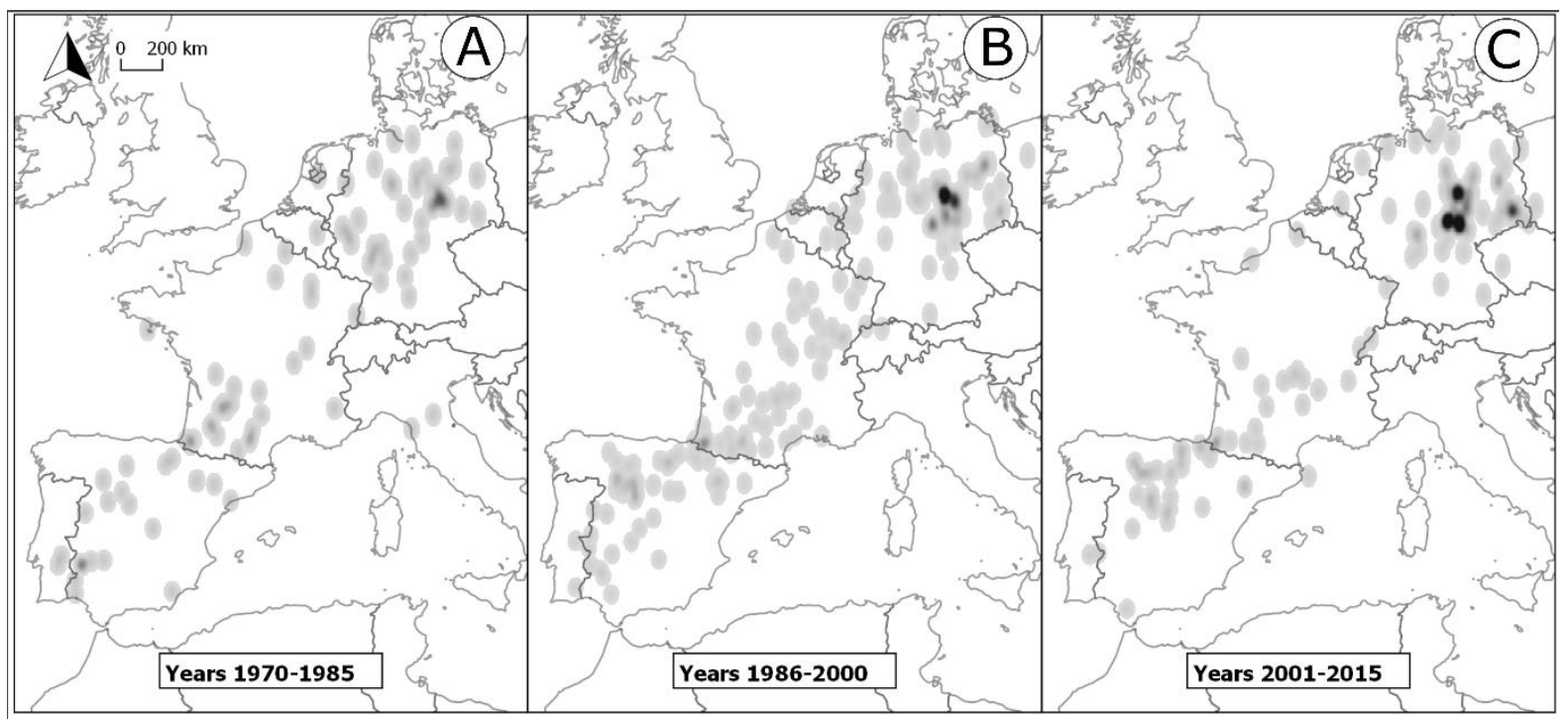

Fig. 2.3: Decrease in recovery distance for juvenile Red Kites marked in Germany and found dead from 1970-2015. Panels AC show Kernel-Density heat-maps with dark shading signalling areas with highest proportions of recoveries.

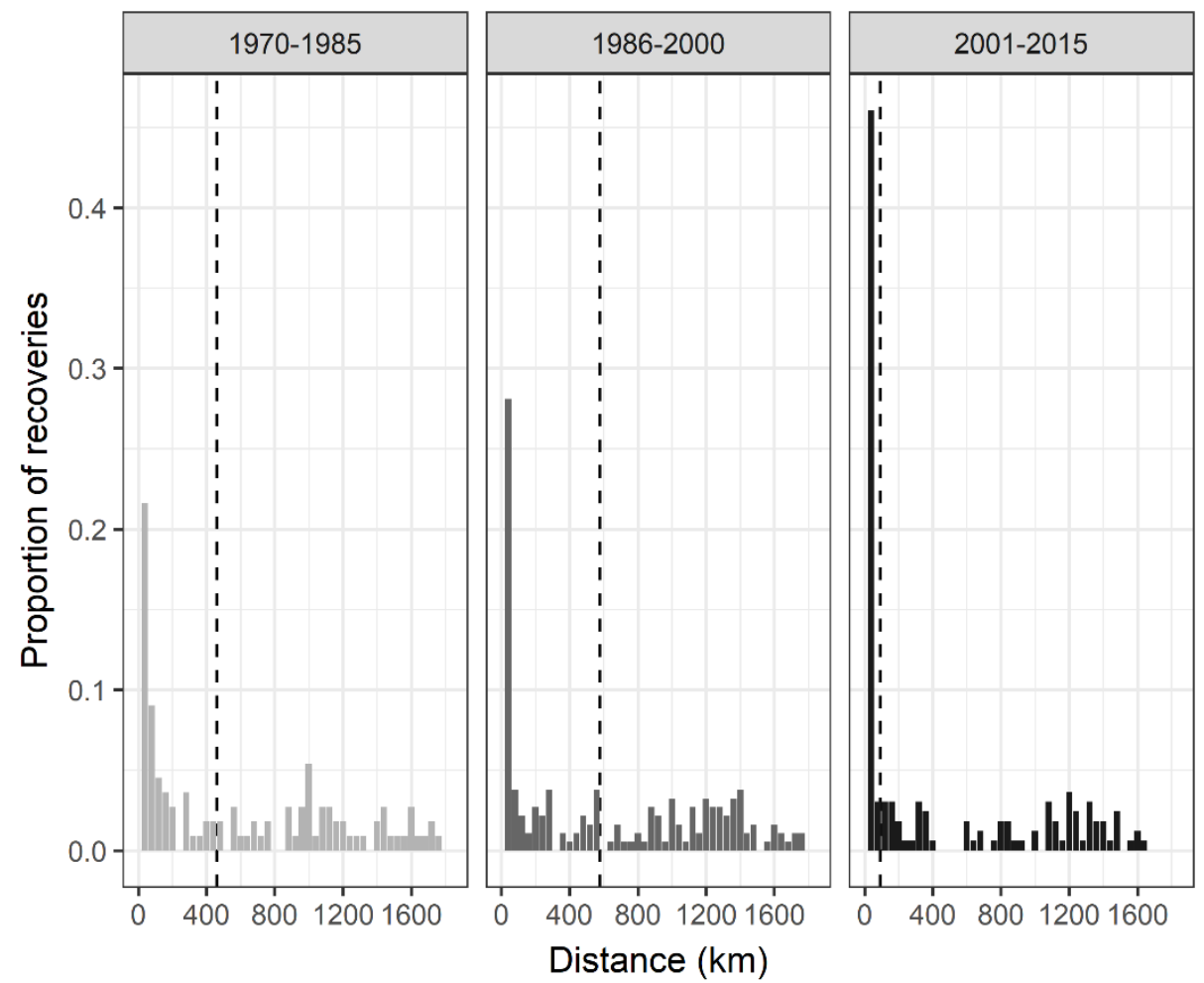

Fig. 2.4: Recovery distances of juvenile Red Kites ringed in Germany in three time periods from 1970-2015 (bin width $50 \mathrm{~km}$ ), vertical dashed line shows the median recovery distance for each time period. 

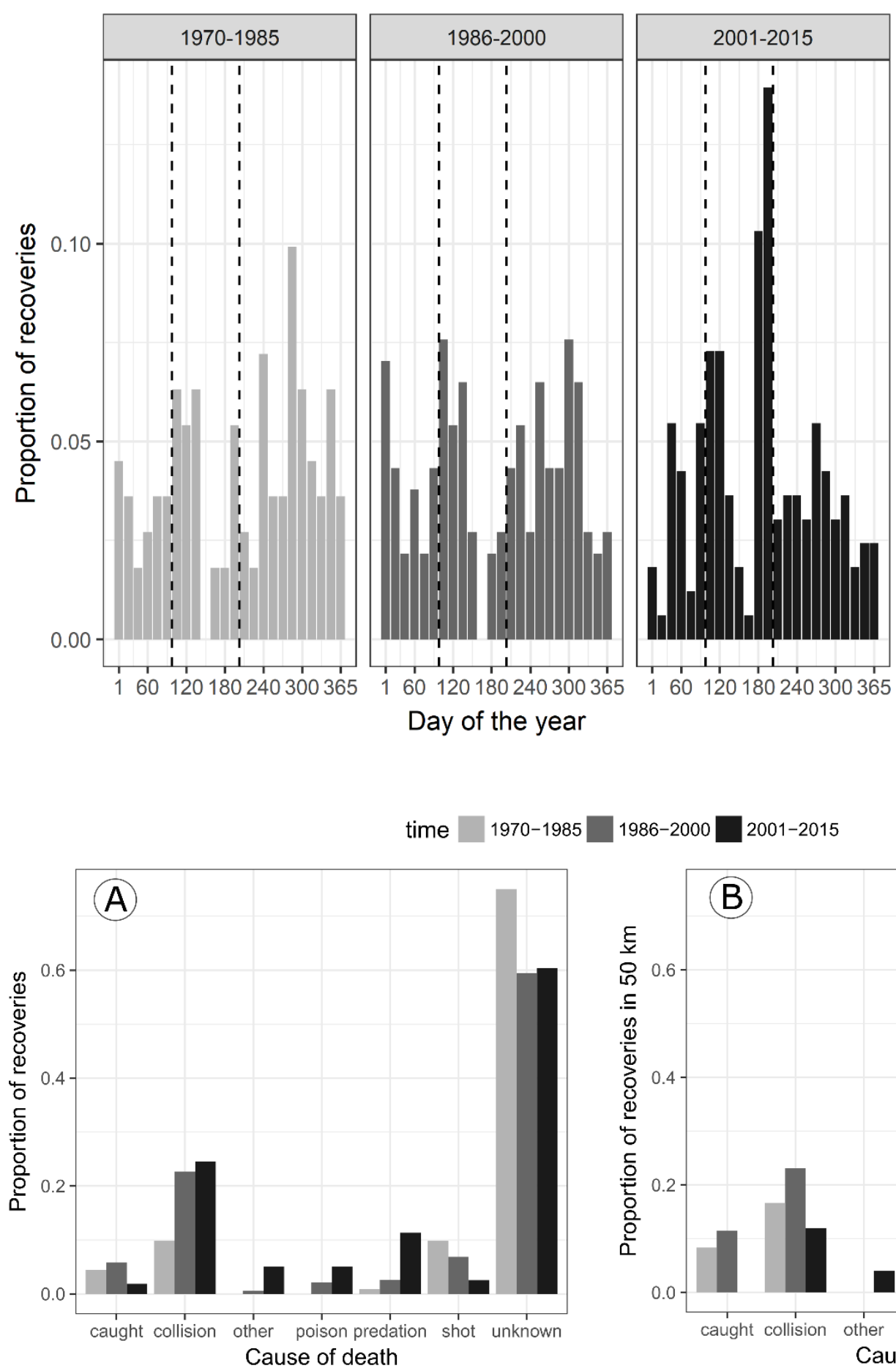

Fig. 2.5: Temporal distribution of juvenile Red Kite recoveries throughout the year in three time periods from 1970-2015 (bin width 14 days), vertical dashed lines mark approximate start (01.04.) and end (15.07.) of the breeding season.

1986-2000 2001-2015

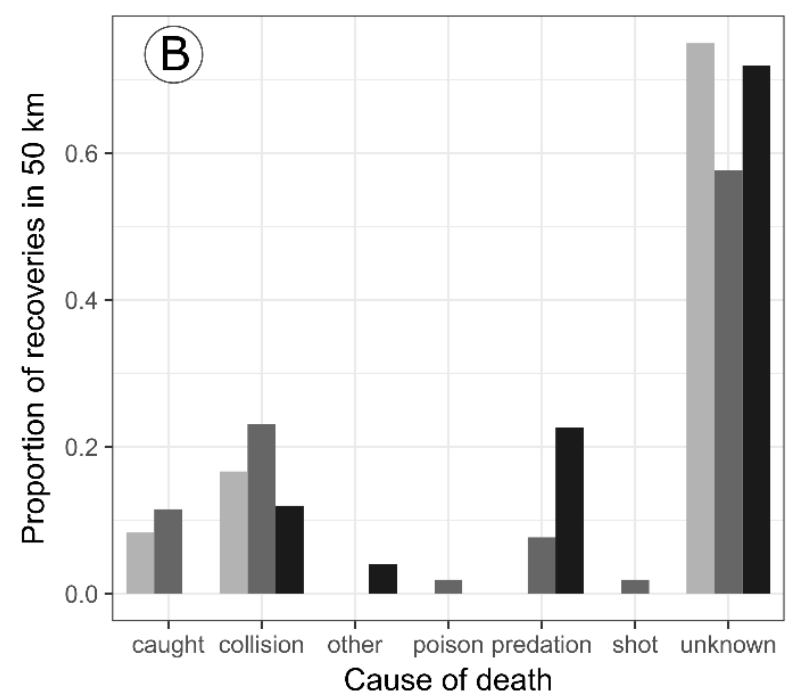

Fig. 2.6: Reported cause of death for juvenile Red Kites ringed in Germany recovered from 1970-2015. Panel A shows proportion of recoveries for all juveniles in the three periods, panel B shows only recoveries within $50 \mathrm{~km}$ of ringing location. Category 'other' sums all cases which do not apply to further categories while 'unknown' shows cases where the cause of death is either not reported or was reported as unknown. 


\subsection{Discussion}

Our results reveal for the first time a substantial long-term decline in the survival of juvenile Red Kites in the German breeding population, with a magnitude of more than $40 \%$ from the 1970 s until today (Fig. 2.2). Additionally, we demonstrate that adult survival probability also shows a decreasing trend - however, this is associated with a higher uncertainty (Fig. 2.2). The key to these new results is the estimation of age-specific recovery probabilities from the existing long-term ringing data on Red Kites, by implementing a multinomial ring-recovery model. As the results were gained from analysing dead recovery data, they represent robust information on true survival of the marked Red Kites - in contrast to mark-recapture studies which usually derive biased 'apparent' survival of the population under study (Kéry and Schaub 2012; Gilroy et al. 2012).

Decreasing survival rates are known to be highly influential for long-lived species like the Red Kite, but they can take several years to manifest as the birds only recruit to the breeding population after a minimum of 2-3 years (Pfeiffer 2009; Bellebaum et al. 2013). In Germany, the species is of central conservation importance and a decline in population size throughout the 1990s has long been documented and discussed (Bezzel 2010; Gedeon et al. 2014; Mammen 2016). The decline of the Red Kite population in the eastern part of Germany after the reunification in 1990 is often related to deteriorating conditions in the agricultural landscape during the breeding season and decreased reproductive productivity (Nachtigall et al. 2010; Mammen et al. 2014). Such a temporal pattern is also visible in our survival estimates, where juvenile survival decreased further in the years following reunification (Fig. 2.1, Fig. 2.2). However, our results also suggest that the survival of all age classes already decreased markedly in a short period of time (1986-1990) before reunification of East and West Germany (Fig. 2.2). Our study thus suggests an additional, yet unconsidered driver of changes in the German Red Kite population size throughout the 1980s and thereafter.

\section{Estimation of age-specific recovery probabilities}

The estimation of age-specific recovery probabilities for the Red Kite population from the long-term ringing data in Germany is an important step towards more reliable survival estimates. In previous analyses of Red Kite survival from ringing data in Germany, imperfect detection and possible agedependence were ignored, and survival rates estimated simply from the life histories of the recovered individuals (Schönfeld 1984; Nachtigall 2008; Pfeiffer 2009). With our analysis, the individuals that were not recovered also contribute towards estimating more reliable survival rates, and changes in recovery probabilities of different age-classes can highlight differences in demographic processes. 
We demonstrated that without looking at age-specific recovery probabilities, the long-term decline of juvenile survival could have also been observed, but at a smaller magnitude. Ignoring the agedependence in recovery would have also masked the temporal pattern of decreasing survival probabilities well before the reunification in 1990 that we have been able to show.

Estimation of recovery probabilities for juveniles and older birds is difficult if most individuals are marked as juveniles, as it requires additional ring recoveries from birds marked as adults or immatures (Kéry and Schaub 2012). Although catching and marking adult Red Kites is relatively difficult, the data generated by doing so allow a more detailed analysis of demographic processes and it is thus highly important and useful to also ring adult individuals. Ring recovery rate of all Red Kites marked in Germany over the last decades was previously estimated as $4.9 \%$ (Bairlein et al. 2014); our model without age-specific differences in recovery probability estimated a similar $5.6 \%$ from 1970-2015 (Tab. S2.1, suppl. mat.). However, it is already known that ring recovery probability is lower for juvenile Red Kites than for older birds in Switzerland, where recovery probability for adults is around $10 \%$ and for juveniles near 5 \% (Aebischer 2009; Kéry and Schaub 2012).

Age-dependent recovery probabilities can occur if the main cause of mortality changes with age and if different mortality causes are associated with different recovery probabilities (Schaub and Pradel 2004; Kéry and Schaub 2012). Most causes of death for the Red Kite are thought to be of anthropogenic nature (Schönfeld 1984; Knott et al. 2009; Langgemach et al. 2010), but depending on whether humans are directly involved the recovery rate of different causes of mortality will differ. Thus, the generally lower recovery probability of dead Red Kites in the first year indicates a cause of death that is less often discovered than others. Another potential reason for age-structured differences in recovery rate could be related to juvenile dispersal and the location of death. If the recovery probability decreases with distance from the place of ringing, as seen with other species, the lower probability of recovery for juveniles could also hint at on average more distal fatalities for this age class. The median recovery distance of birds older than one year in our dataset was approximately only half that of the juvenile age-class - which supports this hypothesis.

\section{Survival probabilities over time in the German Red Kite population}

In long-lived birds, the conditions experienced by the chicks during rearing and in early life can affect fitness and juvenile survival - mediated by natal habitat quality and resource availability (Van De Pol et al. 2006; Payo-Payo et al. 2016). The decrease in Red Kite juvenile survival could therefore reflect a deterioration in habitat quality experienced by the breeding population. As such, it seems plausible that food availability reduced by agricultural intensification not only affects the reproductive output 
of breeding Red Kites, but also lowers fitness and survival of the fledging juveniles. Additionally, resource availability for territorial birds of prey can be density-dependent, where an increase in population size approaching carrying capacity can decrease juvenile survival (Nicoll et al. 2003). Throughout the second half of the $20^{\text {th }}$ century, the German Red Kite population slowly recovered from persecution and increased in size (Ortlieb 1989; Nicolai and König 1990; Bezzel 2010). Monitoring data are only available from 1988 onwards, but until 1991 the population was still continually growing (Mammen 2016). That the fitness of Red Kite nestlings in fact deteriorated after the reunification is known from studies by Pfeiffer (2000), who detected a declining trend in the relative body weight of nestlings from 1989-1999 and related this to decreased food availability.

Another likely candidate to explain increased mortality in Red Kites is poisoning, especially with agricultural pesticides. This is a well-established problem for raptors in general and in particular for the Red Kite (Berny and Gaillet 2008; Coeurdassier et al. 2012; Montaz et al. 2014; Molenaar et al. 2017), which has however received relatively little attention in Germany (but see Hirschfeld 2011). Moreover, the rapidly decreasing trend in recovery probability that we found for both juvenile and subadult/adult Red Kites in the mid-1980s (Fig. 2.1) could indicate a change in the dominant mortality causes - leading to gradually fewer and fewer dead birds being recovered. Fatalities after poison ingestion or accumulation of poison over time would most likely lead to such a trend (Cox 1991), because birds that die from poisoning without direct human contact are much less likely found than those casualties which directly involve humans or which happen near inhabited areas (e.g. collisions on roads or with infrastructure; Wayland et al. 2003).

Environmental contamination in East Germany and the fatal non-target effects of agricultural pesticide application were extensively documented in the former GDR (Grün et al. 1982; Riedel et al. 1988). Between $20-30 \%$ of the agricultural area was regularly treated with organochloride pesticides (mainly Toxaphene/Camphechlor) to control rodent pests, while years 1983/1984 saw a strong increase of aerial DDT application in forestry to cope with pest infestation (Heinisch et al. 1994). Although DDT is mainly known for detrimental effects on reproduction, DDE (a DDT metabolite) and other organochlorine compounds applied in high concentrations can also have lethal toxic effects (Beitz et al. 1991; Cox 1991; Newton 2013). From 1984 onwards, a new strategy for the use of firstgeneration anticoagulant rodenticides (especially Chlorophacinone) was applied in the GDR, by provisioning bait at lower levels of pest infestation, at a $30 \%$ larger area and being extended over longer periods of the year (Wieland and Schellenberg 1984). This strategy was devised in response to several years with high Common Vole (Microtus arvalis) pest abundance (Sellmann 1991). This led to 221 recorded fatal non-target poisoning events affecting wild mammals from 1981-1990 in the GDR, of which $49 \%$ were caused by Chlorophacinone bait intake due to mishandling and bait attraction 
(Beitz et al. 1991). Such poisoned carcasses represent an enormous threat to scavengers, like the Red Kite, which feed on them and get poisoned themselves. For scavenging birds of prey the direct uptake of the poisoned rodents, targeted during control operations, is another major pathway of intoxication with pesticides (Berny and Gaillet 2008; Coeurdassier et al. 2012; Montaz et al. 2014). This process was also documented throughout the 1980s in the GDR - including kites (Milvus spec.) as fatalities (Beitz et al. 1991). Stubbe (1982) already suspected that contamination and the resulting poisoning could affect Red Kite survival in the GDR. Considering the scale of pesticide and especially anticoagulant rodenticide application throughout the 1980s, it is highly likely that this affected Red Kite survival rates through secondary poisoning.

Throughout the 1990s the amount of pesticides used in plant protection generally decreased in Germany (Schmidt 2003). The number of anticoagulants registered for plant protection however increased strongly until after the year 2000, but data on agricultural use are unfortunately not publicly available (Jacob and Buckle 2017). In recent years, EU legislation restricted the open use of anticoagulant rodenticides (Luque-Larena et al. 2018). This led to constraints in agricultural use for plant protection, but rising biocidal application (Jacob and Buckle 2017) - which still holds the potential for secondary poisoning of farmland scavengers like the Red Kite (Ntampakis and Carter 2005; Jacob et al. 2018).

In recent time, after the year 2000, especially adult birds showed an increase in mortality (Fig. 2.1, Fig. 2.2). During the same time period, more and more wind turbines were built in Germany, leading to additional collision mortality for the Red Kite population (Dürr 2009; Bellebaum et al. 2013). In fact, from 2001-2015 more than 300 Red Kites, mostly adults, were discovered dead as victims of wind turbine collisions in Germany (Langgemach and Dürr 2018). These numbers, however, only show a small proportion of the true number of collisions, since they are based on encounters by chance and carcasses are known to disappear quickly after a collision event and are thus seldom found (Bellebaum et al. 2013; Grünkorn et al. 2016). So far, the impact of collision mortality on the Red Kite population has only been assessed on a regional level (Bellebaum et al. 2013), but the potential for a substantial impact on the national population has recently been demonstrated (Busch et al. 2017). Even though proportionally fewer juvenile Red Kites collide with wind turbines, an increasing collision risk may contribute to the decreasing survival rates in the last decades. The increase in awareness for this potentially problematic additional mortality and an ensuing increase in search effort, most likely contributed to the generally increasing trends in both adult and juvenile Red Kite recovery probabilities after the year 2005 (Fig. 2.1). 
A natural cause of death that mainly affects Red Kite nestlings or fledglings is predation, especially by other raptors but also by predatory mammals (Langgemach et al. 2010). The majority of predations are caused by Goshawks (Accipiter gentilis), which preyed on almost $30 \%$ of 40 nestlings studied with nest cameras (Gottschalk et al. 2015). The reported causes of Red Kite juvenile mortality clearly show an increase in predation over time (Fig. 2.6) and the increase in mortality in recent years near the end of the breeding season (Fig. 2.5) could also be related to fledgling predation. With an increasing population density of Goshawks also the proportion of other raptors in the Goshawk diet increases (Hoy et al. 2017) - thus a long-term population recovery of Goshawks after persecution in the $20^{\text {th }}$ century could have also shown a negative effect by superpredation on survival rates of the Red Kite. Similarly, superpredation by the Eagle Owl (Bubo bubo) on the Red Kite seems to be more common than previously expected (Lourenço et al. 2018).

\section{Causes of Red Kite mortality}

Obtaining an accurate picture of the most important causes of death affecting survival of individuals in a population is difficult, particularly when based on opportunistically collected and unstructured ring recoveries. Proportional changes in the reported cause of death should therefore be viewed cautiously, rather suggesting patterns that need further investigation. We can also see from our results on juvenile mortality that in nearly $60 \%$ of cases the cause of death is simply unknown (Fig. 2.6). It is thus at present unclear which factor combination has led to the long-term decrease in juvenile survival of the German Red Kite population. We can however see a trend in the recovery data that more juveniles were found dead close to their place of birth in Germany, just after the end of the breeding season (Fig. 2.3-4). A better understanding of the dominant mortality causes affecting the Red Kite in different age-classes is therefore urgently needed, to ensure that effective conservation measures can be put in place at the breeding grounds in Germany. The most reliable way to gain such unbiased estimates is by telemetry of a suitable number of individuals of all age classes and a thorough investigation of carcasses in the case of mortality to determine the cause of death.

\section{Acknowledgements}

We gratefully acknowledge the effort of all the voluntary Red Kite ringers in Germany that allowed the study of ring recovery over such a long time period. We thank the institutions Vogelwarte Hiddensee (U. Köppen, C. Herrmann, Ringfundmitteilung der Beringungszentrale Hiddensee Nr. 09/2018), Vogelwarte Helgoland (F. Bairlein, O. Geiter) and Vogelwarte Radolfzell (W. Fiedler) for data provision and F. Bairlein and C. Herrmann for helpful comments that improved the quality of the 
manuscript. For comprehensive advice on how to best analyse the data and comments on an earlier draft of the manuscript we are deeply grateful to M. Schaub. The detailed comments by F. KornerNievergelt, J. Bellebaum and an anonymous reviewer greatly helped to further improve our manuscript.

\subsection{Supplementary Material}

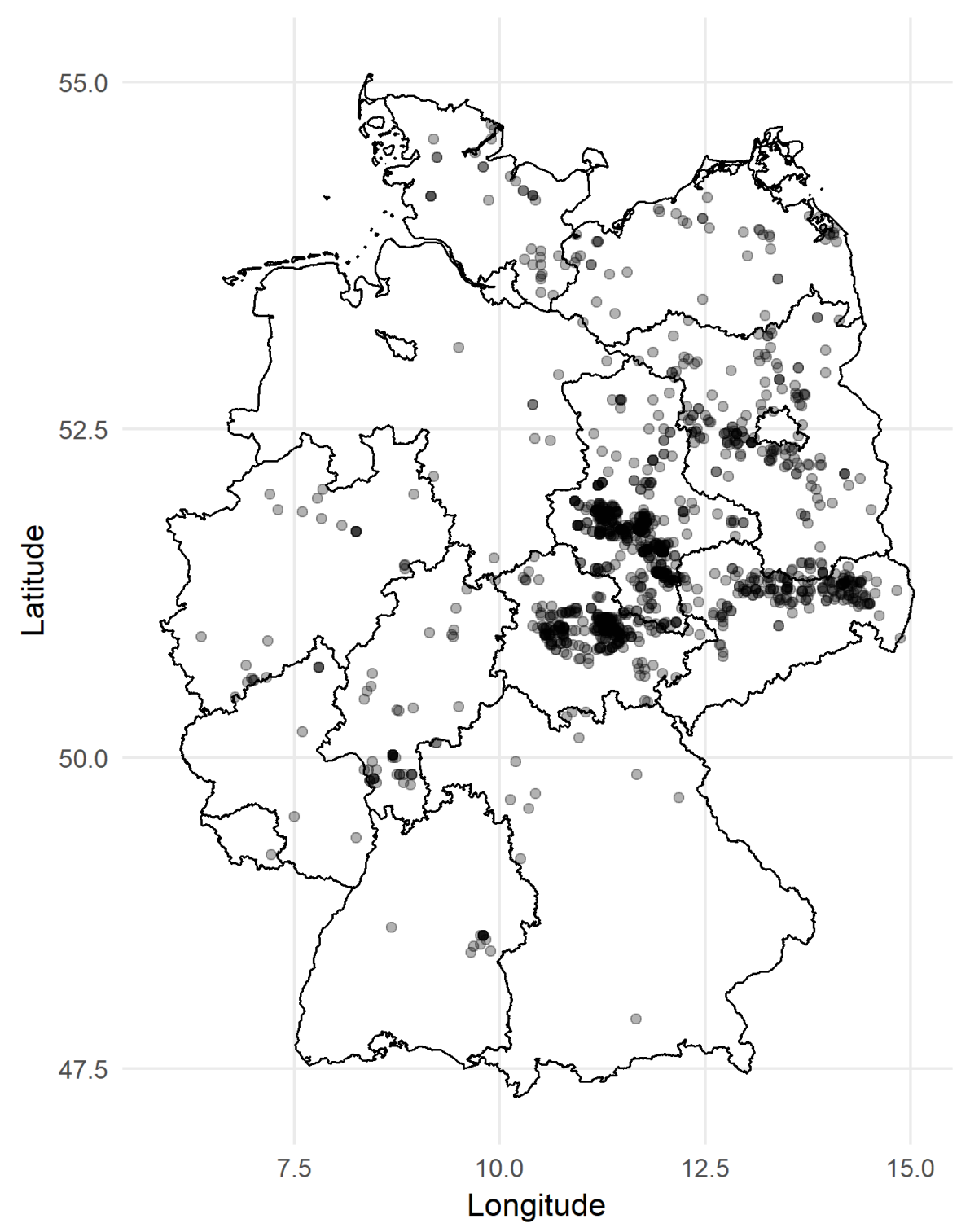

Fig. S2.1: Ringing location of all 1470 recoveries of dead Red Kites from 1970-2015 


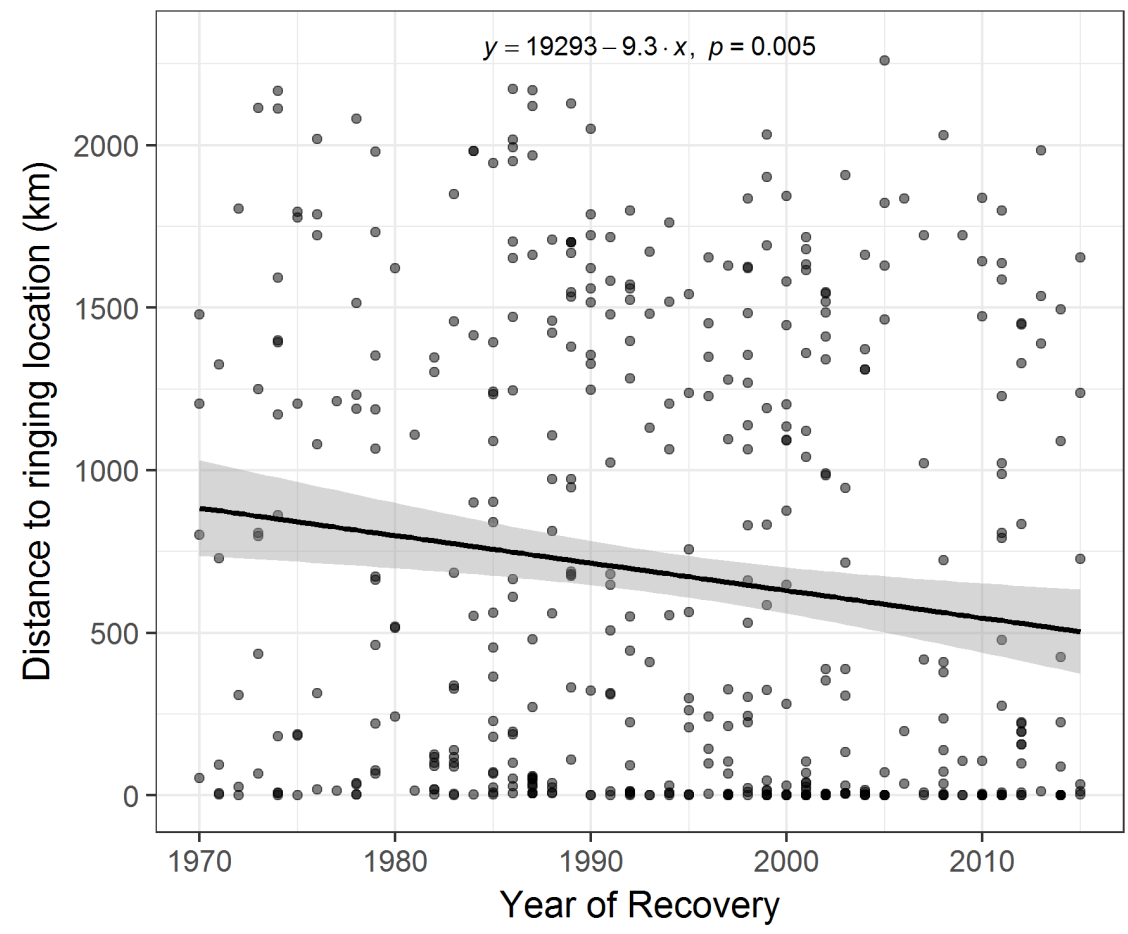

Fig. S2.2: Linear model showing a significantly decreasing recovery distance for ringed juvenile Red Kites over time 19702015 (model coefficients see top of figure).

Tab. S2.1: Posterior estimates from a model with 10 time periods for survival (5-year interval) and recovery probability assumed identical for all age-classes (rall) fitted with a random year effect

\begin{tabular}{ccccccc} 
Parameter & Mean & SD & $\mathbf{2 . 5 \%} \mathbf{C l}$ & $\mathbf{9 7 . 5 \%} \mathbf{C l}$ & Rhat & Time \\
\hline mean.rall & 0.056 & 0.004 & 0.048 & 0.065 & 1.005 & $1970-2015$ \\
mean.sjuv[1] & 0.719 & 0.043 & 0.63 & 0.798 & 1 & $1970-1974$ \\
mean.sjuv[2] & 0.797 & 0.036 & 0.721 & 0.863 & 1 & $1975-1979$ \\
mean.sjuv[3] & 0.802 & 0.033 & 0.734 & 0.863 & 1.001 & $1980-1984$ \\
mean.sjuv[4] & 0.774 & 0.029 & 0.715 & 0.829 & 1 & $1985-1989$ \\
mean.sjuv[5] & 0.685 & 0.044 & 0.597 & 0.77 & 1 & $1990-1994$ \\
mean.sjuv[6] & 0.638 & 0.041 & 0.558 & 0.717 & 1 & $1995-1999$ \\
mean.sjuv[7] & 0.605 & 0.044 & 0.518 & 0.69 & 1 & $2000-2004$ \\
mean.sjuv[8] & 0.616 & 0.055 & 0.509 & 0.72 & 1.001 & $2005-2009$ \\
mean.sjuv[9] & 0.64 & 0.061 & 0.519 & 0.754 & 1 & $2010-2014$ \\
mean.sjuv[10] & 0.408 & 0.191 & 0.042 & 0.748 & 1.002 & $2015-2015$ \\
mean.ssub[1] & 0.731 & 0.055 & 0.616 & 0.831 & 1 & $1970-1974$ \\
mean.ssub[2] & 0.762 & 0.045 & 0.668 & 0.842 & 1 & $1975-1979$ \\
mean.ssub[3] & 0.8 & 0.038 & 0.719 & 0.87 & 1 & $1980-1984$ \\
mean.ssub[4] & 0.769 & 0.034 & 0.701 & 0.832 & 1 & $1985-1989$ \\
mean.ssub[5] & 0.734 & 0.043 & 0.645 & 0.814 & 1 & $1990-1994$ \\
mean.ssub[6] & 0.611 & 0.052 & 0.506 & 0.713 & 1 & $1995-1999$ \\
mean.ssub[7] & 0.712 & 0.046 & 0.617 & 0.799 & 1 & $2000-2004$ \\
mean.ssub[8] & 0.68 & 0.058 & 0.56 & 0.789 & 1 & $2005-2009$ \\
mean.ssub[9] & 0.702 & 0.073 & 0.548 & 0.83 & 1 & $2010-2014$ \\
mean.ssub[10] & 0.464 & 0.212 & 0.051 & 0.826 & 1.002 & $2015-2015$
\end{tabular}




\begin{tabular}{|c|c|c|c|c|c|c|}
\hline mean.sad[1] & 0.612 & 0.068 & 0.476 & 0.743 & 1 & 1970-1974 \\
\hline mean.sad[2] & 0.861 & 0.027 & 0.804 & 0.912 & 1 & 1975-1979 \\
\hline mean.sad[3] & 0.835 & 0.024 & 0.786 & 0.881 & 1 & $1980-1984$ \\
\hline mean.sad[4] & 0.809 & 0.022 & 0.766 & 0.852 & 1 & 1985-1989 \\
\hline mean.sad[5] & 0.821 & 0.022 & 0.777 & 0.862 & 1 & 1990-1994 \\
\hline mean.sad[6] & 0.785 & 0.024 & 0.737 & 0.831 & 1 & 1995-1999 \\
\hline mean.sad[7] & 0.796 & 0.026 & 0.744 & 0.844 & 1 & 2000-2004 \\
\hline mean.sad[8] & 0.74 & 0.031 & 0.68 & 0.8 & 1 & 2005-2009 \\
\hline mean.sad[9] & 0.802 & 0.045 & 0.709 & 0.884 & 1 & 2010-2014 \\
\hline mean.sad[10] & 0.497 & 0.193 & 0.072 & 0.809 & 1.002 & 2015-201 \\
\hline rall[1] & 0.09 & 0.031 & 0.044 & 0.164 & 1 & 1970 \\
\hline rall[2] & 0.096 & 0.027 & 0.052 & 0.159 & 1 & 1971 \\
\hline rall[3] & 0.107 & 0.026 & 0.065 & 0.165 & 1.001 & 1972 \\
\hline rall[4] & 0.113 & 0.025 & 0.071 & 0.167 & 1 & 1973 \\
\hline rall[5] & 0.085 & 0.019 & 0.053 & 0.128 & 1 & 1974 \\
\hline rall[6] & 0.128 & 0.033 & 0.074 & 0.204 & 1 & 1975 \\
\hline rall[7] & 0.074 & 0.019 & 0.042 & 0.117 & 1 & 1976 \\
\hline rall[8] & 0.082 & 0.02 & 0.049 & 0.126 & 1 & 1977 \\
\hline rall[9] & 0.082 & 0.019 & 0.051 & 0.124 & 1.001 & 1978 \\
\hline rall[10] & 0.093 & 0.019 & 0.061 & 0.134 & 1 & 1979 \\
\hline rall[11] & 0.074 & 0.017 & 0.045 & 0.113 & 1 & 1980 \\
\hline rall[12] & 0.087 & 0.018 & 0.056 & 0.128 & 1 & 1981 \\
\hline rall[13] & 0.056 & 0.012 & 0.035 & 0.083 & 1 & 1982 \\
\hline rall[14] & 0.077 & 0.014 & 0.053 & 0.108 & 1 & 1983 \\
\hline rall[15] & 0.071 & 0.013 & 0.05 & 0.099 & 1 & 1984 \\
\hline rall[16] & 0.065 & 0.012 & 0.045 & 0.09 & 1.001 & 1985 \\
\hline rall[17] & 0.089 & 0.013 & 0.067 & 0.118 & 1 & 1986 \\
\hline rall[18] & 0.061 & 0.009 & 0.044 & 0.081 & 1 & 1987 \\
\hline rall[19] & 0.05 & 0.008 & 0.036 & 0.067 & 1.001 & 1988 \\
\hline rall[20] & 0.048 & 0.007 & 0.036 & 0.064 & 1 & 1989 \\
\hline rall[21] & 0.052 & 0.009 & 0.036 & 0.072 & 1 & 1990 \\
\hline rall[22] & 0.039 & 0.007 & 0.027 & 0.054 & 1 & 1991 \\
\hline rall[23] & 0.038 & 0.007 & 0.026 & 0.052 & 1.001 & 1992 \\
\hline rall[24] & 0.042 & 0.007 & 0.03 & 0.057 & 1 & 1993 \\
\hline rall[25] & 0.031 & 0.006 & 0.021 & 0.043 & 1 & 1994 \\
\hline rall[26] & 0.037 & 0.007 & 0.025 & 0.053 & 1 & 1995 \\
\hline rall[27] & 0.036 & 0.006 & 0.025 & 0.05 & 1 & 1996 \\
\hline rall[28] & 0.042 & 0.007 & 0.03 & 0.057 & 1 & 1997 \\
\hline rall[29] & 0.046 & 0.007 & 0.034 & 0.061 & 1 & 1998 \\
\hline rall[30] & 0.042 & 0.006 & 0.03 & 0.055 & 1 & 1999 \\
\hline rall[31] & 0.042 & 0.008 & 0.029 & 0.058 & 1 & 2000 \\
\hline rall[32] & 0.052 & 0.008 & 0.037 & 0.07 & 1 & 2001 \\
\hline rall[33] & 0.055 & 0.008 & 0.041 & 0.073 & 1 & 2002 \\
\hline rall[34] & 0.039 & 0.007 & 0.027 & 0.052 & 1 & 2003 \\
\hline rall[35] & 0.047 & 0.007 & 0.034 & 0.062 & 1 & 2004 \\
\hline rall[36] & 0.038 & 0.007 & 0.025 & 0.054 & 1.001 & 2005 \\
\hline rall[37] & 0.036 & 0.007 & 0.024 & 0.051 & 1 & 2006 \\
\hline rall[38] & 0.038 & 0.007 & 0.026 & 0.053 & 1 & 2007 \\
\hline
\end{tabular}




$\begin{array}{lcccccc}\text { rall[39] } & 0.032 & 0.006 & 0.02 & 0.045 & 1 & 2008 \\ \text { rall[40] } & 0.046 & 0.008 & 0.032 & 0.063 & 1 & 2009 \\ \text { rall[41] } & 0.068 & 0.016 & 0.043 & 0.107 & 1 & 2010 \\ \text { rall[42] } & 0.063 & 0.014 & 0.041 & 0.094 & 1 & 2011 \\ \text { rall[43] } & 0.053 & 0.011 & 0.035 & 0.077 & 1 & 2012 \\ \text { rall[44] } & 0.04 & 0.009 & 0.025 & 0.061 & 1 & 2013 \\ \text { rall[45] } & 0.068 & 0.012 & 0.047 & 0.094 & 1 & 2014 \\ \text { rall[46] } & 0.043 & 0.015 & 0.023 & 0.079 & 1.007 & 2015\end{array}$

For further supplementary data with the code used for model fitting and simulations to assess model performance see: https://static-content.springer.com/esm/art\%3A10.1007\%2Fs10336-018-1619z/MediaObjects/10336 20181619 MOESM2 ESM.docx 


\section{Chapter 3: A model of distribution and habitat suitability for the Red Kite in Germany}

Publication: Katzenberger, J. (2019): Verbreitungsbestimmende Faktoren und Habitateignung für den Rotmilan Milvus milvus in Deutschland. Vogelwelt 139, 117-128. [original in German, with English summary and captions].

\subsection{Abstract}

The distribution of the Red Kite in Germany is relatively well known from complete atlas surveys. It is however much less clear which environmental factors control the distribution of the species. In this article, more than 6000 nest sites from a nationwide Red Kite survey were used to study the main factors determining the distribution with a species distribution model and using high-resolution environmental variables (climate, habitat structure and diversity, land use). Adding to previous work, data on the intensity of agriculture (livestock stocking) as well as protection-status and potential for human disturbance were also considered. To account for spatial autocorrelation in the distribution data, a hierarchical model was used which corrects the estimates of the model parameters using random effects ('Gaussian random fields'). The distribution model showed a very good predictive accuracy (AUC $=0.89$ ) and explained $64.6 \%$ of the variability in the data, of which more than half was attributable to the environmental variables. Local occurrence of the Red Kite was strongly influenced by agricultural use and habitat diversity, but also by human disturbance. A high proportion of grassland in the surroundings, but also arable fields paired with woody margins (groves, hedges etc.) leading to higher landscape diversity increased the probability of a Red Kite nest being present. In addition, the results showed for the first time a substantial negative effect of agricultural intensification on the occurrence of the Red Kite, measured by the density of livestock farming. To support breeding Red Kites, the use of rodenticides and other pesticides should therefore be avoided as far as possible and fertiliser inputs should be reduced. A model prediction of habitat suitability showed that suitable breeding habitats for the Red Kite are available throughout Germany and thus confirms the need of a spatially comprehensive approach for protection. The actual distribution of the Red Kite, however, also deviates in some areas from the prediction based on habitat characteristics. Distribution centres can be found in the north-eastern lowlands of Germany as well as in the western and south-western low mountain ranges. A better understanding of the factors that influence the occurrence of the Red Kite can be used in particular for conservation efforts aiming to improve breeding habitats but also for spatial protection measures. 


\subsection{Introduction}

The distribution of the Red Kite Milvus milvus in Germany is well known and was last surveyed completely for the Atlas of German Breeding Birds from 2005-2009 (Gedeon et al. 2014). The breeding range of the species mainly comprises the north-eastern German lowlands and the northern and central low mountain ranges, with a clear distribution limit in the northwest German lowlands (Wellmann 2013; Gedeon et al. 2014). Somewhat apart from this main distribution area, the Swabian Alb and the western alpine foothills are also inhabited by the species. Mainly in the years 2011-2012, wide areas of the species' distribution were surveyed in Germany within the scope of a nationwide Red Kite survey and more than 6000 nesting sites were recorded (Grüneberg and Karthäuser 2019). The actual distribution of the Red Kite in Germany is therefore well known - but so far it is only partially clear which factors control this distribution pattern. In the context of this work, the occurrence data collected during the nationwide Red Kite survey (Grüneberg and Karthäuser 2019) is used to identify the main factors determining Red Kite breeding occurrence using a species distribution model based on environmental variables (climate, habitat structure and diversity, land use).

A distribution model for the Red Kite in Germany already exists through the work of Heuck et al. (2013), which uses high-resolution climate and land use variables. However, in the sample of Red Kite presence data used by Heuck et al. (2013), the distribution centres of the species in Saxony-Anhalt and Baden-Württemberg are considerably underrepresented (s. Gedeon et al. 2014; Grüneberg and Karthäuser 2019). When selecting important influencing variables in their models, Heuck et al. (2013) also refrained from correcting a significant spatial correlation structure in the model residuals due to the very high computational effort involved, which violates the assumption of independence and thus impairs the robustness of their results from a methodological perspective (Dormann et al. 2007). With the data from the last nationwide Red Kite survey, a substantially larger sample is now available, which almost completely covers the species' distribution centres. In addition, statistical methods to consider spatial autocorrelation have advanced and allow a more robust variable selection by means of hierarchical models (Latimer et al. 2009; Anderson and Ward 2018). Based on the approach of Heuck et al. (2013), this work develops an updated species distribution model for the Red Kite in Germany.

The aim of the study is to identify the most important factors that determine Red Kite distribution nationwide and to derive model predictions of habitat suitability. A better understanding of the factors that substantially influence the occurrence of the species can be particularly important for conservation efforts to improve breeding habitats. Large-scale model predictions can also be used to identify the most important areas for conservation measures or for mitigating conflict with mortality factors (e.g. wind turbines; Heuck et al. 2019; Nagel et al. 2019). The differences between the expected 
and the actual distribution are also of interest, as such discrepancies may help to identify important open questions and further need for research.

\subsection{Methods}

\section{Red Kite distribution data}

As presence data the Red Kite nest locations $(n=6349)$ on completely recorded quadrants of the TK25 map grid (TK25Q) were used, which were reported with geographical coordinates in the nationwide survey from 2010-2014 (68 \% from 2011-2012) (Grüneberg and Karthäuser 2019). The presence data were complemented in QGIS v. 3.4.3 (QGIS Development Team 2019) with an equal number of randomly drawn sample points (pseudo-absences) on fully mapped TK25Q (Fig. 3.1), with a minimum distance of $1.7 \mathrm{~km}$ to recorded nests (median distance to the nearest neighbour of all presences). In the random sampling of the pseudo-absences, the same percentage of points was implemented in the major geographic regions of Germany (BfN 2008) as it occurred in the presence data. The presences and pseudo-absences were buffered with a radius of $1 \mathrm{~km}$ to define the surrounding environment of the sites for further analysis (Heuck et al. 2013).

\section{Environmental variables}

To characterise the sites and the nest surroundings, high-resolution, nationwide raster maps of relevant environmental variables from the period 2010-2013 were used (Tab. 3.1). The following were considered as possible influencing variables: eleven land use classes (proportion of different forest types, arable land, grassland, settlements, wetlands and woody groves/hedges; from Gedeon et al. 2014, updated to 2012), climate (long-term average of precipitation and temperature in the months March-May, DWD 2019), and from IÖR (2019) the proportion of protected area with a high protection category (national park, nature reserve 'Naturschutzgebiet' or NATURA 2000 site), the density of woody margins (ecotone length of: tree rows, hedges, groves and forests), the relief diversity, the proportion of grassland, the proportion of arable land and the density of streets and agricultural roads. To also consider the intensity of agricultural use, the stocking density of large livestock was used (Destatis 2019), which correlates with agricultural fertilisation intensity, but also with the use of antibiotics and rodenticides in agriculture (Wallmann et al. 2017; Wenz and Ziebarth 2017; Jacob et al. 2018; López-Perea et al. 2019). Since small mammals can be an essential part of the Red Kite's diet, the suitability of the soil for vole populations was also considered as a possible influencing variable. Studies on the Common vole Microtus arvalis show that especially soils with high humus content, easy root penetration, high air content as well as good water conductivity and lack of groundwater 
influence favour vole population gradations (Blank et al. 2011). Small mammal suitability was therefore calculated as an index from the sum of the eight basic indicators for arable yield potential, the air capacity of the root zone as well as the groundwater influence on the soil (lower values rated as positive) (BGR 2019). Since agriculturally profitable soils with high yield potential may also indicate intensive agricultural use, high values of the small mammal suitability index could also be interpreted to indicate intensive agricultural use. If data from several sources were available (e.g. proportion arable land and grassland), the most recent version from IÖR (2019) was used. The raster data were processed with QGIS and unified to an identical resolution of $100 \times 100 \mathrm{~m}$. The categorical variable land use class (LU) was extracted for the respective point location, while all other variables were calculated as mean values from the $1 \mathrm{~km}$ radius around the site. All environmental variables were checked for correlations with each other. Due to strong correlation with the density of woody margins $(r>0.54)$, the variable Shannon diversity of the landscape was not included further in the analysis. Likewise, elevation was not further considered due to strong correlations with temperature and precipitation $(r>0.65)$. For the statistical modelling, all environmental variables were made comparable by centring and scaling; the continuous variables can therefore be directly compared in their effect size (Schielzeth 2010). To computationally allow nationwide predictions with the fitted models, the $100 \times 100 \mathrm{~m}$ grid of environmental variables was reduced to a $1 \times 1 \mathrm{~km}$ grid using mean values (only for model-based prediction).

Tab. 3.1: Environmental variables used for modelling Red Kite distribution. All variables except land use class were calculated as the mean within a $1 \mathrm{~km}$ radius around the presence/pseudo-absence location. Colum 'mean' shows mean and std. dev. (SD) of all locations for back-transformation of scaled predictor variables.

\begin{tabular}{|c|c|c|c|c|c|c|}
\hline Variable & Resolution & Year & Unit & $\begin{array}{l}\text { Mean } \\
\text { (SD) }\end{array}$ & Comment & Source \\
\hline $\begin{array}{l}\text { Land use class at } \\
\text { location }\end{array}$ & $25 \mathrm{~m}$ & 2012 & & & $\begin{array}{l}11 \text { classes: arable, grassland, } \\
\text { deciduous forest, coniferous } \\
\text { forest, mixed forest, wetland, } \\
\text { successional/disturbed forest, } \\
\text { discontinuous urban fabric, } \\
\text { continuous urban fabric, } \\
\text { groves/hedges, other }\end{array}$ & $\begin{array}{l}\text { Gedeon et al. } \\
\text { (2014), updated } \\
\text { from year } 2006 \text { to } \\
2012 \text { with CORINE } \\
\text { change layer }\end{array}$ \\
\hline Villages & $25 \mathrm{~m}$ & 2012 & ha & $\begin{array}{l}7.18 \\
(12.4)\end{array}$ & discontinuous urban fabric & $\begin{array}{l}\text { Gedeon et al. } \\
(2014)\end{array}$ \\
\hline Precipitation & $1 \mathrm{~km}$ & $\begin{array}{l}1981- \\
2010\end{array}$ & $\mathrm{~mm}$ & $\begin{array}{l}181 \\
(54.6)\end{array}$ & $\begin{array}{l}\text { long term mean of months } \\
\text { March-May }\end{array}$ & DWD (2019) \\
\hline
\end{tabular}




\begin{tabular}{|c|c|c|c|c|c|c|}
\hline Temperature & $1 \mathrm{~km}$ & $\begin{array}{l}1981- \\
2010\end{array}$ & ${ }^{\circ} \mathrm{C}$ & $\begin{array}{l}8.5 \\
(8.53)\end{array}$ & $\begin{array}{l}\text { long term mean of months } \\
\text { March-May }\end{array}$ & DWD (2019) \\
\hline Protected area & $100 \mathrm{~m}$ & 2012 & $\%$ & $\begin{array}{l}17.4 \\
(29)\end{array}$ & $\begin{array}{l}\text { national parks, } \\
\text { 'Naturschutzgebiet' reserves, } \\
\text { NATURA } 2000 \text { areas }\end{array}$ & $\begin{array}{l}\text { IÖR (2019), 'Natur- } \\
\text { und Artenschutz' }\end{array}$ \\
\hline $\begin{array}{l}\text { Density woody } \\
\text { margins }\end{array}$ & $100 \mathrm{~m}$ & 2012 & $\begin{array}{l}\mathrm{km} / \\
\mathrm{km}^{2}\end{array}$ & $\begin{array}{l}3.64 \\
(2.01)\end{array}$ & $\begin{array}{l}\text { density of woody } \\
\text { ecotones/margins e.g. forest, } \\
\text { groves, hedges (length per } \\
\text { surface area) }\end{array}$ & $\begin{array}{l}\text { IÖR (2019) } \\
\text { 'Gehölzdominierte } \\
\text { Ökotondichte' }\end{array}$ \\
\hline Relief diversity & $100 \mathrm{~m}$ & 2012 & & $\begin{array}{l}1.01 \\
(0.014)\end{array}$ & $\begin{array}{l}\text { ratio of the actual surface area } \\
\text { and a plane surface area }\end{array}$ & $\begin{array}{l}\text { IÖR (2019) } \\
\text { 'Reliefvielfalt' }\end{array}$ \\
\hline $\begin{array}{l}\text { Proportion } \\
\text { grassland }\end{array}$ & $100 \mathrm{~m}$ & 2012 & $\%$ & $\begin{array}{l}17.6 \\
(16.6)\end{array}$ & & $\begin{array}{l}\text { IÖR (2019) 'Anteil } \\
\text { Grünland' }\end{array}$ \\
\hline $\begin{array}{l}\text { Proportion } \\
\text { arable fields }\end{array}$ & $100 \mathrm{~m}$ & 2012 & $\%$ & $\begin{array}{l}39.9 \\
(28.4)\end{array}$ & & $\begin{array}{l}\text { IÖR (2019) 'Anteil } \\
\text { Ackerland' }\end{array}$ \\
\hline Road density & $100 \mathrm{~m}$ & 2012 & $\begin{array}{l}\mathrm{km} / \\
\mathrm{km}^{2}\end{array}$ & $\begin{array}{l}3.11 \\
(2.08)\end{array}$ & $\begin{array}{l}\text { length of road network (streets } \\
\& \text { agric. roads) per surface area }\end{array}$ & $\begin{array}{l}\text { IÖR (2019) } \\
\text { 'Verkehrsnetz- } \\
\text { dichte' }\end{array}$ \\
\hline $\begin{array}{l}\text { Large livestock } \\
\text { units }\end{array}$ & $5 \mathrm{~km}$ & 2010 & $\begin{array}{l}\text { per } \\
100 \\
\text { ha }\end{array}$ & $\begin{array}{l}87.5 \\
(48)\end{array}$ & $\begin{array}{l}\text { large livestock units (cattle, pigs } \\
\text { etc.) per } 100 \text { ha agric. area }\end{array}$ & $\begin{array}{l}\text { DESTATIS (2019) } \\
\text { 'Großvieheinheit- } \\
\text { enbesatzdichte' }\end{array}$ \\
\hline $\begin{array}{l}\text { Small mammal } \\
\text { suitability }\end{array}$ & $200 \mathrm{~m}$ & 2013 & & $\begin{array}{l}2.97 \\
(2.56)\end{array}$ & $\begin{array}{l}\text { Summed index: } 8 \text { basic } \\
\text { indicators for arable yield } \\
\text { potential, the air capacity of the } \\
\text { root zone as well as the } \\
\text { groundwater influence of the } \\
\text { soil (lower values rated as } \\
\text { positive) }\end{array}$ & $\begin{array}{l}\text { BGR (2019) } \\
\text { 'Ackerbauliches } \\
\text { Ertragspotential', } \\
\text { 'Luftkapazität im } \\
\text { effektiven } \\
\text { Wurzelraum', } \\
\text { 'Grundwasser- } \\
\text { beeinflussung' }\end{array}$ \\
\hline
\end{tabular}

\section{Statistical analysis}

For further analysis, the total data set was randomly divided into an $80 \%$ training data set and a $20 \%$ test data set, stratified according to the major geographical regions (BfN 2008). A generalized linear mixed model (GLMM) with a binomial error distribution (logit link function) was used for analysis. In order to take into account the spatial correlation of the model residuals, a hierarchical model was used, which captures the autocorrelation of the data as random effects ('Gaussian random fields', GRF) and thereby corrects the estimates of the fixed effects (Latimer et al. 2009; Anderson and Ward 2018). The model was built using the package sdmTMB (Anderson 2020) in R v. 3.5 .2 (R Core Team 
2018). The number of nodes (GRF, to estimate the spatial correlation) should be at least $100-400$ for similar data (Latimer et al. 2009). An optimal number of 1175 nodes was determined by a stepwise validation with the maximal model on training and test data set (100-1500 nodes, step size 25). This validation was performed with the AUC (Fielding and Bell 1997). The derived pattern of spatial correlation was therefore only complicated in so far as it increased the predictive power of the model. To assess the autocorrelation in the model residuals, Moran's I was computed with the package spdep (Bivand and Wong 2018).

The fixed effects in the model (influences of environmental variables) were specified with two-way interactions as well as quadratic effects (possible non-linear effects), where biologically plausible. The selection of the fixed effects in the model was carried out stepwise backwards, starting from a maximal model, using the $95 \%$ confidence interval $(95 \% \mathrm{Cl})$. If the $95 \% \mathrm{Cl}$ of a predictor variable overlapped with zero (no effect), the corresponding predictor was removed from the model. Main effects represented in further interactions or quadratic effects in the model were not removed. The validation of the model predictions was performed with the AUC in the package pROC (Robin et al. 2011), while for the calculation of the explained variability Nagelkerkes $\mathrm{R}^{2}$ with package modEvA (Barbosa et al. 2016) was used (Heuck et al. 2013). To determine an optimal threshold for a binary classification (presence/absence), the maximum of the true skill statistic (TSS) was applied (Allouche et al. 2006; Somodi et al. 2017).

To visualize the fixed effects in the model and to better interpret the effect size, model predictions were calculated as marginal effects: All other fixed effects in the model were kept at their mean value and an identical scale was used for display of the response variable. The marginal predictions for the respective effects were made only within the actual range occurring in the data.

\subsection{Results}

\section{Model validation}

The final GLMM, which modelled the Red Kite distribution using environmental variables (fixed effects, Tab. 3.2) and the spatial correlation pattern (random effects/GRF, Fig. 3.1), showed a very good predictive accuracy, since in $89 \%$ of the cases it was possible to correctly distinguish between presence and pseudo-presence in the validation data ( $\mathrm{AUC}=0.89$; TSS $=0.62$ with presence threshold 0.55). The model explained $64.6 \%$ of the variability in the distribution data. The predictions of a model limited to the fixed effects (corrected for spatial correlation) showed good predictive accuracy on the validation data $(\mathrm{AUC}=0.79 ; \mathrm{TSS}=0.46$ with presence threshold 0.3 ). The decrease in predictive accuracy was mainly caused by a 0.13 decrease in sensitivity (reduced rate of cases correctly classified 
as presences). The explained variability of the model limited to the fixed effects was $35.9 \%$. A simple GLM without spatial correction showed a strong autocorrelation of the residuals (Moran's I nearest neighbour: $0.32 ; \mathrm{p}<0.001$ ), while the GLMM showed no autocorrelation of residuals (Moran's I nearest neighbour: $-0.001 ; p=0.53)$.

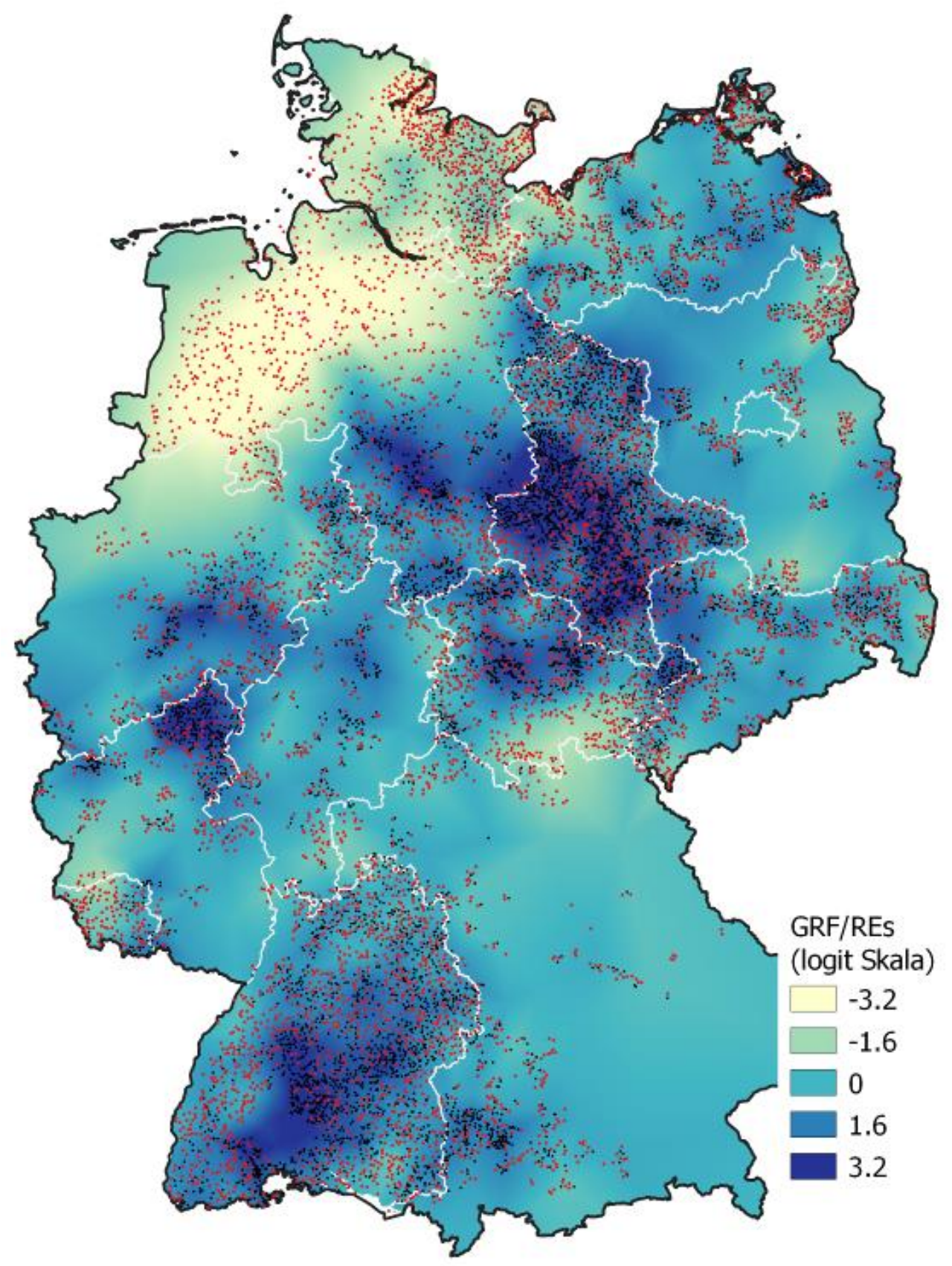

Fig. 3.1: Spatial correlation structure in the model residuals (logit scale) that was included as random effects (GRFs) in the model. Black points show Red Kite presences, red points show pseudo-absences (Grüneberg and Karthäuser 2019). Positive GRF values show a higher Red Kite presence, negative values a lower Red Kite presence than expected from the environmental variables. The probability of presence is calculated by adding local fixed and random effects and then backtransforming from the logit scale (binomial error distribution). 


\section{Factors determining breeding occurrence}

The main environmental variables that determined the occurrence of Red Kites in the present data set were the land use class at the immediate nest site, as well as linear and non-linear relationships with agricultural use, landscape structure and human impact in the nest surroundings (Tab. 3.2). Topography (relief diversity), climate (temperature) and soil type (suitability for small mammals) also showed an influence on Red Kite distribution, but these effects were of lesser importance (Tab. 3.2).

Tab. 3.2: Fixed effect estimates (logit scale, corrected for spatial autocorrelation) for the parameters in the binomial Red Kite distribution model. Values greater null show a positive effect and values less than null a negative effect on nest-site selection. Effect size of the continuous variables is directly comparable due to scaling. LU = land use class, reference category: arable land. Non-linear effects are reflected by the quadratic terms, interactions are shown by x. See Tab. 3.1 for details on the model parameters.

\begin{tabular}{|c|c|c|c|c|}
\hline Parameter & Estimate & Std. error & $\begin{array}{l}\text { min. } \\
95 \% \mathrm{Cl}\end{array}$ & $\begin{array}{l}\max . \\
95 \% \mathrm{Cl}\end{array}$ \\
\hline Intercept (LU: arable) & $-1,82$ & 0,26 & $-2,33$ & $-1,31$ \\
\hline Proportion arable & 0,92 & 0,07 & 0,78 & 1,07 \\
\hline Proportion arable ${ }^{2}$ & $-0,60$ & 0,06 & $-0,71$ & $-0,48$ \\
\hline Woody margins & 0,26 & 0,05 & 0,16 & 0,36 \\
\hline Woody margins ${ }^{2}$ & $-0,11$ & 0,03 & $-0,16$ & $-0,06$ \\
\hline Proportion grassland & 0,89 & 0,07 & 0,76 & 1,02 \\
\hline Proportion grassland ${ }^{2}$ & $-0,34$ & 0,03 & $-0,41$ & $-0,27$ \\
\hline Large livestock units & $-0,15$ & 0,05 & $-0,24$ & $-0,06$ \\
\hline Small mammal suitability & $-0,07$ & 0,06 & $-0,19$ & 0,06 \\
\hline Temperature & 0,13 & 0,08 & $-0,03$ & 0,28 \\
\hline Temperature $^{2}$ & $-0,10$ & 0,03 & $-0,16$ & $-0,03$ \\
\hline Relief diversity & $-0,18$ & 0,05 & $-0,28$ & $-0,07$ \\
\hline Protected areas & 0,20 & 0,04 & 0,12 & 0,28 \\
\hline Villages & 0,00 & 0,07 & $-0,12$ & 0,13 \\
\hline Road density & $-0,15$ & 0,07 & $-0,28$ & $-0,02$ \\
\hline LU: wetland & 1,89 & 0,74 & 0,43 & 3,35 \\
\hline LU: succession forest & 1,98 & 0,39 & 1,22 & 2,74 \\
\hline LU: grassland & 1,09 & 0,10 & 0,89 & 1,28 \\
\hline LU: villages & 0,01 & 0,29 & $-0,56$ & 0,58 \\
\hline LU: urban settlement & $-0,33$ & 0,20 & $-0,71$ & 0,05 \\
\hline LU: deciduous forest & 3,32 & 0,13 & 3,06 & 3,58 \\
\hline LU: coniferous forest & 2,43 & 0,13 & 2,18 & 2,67 \\
\hline
\end{tabular}




\begin{tabular}{llccc}
\hline LU: mixed forest & 3,08 & 0,10 & 2,87 & 3,28 \\
\hline LU: groves/hedges & 1,18 & 0,18 & 0,81 & 1,54 \\
\hline LU: other & 0,68 & 0,23 & 0,23 & 1,13 \\
\hline Prop. arable x woody margins & 0,15 & 0,06 & 0,04 & 0,27 \\
\hline Prop. arable x prop. grassland & $-0,72$ & 0,07 & $-0,86$ & $-0,57$ \\
\hline Woody margins x small mammal suit. & 0,17 & 0,05 & 0,07 & 0,27 \\
\hline Villages x road density & $-0,24$ & 0,04 & $-0,32$ & $-0,17$ \\
\hline Prop. grassland x villages & $-0,30$ & 0,06 & $-0,41$ & $-0,18$ \\
\hline Prop. arable x villages & $-0,30$ & 0,07 & $-0,43$ & $-0,17$ \\
\hline Prop. arable x road density & $-0,21$ & 0,06 & $-0,32$ & $-0,10$ \\
\hline Large livestock units x road density & $-0,14$ & 0,05 & $-0,23$ & $-0,05$ \\
\hline Woody margins x prop. grassland & 0,15 & 0,04 & 0,07 & 0,23 \\
\hline
\end{tabular}

The strongest influence on the probability of Red Kite occurrence was found for non-linear effects of the proportion of grassland and the proportion of arable land in the nest surroundings (Tab. 3.2, Fig. 3.2A+C). The proportions of arable land and grassland also showed a strong interaction with each other, making the respective effect-size dependent on the other parameter (Tab. 3.2, Fig. 3.2B). The effect size of the proportion of grassland and the proportion of arable land also interacted positively with the density of hedges and other woody margins, which also showed a significant non-linear relationship with the Red Kite presence (Tab. 3.2, Fig. 3.2D+E). The positive effect of the density of woody margins was further enhanced by a higher soil suitability for small mammals, but otherwise the small mammal suitability showed an inconsistent effect (Tab. 3.2).

The relationship between Red Kite occurrence and the area of villages in the nest surroundings depended strongly on the proportions of grassland and arable land as well as on road density (Tab. 3.2). A larger area of villages with small proportions of arable or grassland in the nest surroundings had a positive effect on the probability of Red Kite breeding, but a negative effect under higher proportions of grassland or arable land (Tab. 3.2, Fig. 3.2F). The effect of villages was also negative when there was a high road density in the nest surroundings (Fig. 3.3D). Road density also showed an overall negative influence on the Red Kite presence, as did the number of large livestock units (Tab. 3.2, Fig. 3.3A-B). These two parameters also interacted with each other, whereby the negative effect of road density was much more pronounced with a high stocking density of large livestock in the nest surroundings (Fig. 3.3C). 
Designation as a protected area with a high conservation status (national park, nature reserve, NATURA 2000 area) had a clear positive influence on the probability of Red Kite breeding, while an increased relief diversity showed a negative relationship (Tab. 3.2, Fig. 3.4A-B). Of the climate variables, only temperature showed a clear effect on Red Kite distribution (Tab. 3.2, Fig. 3.4C), while precipitation did not show a consistent effect and was therefore removed from the final model. The land use class at the nest site showed the highest probability of Red Kite occurrence for the different forest types as well as for woody groves, but also in wetlands or grassland the probability of nesting was higher than for the reference category arable land (Tab. 3.2). On settlement areas, there was no statistical difference in the probability of breeding compared to the reference category arable land (Tab. 3.2). 

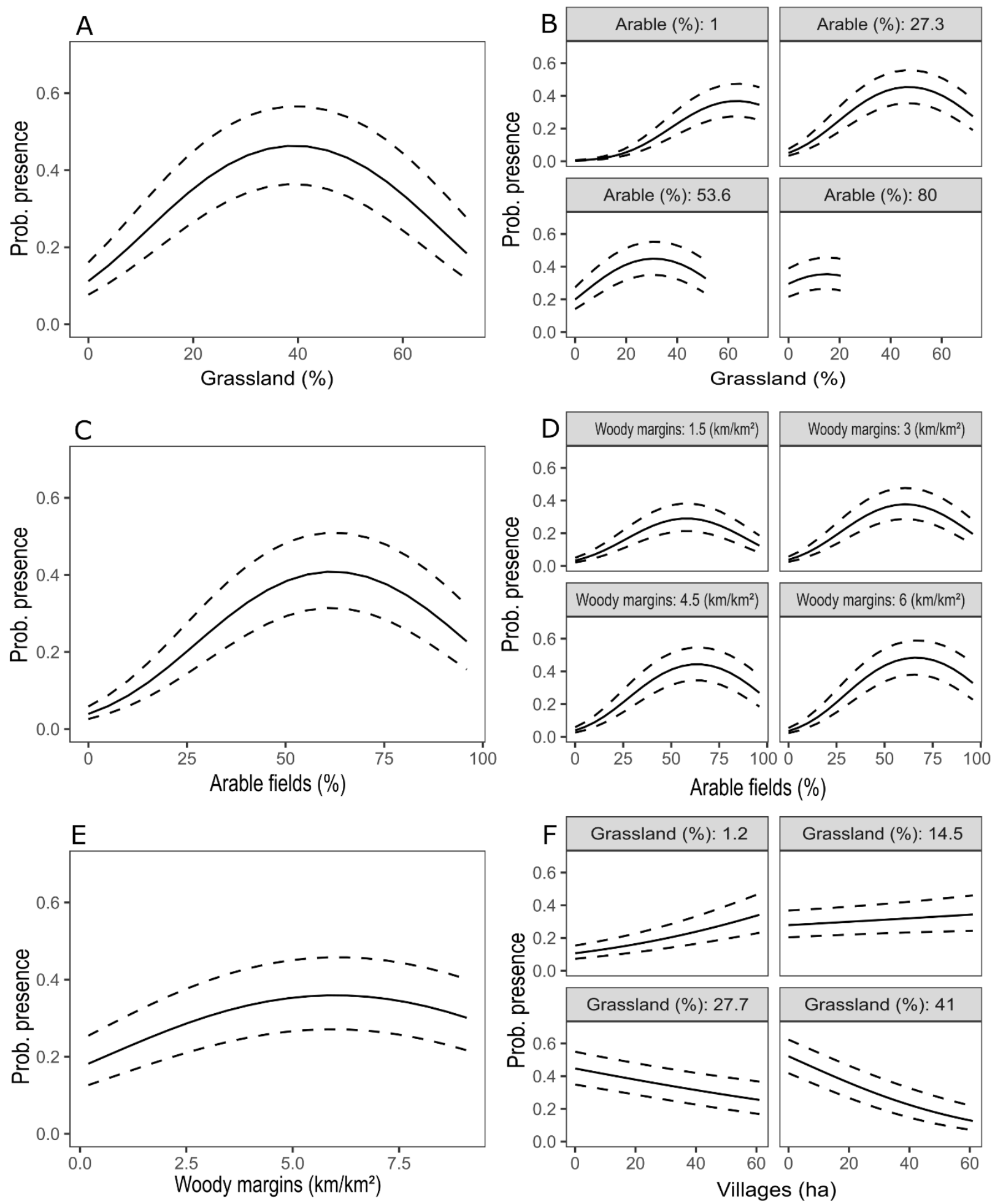

Fig. 3.2: Marginal effect plots for prop. arable fields, prop. grassland, woody margins and interaction with villages on the probability of a Red Kite presence. Dashed lines show one std. error around the mean, see Tab. 3.1 for details on the model predictors. 

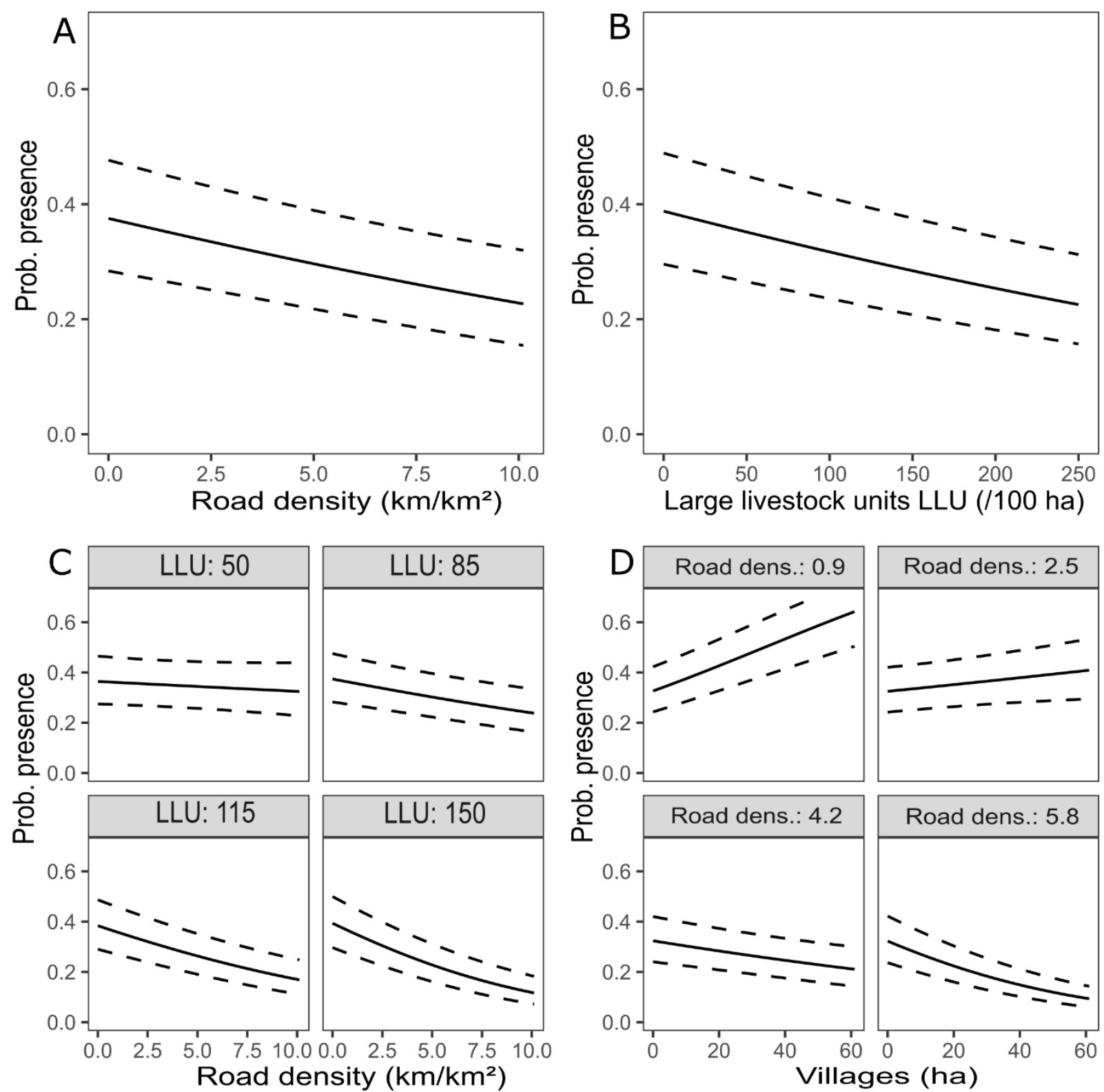

Fig. 3.3: Marginal effect plots for road density, large livestock units (LLU) and interaction with villages on the probability of a Red Kite presence. Dashed lines show one std. error around the mean, see Tab. 3.1 for details on the model predictors. 

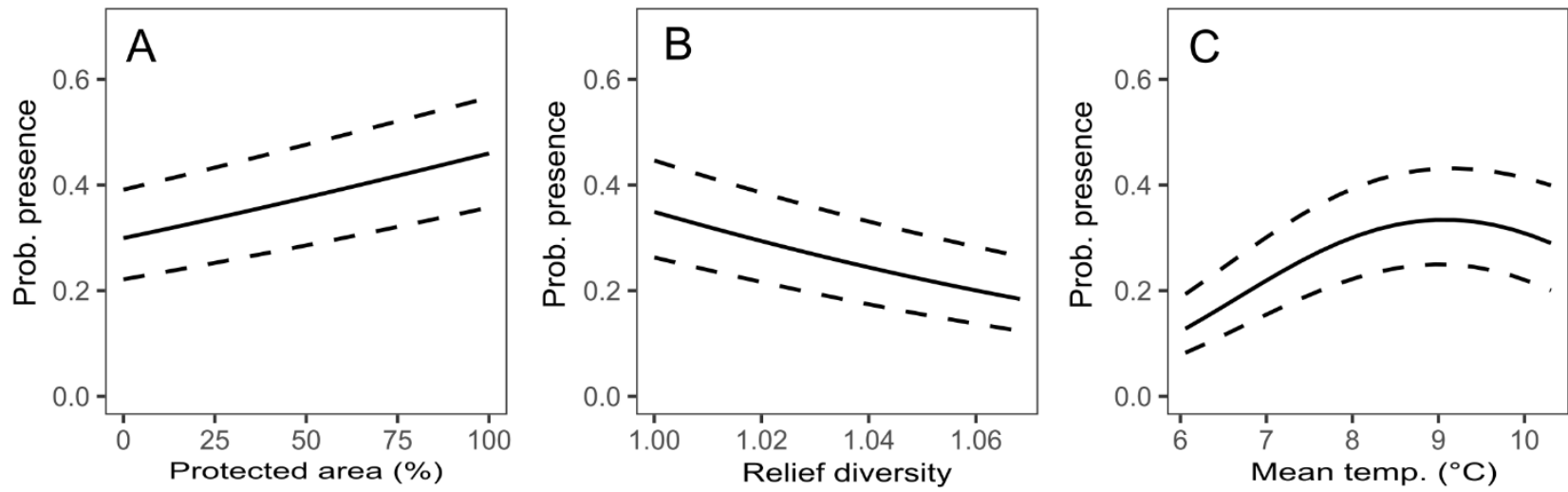

Fig. 3.4: Marginal effect plots for protected area coverage, relief diversity and temperature on the probability of a Red Kite presence. Dashed lines show one std. error around the mean, see Tab. 3.1 for details on the model predictors.

\section{Model predictions}

The model prediction of habitat suitability for the Red Kite (probability of presence based only on the fixed effects) showed that suitable breeding habitat for the species is generally available throughout Germany (Fig. 3.5). Only in densely populated urban areas, large and closed forests and in areas with a very high relief diversity the probability of breeding was estimated as very low (Fig. 3.5). Assuming the optimal threshold value (0.3) for classification into presence/absence using this model, $14.7 \%$ of the $1 \times 1 \mathrm{~km}$ grid cells in Germany were classified as suitable for the Red Kite. According to the model prediction, good habitat structures for the Red Kite were also present in the northwest and southeast of the country (Fig. 3.5), although these areas were in large parts not occupied by the species (Fig. 3.1).

The model prediction of the Red Kite breeding probability (additionally taking into account the spatial correlation structure) clearly showed that the distribution was concentrated in the north-eastern German lowlands and the western and south-western central uplands (Fig. 3.6). In particular, the north-eastern Harz foreland, the Westerwald, the Elbe valley, the Swabian Alb, the Thuringian Basin and the hill country of Mecklenburg and Brandenburg showed a consistently high probability of Red Kite occurrence. 


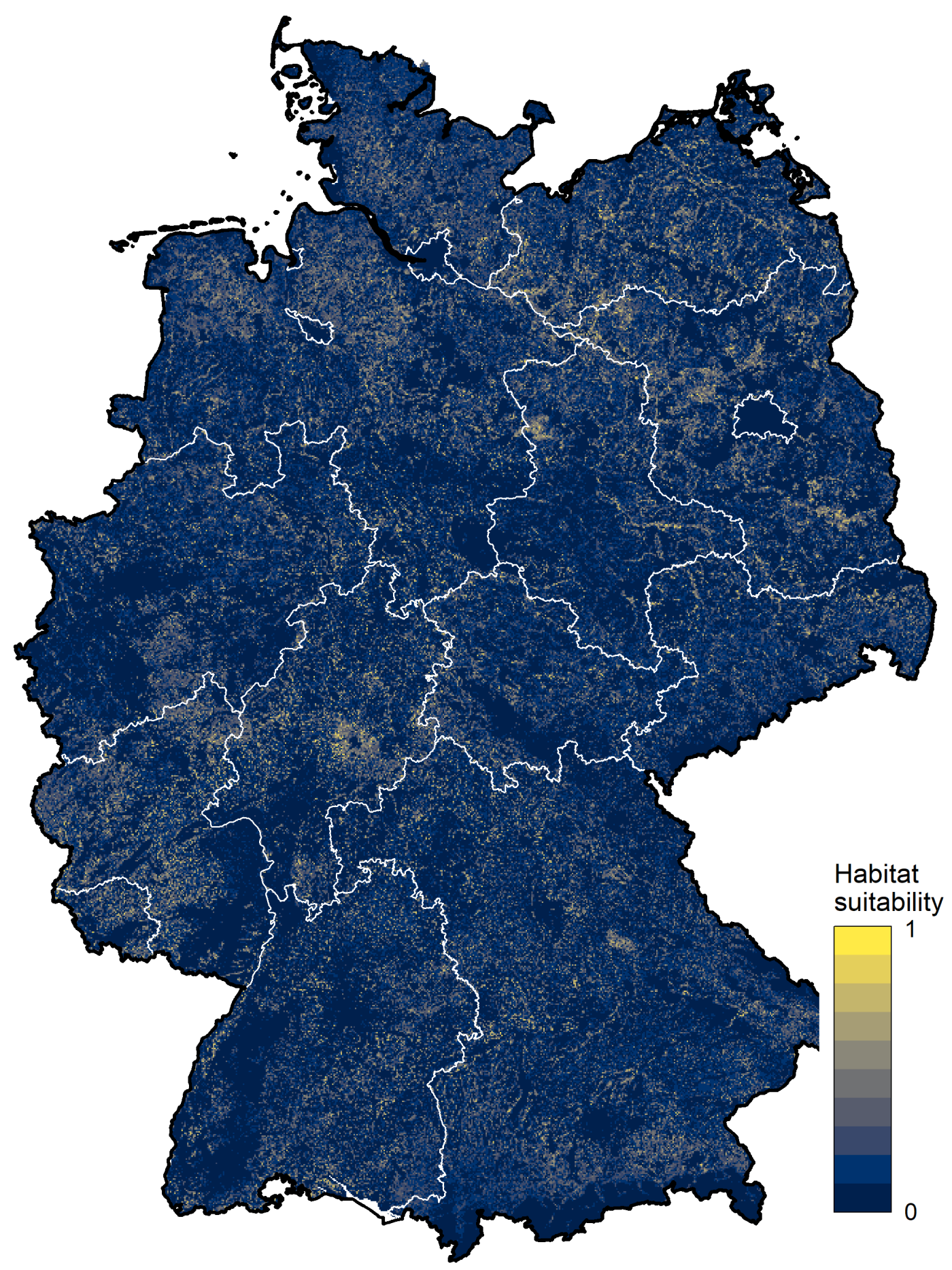

Fig. 3.5: Model prediction of Red Kite habitat suitability in Germany on a $1 \times 1 \mathrm{~km}$ raster. Habitat suitability was calculated as the probability of presence based only on the fixed effects in the model. 


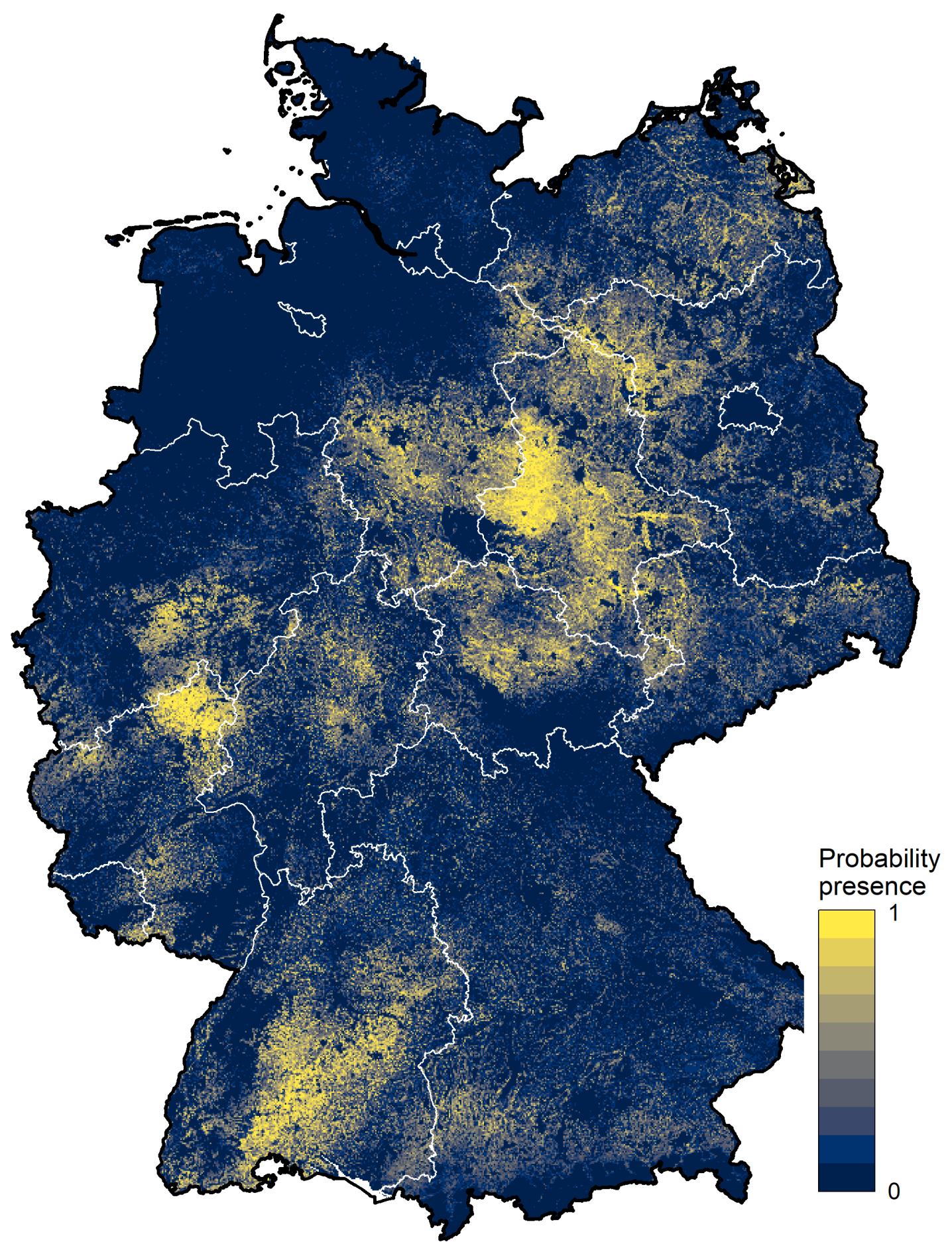

Fig. 3.6: Model prediction of Red Kite breeding probability for the period 2010-2014 in Germany on a 1 x 1 km raster. Breeding probability is based on the combination of the fixed and random effects (GRF, Fig. 3.1) in the model. 


\subsection{Discussion}

The results of the distribution modelling clearly show that the occurrence of the Red Kite in Germany is significantly influenced by agricultural use and habitat diversity, which are closely related to food availability for the species, as well as by human presence and disturbance (Fig. 3.2-4). Both high percentages of grassland around the nest and extensive arable landscapes, coupled with shrubs, hedges and other marginal structures that increase landscape diversity, increase the probability of breeding Red Kites (Fig. 3.2). The positive effect of grassland on the Red Kite is widely known and documented, as well as positive relationships with landscape diversity (see Heuck et al. 2013). However, previous studies have not been able to demonstrate the equally high importance of arable land and its interaction with grassland (Fig. 3.2), which means that the nest environment for Red Kites ideally contains both land use types as well as a high number of marginal structures. In addition, the model results showed for the first time a detectable negative effect of agricultural intensification, measured by the density of livestock farming, on the occurrence of Red Kites (Fig. 3.3). In areas with high livestock density, the loss of landscape diversity due to a homogenisation of land use and monoculture farming probably has negative effects on the Red Kite. In addition, the greatly increased fertilizer inputs reduce biodiversity (Isbell et al. 2013), which may also indirectly decrease food availability for raptors - while the increased use of rodenticides in intensive livestock farming not only affects the target species (small mammals), but also predators such as the Red Kite through secondary poisoning (e.g. Berny and Gaillet 2008; Jacob et al. 2018; López-Perea et al. 2019). To promote breeding occurrence of Red Kites, the use of rodenticides and other pesticides should therefore be avoided as far as possible, and high fertilizer inputs should be minimized.

A major negative effect on Red Kite occurrence can be human disturbance, which was most likely represented indirectly in the model results by the negative effect of road density in the nest surroundings, especially in combination with a simultaneous increase in the proportion of settlements (Fig. 3.3). Although roads are also used by Red Kites for foraging, the importance of the food consumed there is low overall (Orros and Fellowes 2015). In addition, a high road density, and thus probably also the associated disturbances, had a particularly negative effect in areas with very intensive agricultural use (under high livestock density, Fig. 3.3). Since a better habitat quality in protected areas is at least partly taken into account by the fixed effects in the model, the clearly positive effect of protected areas with high conservation status (Fig. 3.4) can probably also be explained by a lower influence of human disturbance. That human settlements can have a negative effect on the probability of breeding for the Red Kite was already shown by Heuck et al. (2013). Human disturbance is caused unintentionally by recreational use, but also by improper forestry work or maintenance of tree stands 
during the breeding season (Bezzel 2010). In addition, there is the deliberate, illegal persecution of Red Kites by humans, but also the unspecific persecution of raptors in general (Hirschfeld et al. 2017). However, the model results also show that villages can also have a positive effect on Red Kites provided there is otherwise a low road density in the vicinity and the proportion of arable land and grassland is also rather low (Fig. 3.2-3). This is presumably due to the fact that Red Kites also use human settlements to a considerable extent for food acquisition (Walz 2014; Nicolai et al. 2017; Bischofberger et al. 2019), and in some cases they are even deliberately fed by humans (Orros and Fellowes 2015; Cereghetti et al. 2019). In general, a return of many formerly heavily hunted and persecuted raptor species to rural settlement areas is increasingly being observed (Martínez-Abraín et al. 2019). It could therefore also be the case with the Red Kite that, due to a change in the behaviour of individuals, the rural settlement area is becoming increasingly important for the entire population.

The prediction of habitat suitability for the Red Kite in Germany, which is based on the estimates of the fixed model parameters and the available data on land use, climate and topography, clearly shows that suitable habitats for the species are in principle available everywhere in Germany (Fig. 3.5). For this reason, the protection of this rather widespread but mostly rarely occurring species is of major importance throughout Germany. Especially, because of the high proportion of the world's Red Kite population that is native to Germany (BirdLife International 2015; Grüneberg and Karthäuser 2019), Germany bears the highest international responsibility for its protection. However, the present analysis, as well as the work of Heuck et al. (2013), showed that the actual distribution in parts deviates substantially from the distribution predicted on the basis of habitat characteristics (Fig. 3.6). The spatial correlation structure of the model residuals (Fig. 3.1) shows a high similarity with the regional population density of the Red Kite in many areas (Gedeon et al. 2014; Grüneberg and Karthäuser 2019). A major driver for the observed discrepancy in the distribution pattern could therefore be a high breeding site fidelity of the adult birds, but also short settlement distances to the place of birth at the time of first breeding by young individuals - as already suggested by Heuck et al. (2013). In addition, it seems plausible that higher densities of conspecifics are perceived as social information about habitat suitability by non-breeders in search of a territory - and thus new Red Kite settlements are encouraged (Mateo-Tomás and Olea 2011).

Despite different input data and model formulations, the comparison with the work by Heuck et al. (2013) shows widely consistent results - which further substantiates the transferability and validity of the presented conclusions. The quality of the present species distribution model is also comparable with the previous work: the explained variability was about five percentage points higher overall, 
while the fixed effects even explained about eleven percentage points more than in the model by Heuck et al. (2013). In contrast, the prediction accuracy (AUC) of the entire model was seven percentage points lower here, which is surely also related to the even finer spatial resolution $(10 \times 10$ m) of the land use data used by Heuck et al. (2013). Since in the present study additionally relevant influencing variables, e.g. for intensity of agricultural use, as well as interactive and non-linear effects were also taken into account, and a statistically more robust variable selection was carried out, the knowledge about the distribution-determining factors for the Red Kite could be further improved overall.

\section{Acknowledgments}

Without the effort by the numerous contributors to the last nationwide Red Kite survey (2010-2014) this work would not have been possible, I am therefore greatly thankful to everyone involved (fully named in the original work by Grüneberg and Karthäuser 2019). I am also grateful to the Federal Agency for Nature Protection (BfN), which supported the work financially with funds from the Ministry for the Environment, Nature Conservation and Nuclear Safety (FKZ 3511685C10). For constructive comments on previous versions of this manuscript I am thankful to C. Heuck, J. Kamp, E. Gottschalk, S. Fischer and C. Sudfeldt. 


\section{Chapter 4: A reconstruction of the long-term population dynamics for the Red Kite in Germany}

Publication: Katzenberger, J., Gottschalk, E., Balkenhol, N. \& Waltert, M. (2021): Density-dependent age of first reproduction as a key factor for population dynamics: Stable breeding populations mask strong floater declines in a long-lived raptor, Animal Conservation, doi: 10.1111/acv.12687

\subsection{Abstract}

The age at which individuals reproduce for the first time is a key demographic factor impacting population dynamics and is subject to substantial variation across animal populations. There is also widespread empirical evidence that age of first reproduction responds to changes in population density over time, especially for long-lived birds and mammals. The density-dependence in age of first reproduction has profound impacts on the size of the non-breeding ('floater') part of the population. A better understanding of floater dynamics in raptor populations is urgently needed for comprehensive assessments of conservation status and management. We use the European nearendemic Red Kite Milvus milvus, a long-lived raptor of conservation concern, as an example to investigate total population dynamics with an age-structured demographic model. Using published estimates of survival and reproduction, we model the Red Kite population in Germany over four decades, considering also density-dependence in the age of first reproduction in different model scenarios. Based on the literature and the results of our simulations, we show that age of first reproduction for the Red Kite most likely responds non-linearly to density and that this general feedback mechanism should regularly be considered in demographic simulations. Our model results have far-reaching implications for the conservation status of the Red Kite, as they highlight a drastic decrease of juvenile and non-breeding individuals in the population over time - driven both by declining vital rates and a density-dependent shift towards a younger age of first breeding. This process is however not visible when judged only by the size of the breeding population, which our model estimates to be of similar size today as in the 1980s. The total Red Kite population reconstructed for Germany, however, seems diminished to nearly $50 \%$ of its former size. 


\subsection{Introduction}

Management and conservation of animal populations critically rely on an understanding of the key vital rates that impact population dynamics, especially for building robust models of population development (Reed et al. 2002; Pe'er et al. 2013). Apart from survival, reproduction, emigration and immigration, the age at which individuals first reproduce is a key demographic factor (Clobert et al. 1990; Pradel et al. 1997; Oli and Dobson 1999; Neubert and Caswell 2000). The absolute limits of minimum and maximum reproductive age (sexual maturation and senescence) for a species are determined by physiology, but the individual age of first reproduction can vary spatially or temporally across animal populations (e.g. Langvatn et al. 1996; Antor et al. 2007; Furness 2015). Especially for long-lived vertebrates with age-structured populations, variation in the age of first reproduction can substantially affect the total number of reproducing individuals and thus overall productivity (Ferrer et al. 2004; Morandini et al. 2019). We conclude that density-dependent variation in age of first reproduction can buffer breeding population size, potentially masking total population declines.

A density-dependent feedback mechanism acting on age of first reproduction, where an increase in population density leads to a delayed age of first reproduction, is well grounded in ecological theory and population biology (Stearns 1992; Oli and Dobson 1999; Neubert and Caswell 2000; Eberhardt 2002; Tavecchia et al. 2007). Empirical studies of this relationship largely support the theory; especially for long-lived birds and large herbivores there is clear evidence for a positive density effect on age of first reproduction (Croxall et al. 1990; Jorgenson et al. 1993; Ferrer et al. 2004; Krüger 2005; Tavecchia et al. 2007; Bonenfant et al. 2009; Borowik and Jędrzejewska 2018). Such a density feedback on age of first reproduction is also well documented for smaller, short-lived bird and mammal species (Clobert et al. 1990; Cooper et al. 2009; Ergon et al. 2011; Melero et al. 2015; Gamelon et al. 2016). However, the variation in age of first reproduction does not always follow the expected relationship with population density, which could be due to overriding environmental factors or because density effects are restricted to specific age or sex classes (Trites and York 1993; Furness 2015; Gamelon et al. 2016; Fay et al. 2017; Millsap 2018). For example, the albatross population studied by Fay et al. (2017) only initially showed the expected decrease in age of first reproduction with decreasing population size; later on recruitment age still declined even with increasing density- which according to the authors could be explained either by non-linear density regulation, an Allee effect on mating processes or the effect of climatic variables on body condition (Fay et al. 2017). 
Especially for larger birds, like raptors, it is evident that a density-dependence in the age of first reproduction is also directly linked to the size of the non-breeding ('floater') part of the population (Ferrer et al. 2004; Penteriani et al. 2006; Antor et al. 2007; Ortega et al. 2009; Elliott et al. 2011; Morandini et al. 2019), and a better understanding of floater dynamics is essential for conservation and management of these bird populations (Hunt 1998; Carrete et al. 2006; Penteriani et al. 2011). Despite its clear relevance, empirical data about the variation in age of first reproduction in animal populations is often severely limited and therefore this aspect is also often ignored in demographic simulations and population viability analyses (PVAs) (cf. Ferrer et al. 2004; Morandini et al. 2019; this study). The reliability and robustness of PVAs, however, depends critically on the assumptions made and many PVAs need to be improved in this regard (Pe'er et al. 2013; Chaudhary and Oli 2020).

Here, we investigate the population dynamics of the European near-endemic Red Kite Milvus milvus, a medium sized but remarkably long-lived raptor of conservation concern (BirdLife International 2019; Bird et al. 2020), in the centre of its breeding range. Both juvenile survival and productivity of the Red Kite population in its breeding stronghold Germany are showing long-term declines (Hoffmann et al. 2017; Mammen et al. 2017; Katzenberger et al. 2019a). We highlight that existing studies indicate a substantial, but widely overlooked, density-dependent variation in age of first reproduction for the Red Kite (but see Walz 2005; Tab. 4.1). Based on two case studies, we formulate a simple function to include density-dependence in the age of first reproduction into matrix population models. Using published estimates of Red Kite survival and reproduction and an age-structured matrix model, we then reconstruct key aspects of the population dynamics from 1975-2015 in Germany - adjusting the age of first reproduction in different scenarios. Finally, we compare the resulting simulations to Red Kite breeding bird surveys in Germany, to investigate the interacting effects of density-dependent variation in age of first reproduction and declining vital rates on the temporal dynamics of the breeding and the non-breeding part of the population. 


\subsection{Methods}

\section{Estimating density-dependent age of first reproduction for the Red Kite}

Several studies used demographic models to analyse Red Kite population dynamics, but they differed widely in the assumptions made about the age of first reproduction and also in Red Kite population density (Tab. 4.1). Throughout the manuscript we use a general expression of density as the ratio of the total population size $(\mathrm{N})$ to carrying capacity $(\mathrm{K})$, rather than defining it as local breeding density in pairs per $100 \mathrm{~km}^{2}$ or a similar spatial measure. The absolute population size is therefore not important because it is used as a relative value. We use the term breeding individuals to describe birds that have acquired a breeding territory (including 'territorial individuals', that may or may not lay eggs in a given year), while the term non-breeding individuals describes birds in the age classes 2-6 years which have not acquired a breeding territory. In the previous studies modelling Red Kite populations, the age of first reproduction is usually set to a constant age ( 2 or 3 years) or as fixed proportions in different age classes (ages 2-3 or 2-5 years; Tab. 4.1). A potential variation in age of first reproduction over time is only partly considered by Tenan et al. (2012), where the mean proportion of breeders is estimated as a latent variable in the model and thus reflects the best fit to the data and not an a priori assumption.

Tab. 4.1: Assumptions on age of first reproduction in previous studies using demographic models for the Red Kite (Milvus milvus). The density simply reflects a general approximation of Red Kite population size in relation to carrying capacity.

\begin{tabular}{|c|c|c|c|c|}
\hline Study & $\begin{array}{l}\text { Age of first } \\
\text { reproduction }\end{array}$ & Reference for breeding age & Location & Density \\
\hline $\begin{array}{l}\text { Hötker et al. } \\
\text { (2005) }\end{array}$ & $2 y$ & standard textbooks & Germany & $\begin{array}{l}\text { high, core } \\
\text { breeding area }\end{array}$ \\
\hline $\begin{array}{l}\text { Smart et al. } \\
(2010)\end{array}$ & $\begin{array}{l}80 \% 2 y \\
100 \% 3 y\end{array}$ & Evans et al. (1999) & UK & $\begin{array}{l}\text { low, } \\
\text { reintroduction }\end{array}$ \\
\hline Schaub (2012) & $3 y$ & - & $\begin{array}{l}\text { central } \\
\text { Europe }\end{array}$ & high? \\
\hline $\begin{array}{l}\text { Tenan et al. } \\
(2012)\end{array}$ & $3 y$ & $\begin{array}{l}\text { 2y old breeders do occur (Tavecchia et al. } \\
2012 \text { ), but only avg. proportion of breeders } \\
\geq 3 \text { y estimated as latent variable }\end{array}$ & $\begin{array}{l}\text { Spain } \\
\text { (Mallorca) }\end{array}$ & low \\
\hline $\begin{array}{l}\text { Bellebaum et } \\
\text { al. (2013) }\end{array}$ & $2 y-5 y$ & $\begin{array}{l}\text { fixed proportions per age class chosen after } \\
\text { Newton et al. (1989); Nachtigall (2008) }\end{array}$ & Germany & $\begin{array}{l}\text { high, core } \\
\text { breeding area }\end{array}$ \\
\hline $\begin{array}{l}\text { Ceccolini et al. } \\
\text { (2013) }\end{array}$ & $2 y$ & based on field data (telemetry) & Italy & $\begin{array}{l}\text { low, } \\
\text { reintroduction }\end{array}$ \\
\hline $\begin{array}{l}\text { Mammen et } \\
\text { al. (2014) }\end{array}$ & $3 y$ & Walz (2005); Aebischer (2009) & Germany & $\begin{array}{l}\text { high, core } \\
\text { breeding area }\end{array}$ \\
\hline
\end{tabular}




\begin{tabular}{llllc}
\hline $\begin{array}{l}\text { Meyer et al. 3y? } \\
\text { (2016) }\end{array}$ & $\begin{array}{l}\text { refer only to 'breeding proportions' from } \\
\text { Tenan et al. (2012) }\end{array}$ & UK & low? \\
$\begin{array}{l}\text { Potiek and } 2 y-5 y \\
\text { Krüger (2016) }\end{array}$ & Bellebaum et al. (2013) & Germany & $\begin{array}{l}\text { high, } \\
\text { breeding area }\end{array}$ \\
$\begin{array}{l}\text { Sansom et al. } 80 \% 2 y, \\
(2016)\end{array}$ & Evans et al. (1999); Smart et al. (2010) & UK & low? \\
$\begin{array}{l}\text { Sergio et al. } 3 y \\
\text { (2019) }\end{array}$ & - & Spain & low \\
$\begin{array}{l}\text { Sergio et al. } 100-5 y \\
(2020)\end{array}$ & $\begin{array}{l}\text { fixed proportions per age class, based on } \\
\text { field data from } 18 \text { individuals }\end{array}$ & Spain & low \\
\hline
\end{tabular}

To describe density-dependence in the age of first reproduction for the Red Kite, we used two empirical case studies, as also communicated in German language by Katzenberger \& Gottschalk (2019). For details about the matrix models applying this density-dependent age of first reproduction please see the next section 'simulation models'. To estimate a situation under high density, we used published data on the Red Kite population in the surroundings of Weimar, Germany (Pfeiffer 2009). This population showed a long-term stable development from 1988-2008, fluctuating mostly between 40-50 breeding pairs (Pfeiffer 2009), and we therefore assumed the population was breeding near the local carrying capacity. For a sample of 44 individuals from this population, Pfeiffer (2009) reported the age while breeding (not age of first breeding); birds aged seven years made up the highest proportion in this sample (16 \% or 7 individuals; Tab. 4.2). As older individuals generally represent an increasingly smaller proportion in the population and earliest breeding in Red Kites usually occurs with two or three years of age (rarely after the first year; Newton et al. 1989; Evans et al. 1999; Pfeiffer 2009), we assumed from these data that by seven years of age all birds had recruited as breeders for the first time. This assumption is in line with other studies on the Red Kite in Wales (Newton et al. 1989) and the closely related black kite Milvus migrans (Sergio et al. 2009), where by seven years all individuals bred for the first time as well. With this assumption, and a proportion of $4.7 \%$ for the age class seven years in the Red Kite population obtained from ringing data (Pfeiffer 2009), we calculated a total population size of 149 individuals for this model population (7 individuals aged seven years / proportion $0.047=149$ ). This total population size was then used to construct the age structure of a model population under high density (based on the proportional data in Pfeiffer 2009; Fig. 4.1) and to calculate the percentage of non-breeding birds in the age classes two to six years (Tab. 4.3). To infer a situation of breeding under low density, with a population much below carrying capacity, we used the data from the successful re-introduction project of the Red Kite in the United Kingdom (UK). For the phase of recolonization, the proportion of individuals breeding for the first time at age two years 
is estimated at $80 \%$, while at three years of age all birds are expected to breed for the first time (Evans et al. 1999; Smart et al. 2010).

Tab. 4.2: Ages of 44 breeding Red Kites by Pfeiffer (2009). The individuals were sampled from the local population from 1991-2008, see also Pfeiffer (2009).

\begin{tabular}{cc}
\hline Age class (years) & No. of Indivdiduals \\
\hline 2 & 4 \\
3 & 5 \\
4 & 6 \\
5 & 5 \\
6 & 6 \\
7 & 7 \\
8 & 3 \\
$9-18$ & 8 \\
\hline
\end{tabular}

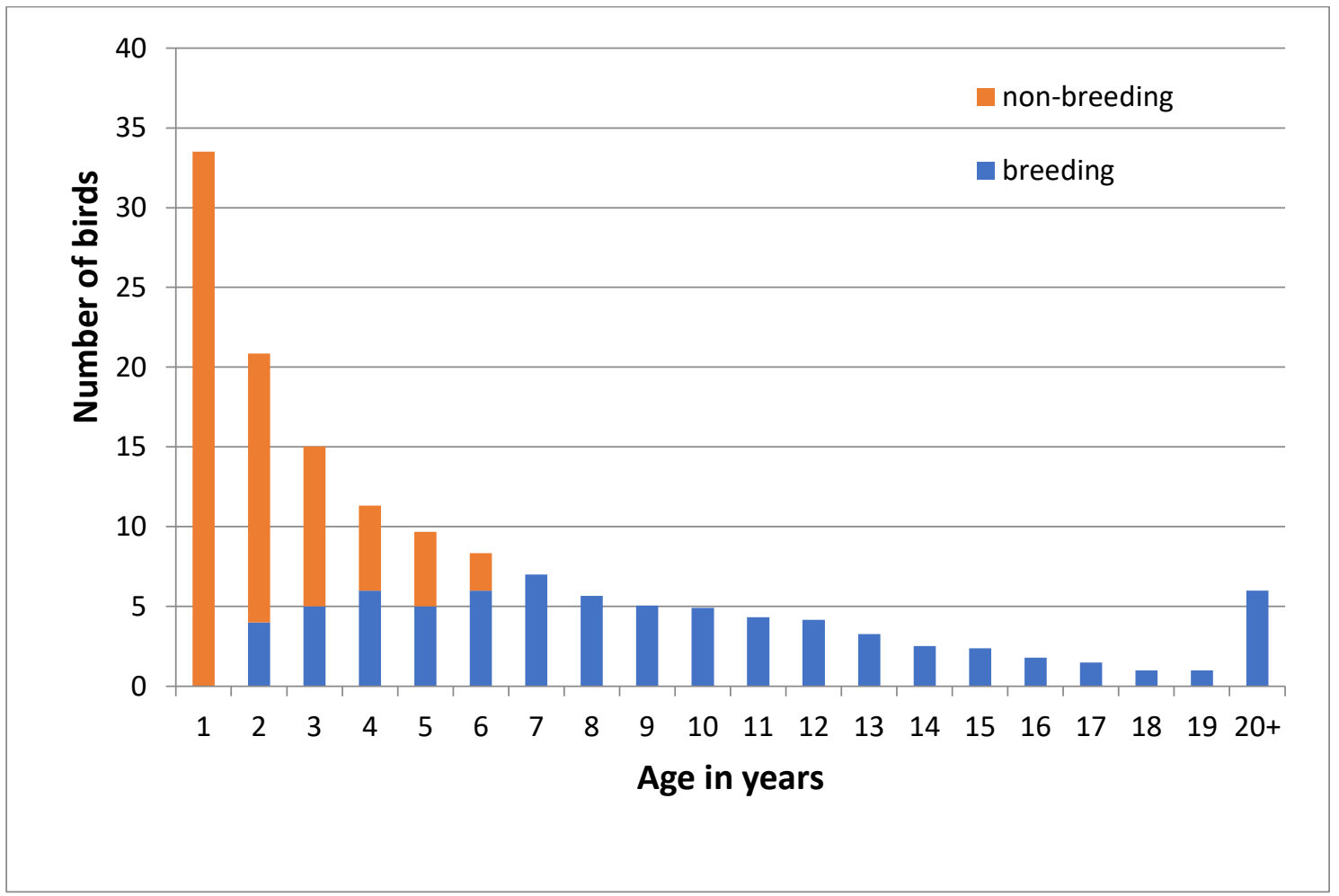

Fig. 4.1: Estimated population structure for a Red Kite model population ( $N=149$ ) at high density, derived from Pfeiffer (2009). The total population size of 149 individuals (see text) is multiplied by the proportion for each age class from ringing data from Pfeiffer (2009), to calculate the number of individuals per age class in the model population. The proportion of breeders for ages 2-6 is based on the sample of 44 breeding individuals (Tab. 4.2). 
From these two case studies we derived a simple density-dependent formula for Red Kite age of first reproduction in different age classes, adapted from the standard formula used in the VORTEX software (Lacy and Pollak 2018):

$$
B a_{(N)}=B a_{(0)}-\left[\left(B a_{(0)}-B a_{(K)}\right) *\left(\frac{N}{K}\right)^{x}\right]
$$

Here, $\mathrm{Ba}_{(\mathrm{N})}$, the percentage of breeders in age class a at total population size $\mathrm{N}$, is calculated from the percentage breeding at low density $\left(\mathrm{Ba}_{(0)}\right)$ and the percentage breeding near carrying capacity $\mathrm{K}\left(\mathrm{Ba}_{(\mathrm{K})}\right)$ in the respective age class and with a density-dependence component modulated by the exponent $\mathrm{x}$. At low densities, the resulting percentage of breeders for each age class approaches the values from Smart et al. (2010), while at high densities the percentages reach the values estimated here (Tab. 4.3). With an increasing value of the exponent $\mathrm{x}$ in the formula, the age of first reproduction is only regulated substantially at higher densities (Fig. 4.2). For an example how to include this formula as a function in a VORTEX model see Tab. S4.1 (Supporting information).

Tab. 4.3: Percentage of breeders in age 1-7 years in a Red Kite population at low density ( $\mathrm{Ba}_{(0)}$, Smart et al. 2010) and at high density $\left(\mathrm{Ba}_{(\mathrm{K})}\right.$, estimated from Pfeiffer 2009). See also Fig. 4.1, the calculated percentages for $\mathrm{Ba}_{(\mathrm{K})}$ are based on a random sample of breeding age and not a cumulative sample of individuals (see text).

\begin{tabular}{lllllllll}
\hline Age in years & & $\mathbf{1}$ & $\mathbf{2}$ & $\mathbf{3}$ & $\mathbf{4}$ & $\mathbf{5}$ & $\mathbf{6}$ & $\mathbf{7 +}$ \\
\hline $\begin{array}{l}\text { \% breeding at } \\
\text { density }[\mathrm{Ba}(\mathrm{K})]\end{array}$ & high & 0 & 19 & 33 & 53 & 52 & 72 & 100 \\
$\begin{array}{l}\% \quad \text { breeding at low } \\
\text { density }[\mathrm{Ba}(0)]\end{array}$ & & & 80 & 100 & 100 & 100 & 100 & 100 \\
\hline
\end{tabular}

\section{Simulation models}

Fundamentally, the size of a population is determined by mortality, reproduction, emigration and immigration. As far as currently known, the Red Kite is a species showing high natal philopatry as well as high adult breeding-site philopatry (Newton et al. 1989; Nachtigall 2008; Pfeiffer 2009) and thus emigration and immigration processes should mainly take place within the large-scale population that we are addressing here. We therefore did not consider emigration and immigration further in the population models. For local or regional studies however, this assumption may not hold and should be further investigated.

To model population development of the Red Kite population in Germany from 1975-2015, we used 1,000 stochastic simulations with VORTEX (v. 10.3.5.0, Lacy and Pollak 2018), based on the values in Tab. S4.1 (Supporting information). Because the first timestep in the model (1975 to 1976) is needed 
to constitute the correct proportions of the different age groups in the total population, we only display model results from 1976 onwards. Age-dependent mortality for individuals in the first year, second year and third year and older was taken from the 5-year periods reported in Katzenberger et al. (2019a). The annual productivity of the breeding population (number of young/all breeding pairs) from 1988-2012 is published by the MEROS project (Mammen et al. 2017). For years where no productivity estimates were reported (1975-1987 \& 2013-2014), the average of the nearest five years in the existing data were used. The starting population was set to 400 individuals and a capacity of 1000 (initial density $=0.4$ ). The absolute number of breeding individuals is of course much higher in Germany (Grüneberg and Karthäuser 2019); we focus here only on the relative changes in the population over time. To set up the initial density, we used existing long-term population estimates for the Red Kite in Germany: In the 1970s the population was estimated to number 4.000-6.000 breeding pairs, approximately half of its previous maximum estimated in the $19^{\text {th }}$ century and onethird of its later maximum in the early 1990s (Nicolai and Kostrzewa 2001; Mammen et al. 2014). Based on this information, we assumed the initial density to be in a range of 0.3-0.5 and used a mean value of 0.4 as described above. To test the effect of the initial density assumption on our results, we replicated all analyses with starting populations of 200 and 600 individuals (density 0.2 and 0.6 respectively).

We simulated five scenarios using different formulations for the age of first reproduction (Tab. 4.4): scenario ' $3 y$ ' used the common assumption that all birds start breeding at three years of age, scenarios 'D-E1' to 'D-E8' all used the density-dependent formula of breeding age described above (min. breeding age 2 years), but differed in the exponent used (1, 2, 4 or 8; Fig. 4.2). Independently of age, we added a stochastic variation in the annual percentage of breeding individuals (std. dev. $10 \%$ ). As the actual relationship between density and age of first reproduction is currently unknown, the scenarios with the differing exponents were used to test different functional forms of the relationship between density and age of first reproduction. The standard population size reported in VORTEX is the total population, but separate values for the different age groups (first year, non-breeding, breeding individuals) at each time step can be extracted from the optional census files (.yr file format). From the 1,000 stochastic simulations for each scenario we calculated the average and standard deviation of population size at each time step in the different age groups using R (v. 3.5.2, R Core Team 2018). The number of non-breeding individuals was calculated by subtracting the number of breeders from the sum of all individuals older than one year. 
Tab. 4.4: Description of the model scenarios with different assumptions on age of first reproduction.

\begin{tabular}{ll}
\hline Scenario & Description (see also Fig. 4.2) \\
\hline $3 y$ & This scenario uses the common assumption of a fixed age of first reproduction at three years, \\
without any density-dependent regulation. & $\begin{array}{l}\text { In this scenario, age of first reproduction is regulated linearly by density (exponent } 1 \text { in density } \\
\text { function). An increase in density thus has the same effect on recruitment age at low and at high } \\
\text { densities and already at very low densities (<0.15) a slight density regulation takes effect. }\end{array}$ \\
D-E2 & $\begin{array}{l}\text { In this scenario, age of first reproduction is regulated non-linearly by density (exponent } 2 \text { in } \\
\text { density function). Under low densities (<0.25), the effect of density on age of first reproduction } \\
\text { is minimal, but at densities }>0.25 \text { the regulation increasingly affects recruitment age. }\end{array}$ \\
D-E4 & $\begin{array}{l}\text { In this scenario, age of first reproduction is regulated non-linearly by density (exponent } 4 \text { in } \\
\text { density function). Until intermediate densities (<0.45), the effect of density on age of first } \\
\text { reproduction is minimal, but at densities }>0.45 \text { the regulation shows a strongly increasing effect } \\
\text { on recruitment age. }\end{array}$ \\
In this scenario, age of first reproduction is regulated non-linearly by density (exponent 8 in \\
density function). Until high densities (<0.75), the effect of density on age of first reproduction is \\
minimal, but at densities $>0.75$ the regulation shows a very rapidly increasing effect on \\
recruitment age.
\end{tabular}




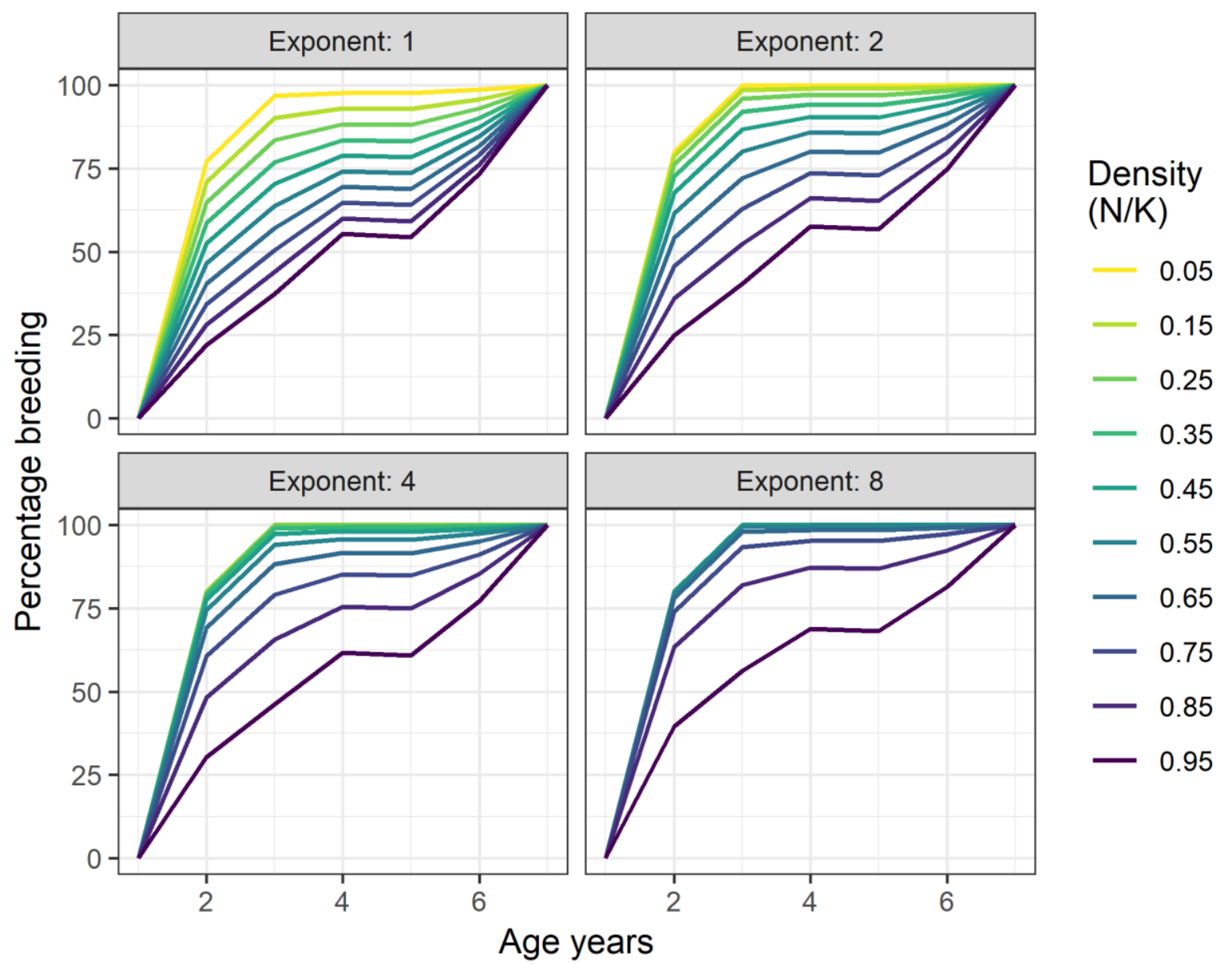

Fig. 4.2: Percentage of breeders in age 1-7 years according to different forms (exponent 1-8) of the derived function for density-dependence in the age of first reproduction. $\mathrm{N}=$ total population size, $\mathrm{K}=$ capacity.

The model estimates for the breeding part of the population in each scenario were compared based on relative annual changes (\%) to published estimates of Red Kite breeding population size in Germany for 1988-2014 (Mammen 2016). These estimates of Red Kite breeding population size are based on field surveys of breeding individuals and reported as index data by the MEROS project (Mammen 2016). Comparing the model predictions of breeding individuals to the index data based on relative annual changes assured that the choice of a base year for indexing did not affect the comparison. To quantify the difference between the model scenarios and the breeding population index data we used the root mean square error (RMSE). Because the RMSE in this case is calculated from relative annual changes, it describes the overall annual prediction error expected to occur when making a model prediction for a single year (in percent). 


\subsection{Results}

\section{Model-based reconstruction of Red Kite breeding population}

The Red Kite breeding population reconstructed in the different model scenarios generally increased until the early 1990s and then showed either continuing or gradually slowing declines thereafter (Fig. 4.3A). Changing the age of first reproduction in the different model scenarios showed a considerable effect on the development of the breeding population over time. In comparison with existing breeding population estimates for the German Red Kite population, the scenarios 'D-E4' and 'D-E8' best reflected the long-term development (Fig. 4.3B). The scenario 'D-E4', with a noticeable regulation of age of first reproduction occurring at intermediate densities, also showed the best fit to the annual index data from breeding population surveys from 1988-2014 (RMSE: 8.11). Scenario ' $3 y^{\prime}$, assuming a fixed age of first reproduction at 3 years, showed the worst fit to the annual breeding population index (RMSE: 8.84). Based on the difference in RMSE, scenario 'D-E4' improved the prediction error of the model for a single year by about 8 \% compared to scenario ' $3 y$ '. When projecting a population development over 30 years, the annual prediction error accumulates and the number of breeding individuals at the end of the time-series would be expected to differ on average by $22 \%$ between the two scenarios. The RMSE for the other scenarios was 8.48 for 'D-E8', 8.20 for 'D-E2' and 8.19 for 'DE1'. Replicating the simulations with differing starting densities of 0.2 and 0.6 always showed the lowest RMSE for scenario 'D-E4' or 'D-E2' and the highest RMSE for scenario ' $3 y$ '. Comparing the annual relative changes between the index data and the model scenarios ' $3 y$ ' and 'D-E4' showed that the changes in breeding population size from year to year were often stronger in the index data from population surveys than in the model population (Fig. 4.4). Scenario ' $3 y$ ' reflected the initial breeding population changes until the late 1990s relatively well, but thereafter strongly deviated from the population index. Scenario 'D-E4' generally reflected the alternating phases of declines and increases in the breeding population index better. 

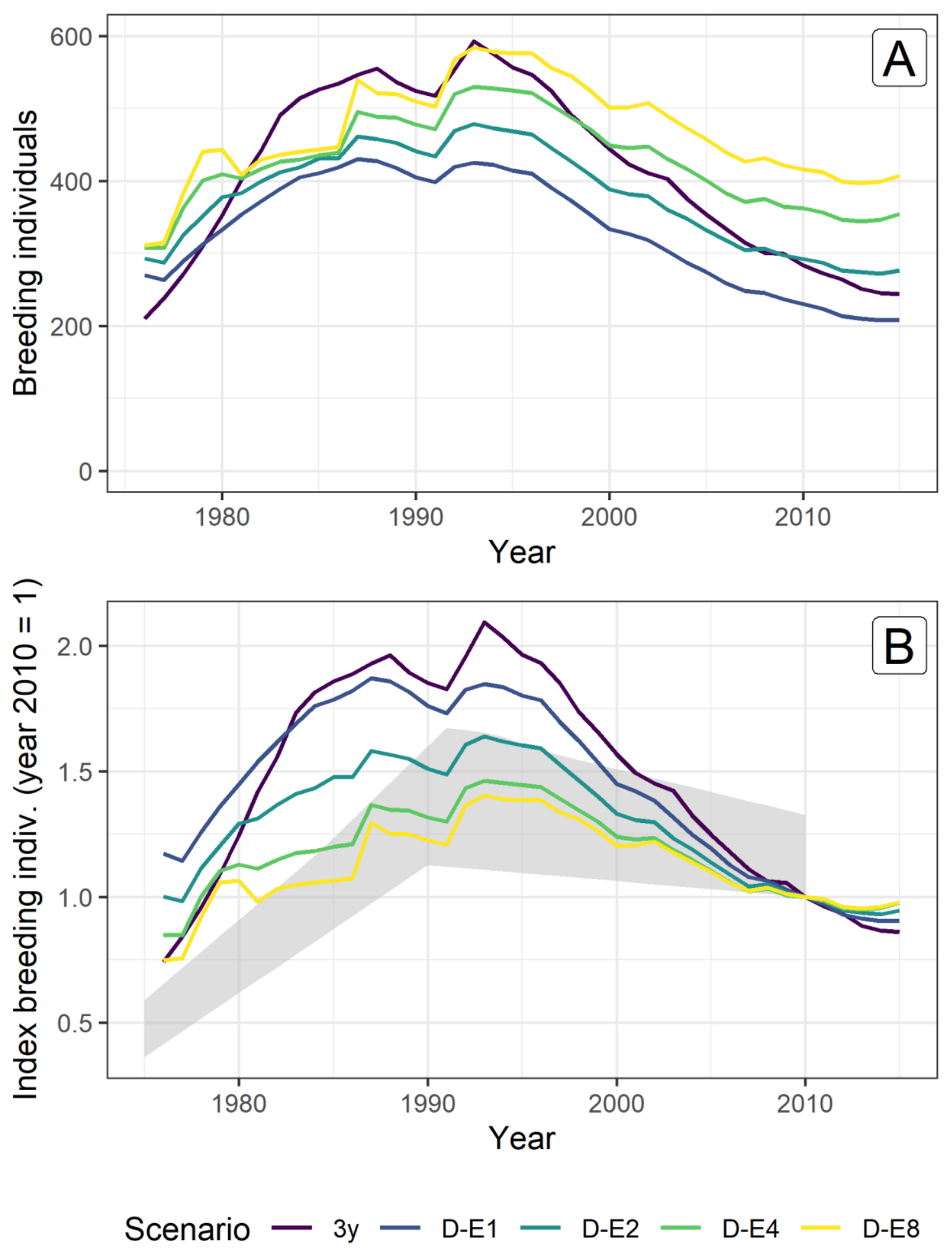

Fig. 4.3: Part A: Number of breeding Red Kites predicted by the different model scenarios over time without (' $\left.3 y^{\prime}\right)$ and with ('D-E1' to 'D-E8') density-dependence in age of first reproduction. The numbers at the start of the time series differ according to the density-dependent model formulation. Part B: Number of breeding individuals in the model scenarios indexed to year 2010, for comparison with long-term breeding population estimates for the German Red Kite population (grey shading) reported in Mammen et al. (2014) based on Nicolai \& Kostrzewa (2001). 


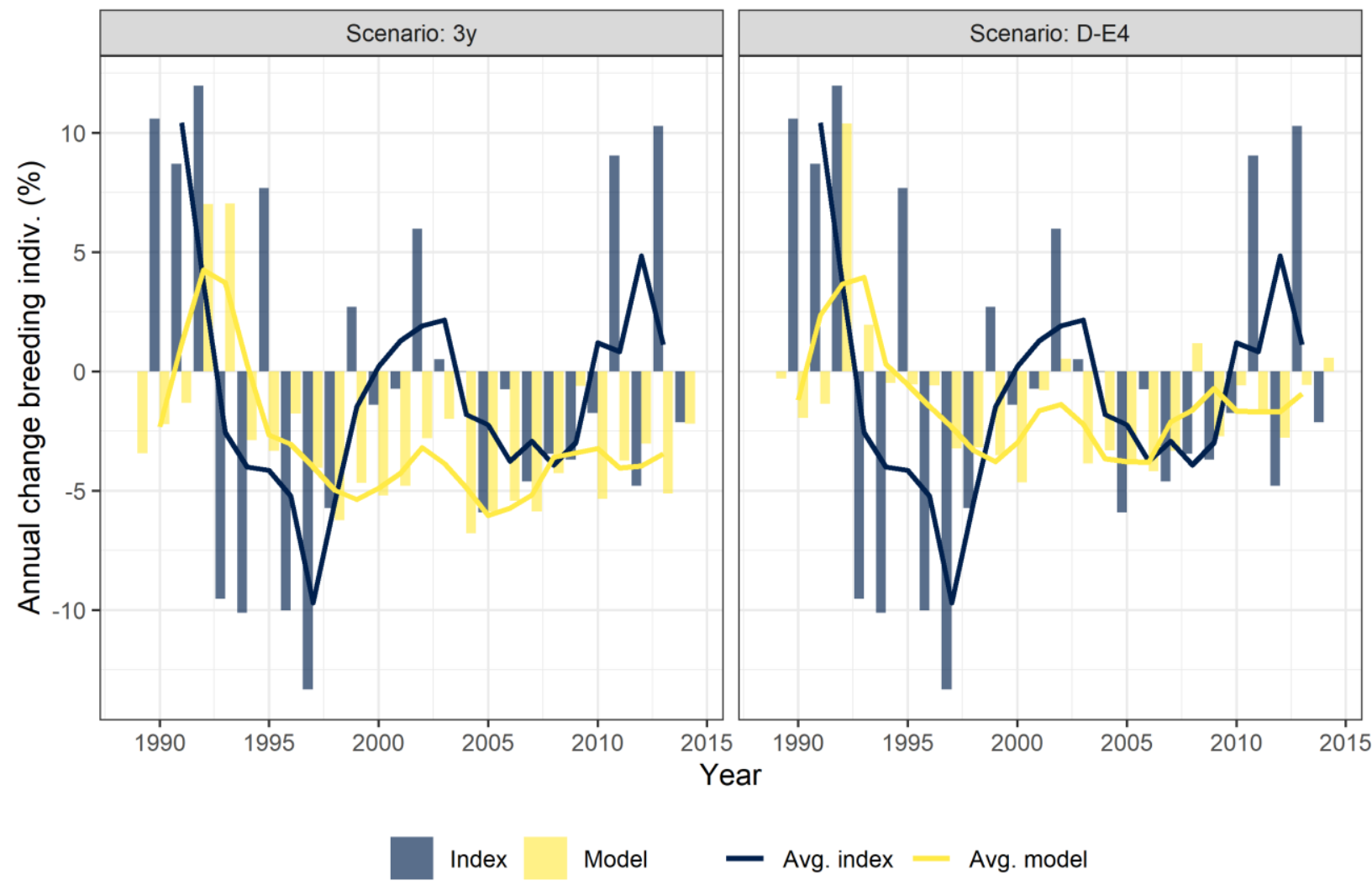

Fig. 4.4: Comparison between annual relative change in the number of breeding Red Kites from 1989-2014 based on index data from MEROS breeding population surveys (Mammen 2016) and model predictions without ('3y') and with ('D-E4') density-dependence in age of first reproduction. Lines show a 3-year moving average of annual change.

\section{Population dynamics and density-dependent age of first reproduction}

Based on the model scenario 'D-E4', which represents a noticeable regulation of age of first reproduction starting only at intermediate densities, the development of the breeding and the nonbreeding part of the population can be viewed separately (Fig. 4.5). Under the conditions at the beginning of the time series, an increase and overall a very high proportion of non-breeding birds in the model population was observed. Thus, by the mid-1980s, the capacity limit of the total population was reached, despite the relatively low number of breeding birds. Already from 1985 onwards, a continuous decline of the non-breeding and the total population became apparent (Fig. 4.5). However, due to the high number of individuals recruiting as breeders for the first time during this period, the breeding population in the model continued to increase until the early 1990s (Fig. 4.5). From 1995 onwards, the breeding population also started to decline, but gradually stabilised after the year 2010 . At the end of the time series, the total population was about $50 \%$ lower than the maximum in the early 1980s, while the breeding population was only slightly smaller than in the 1980s but about $33 \%$ lower than the maximum in the early 1990s (Fig. 4.5). 
The density-dependent proportion of breeding individuals aged 2 and 3 years in the population decreased sharply at the beginning, as high total densities were reached (Fig. 4.6). With the decline of the total population, however, more and more birds aged 2 and 3 years started to breed, and the proportion of breeding birds in these age groups reached a plateau near their maximum values by the year 2005 (Fig. 4.6). Under the given vital rates and a density-dependent regulation of age of first reproduction, the proportion of non-breeders in the population was largely minimised over time. The number of first year birds in the model in 2015 was nearly 50 \% lower than in the early 1980s, while the mean number of non-breeding individuals (ages 2-6 years) even decreased by $90 \%$ during this period (Fig. 4.5).

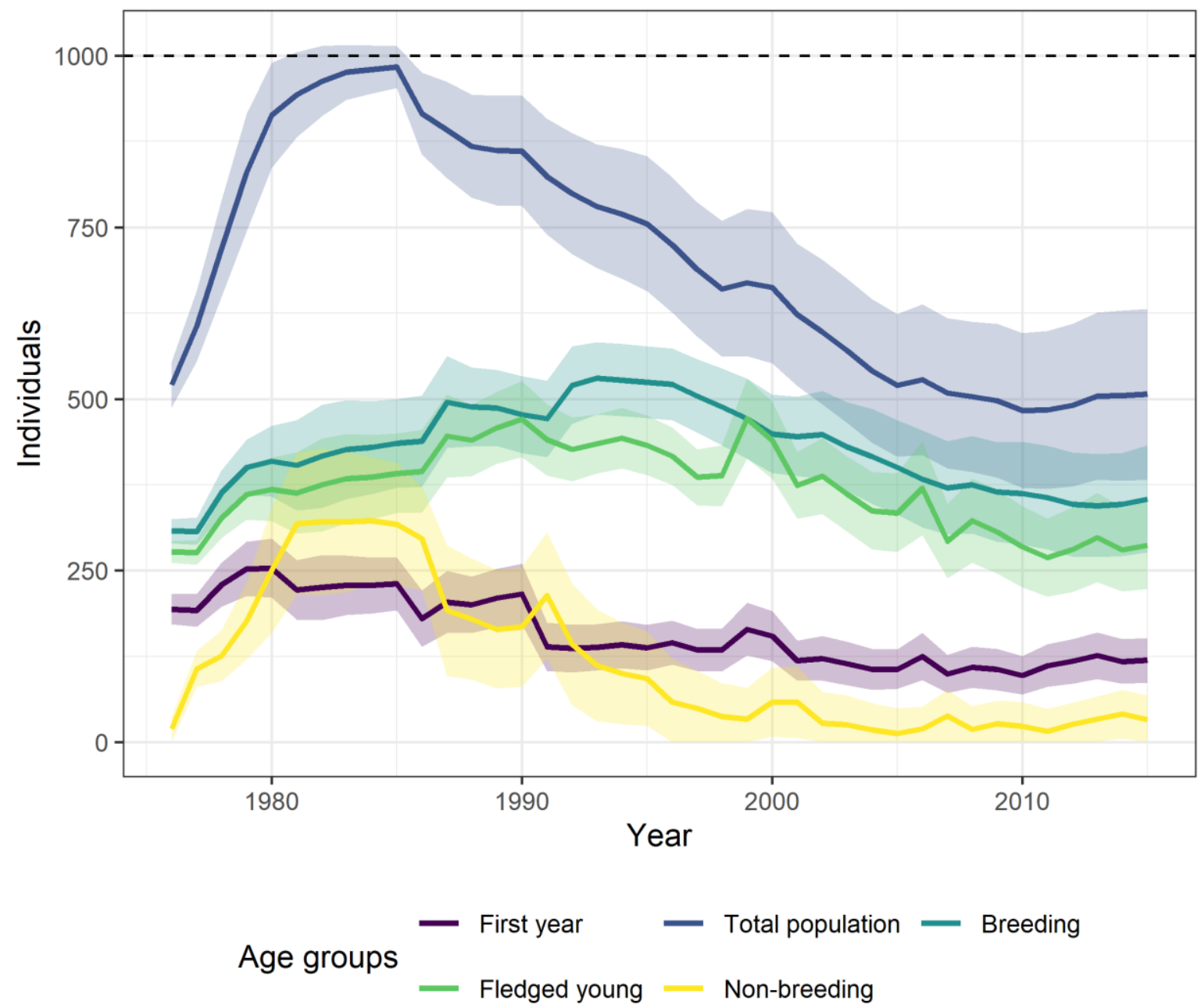

Fig. 4.5: Mean number of Red Kites in different age groups from 1000 simulations with the density-dependent model scenario 'D-E4'. Shading shows one standard deviation around the mean; the dashed horizontal line shows the assumed capacity. 
In the model scenario ' $3 y$ ', without a density-dependent regulation of age of first reproduction, the breeding population showed extremely rapid changes over time, nearly doubling in size within 5 years from 1976 to 1981 and declining by almost 50 \% from the early 1990s until just after the year 2000 (Fig. S4.1, Supporting information). The total population in scenario ' $3 y^{\prime}$ also supported few nonbreeding individuals and they were minimised over time.

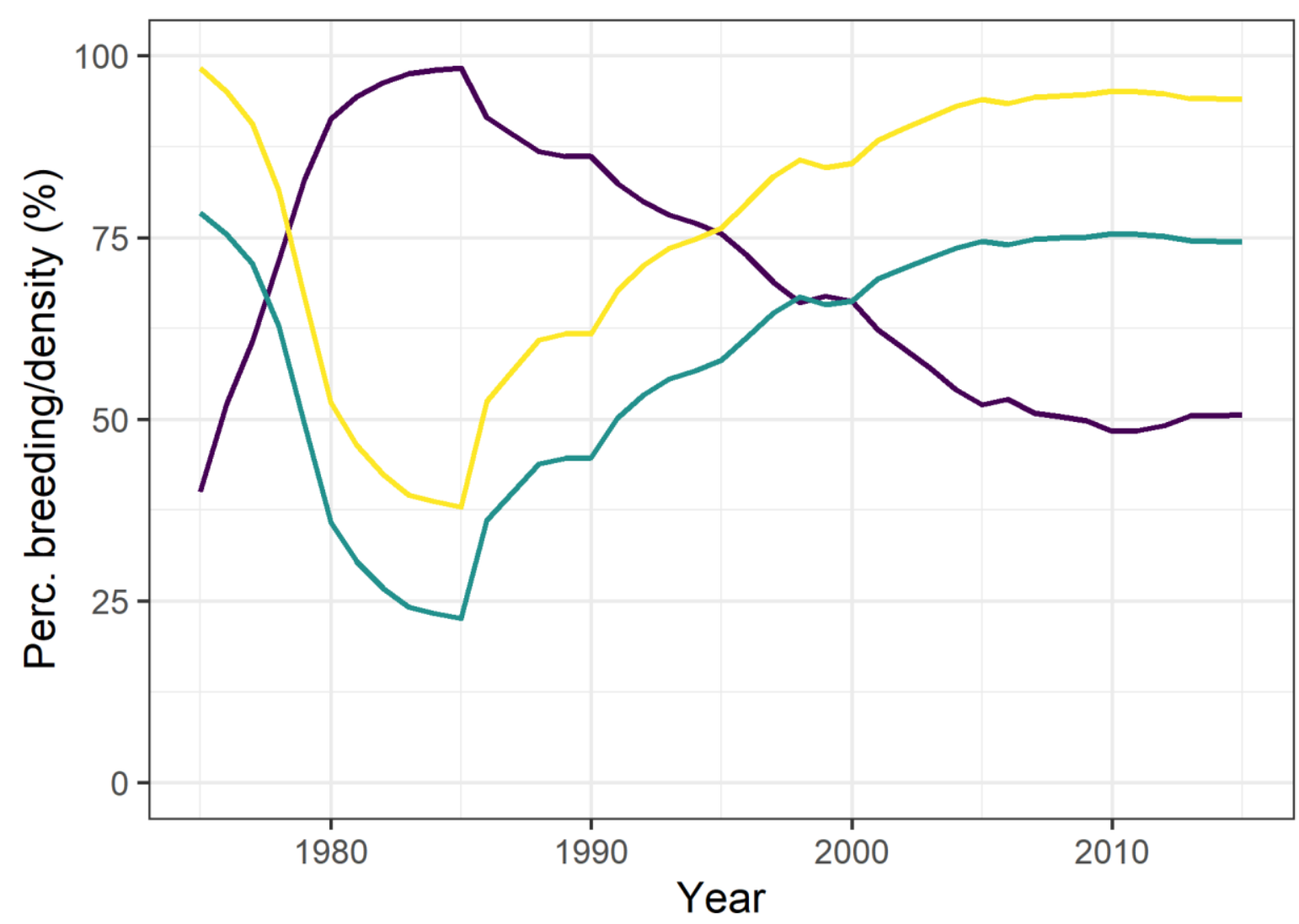

- Density (N/K) - Age 2y - Age 3y

Fig. 4.6: Density-dependence of the mean percentage of breeding Red Kites in ages 2-3 years from model scenario 'D-E4'. 


\subsection{Discussion}

Using an age-structured demographic model and published estimates of survival and reproduction, we were able to reconstruct key features of the population dynamics of the Red Kite in Germany over four decades. A substantial growth of the breeding population throughout the 1970-1980s, in part due to legal protection of the Red Kite and other raptors, is documented by large-scale field surveys in Germany (Nicolai and König 1990; Aebischer 2009). Our model also reproduces the peak of the Red Kite breeding population size in the early 1990s and the following decline and stabilisation, known from annual field surveys starting in the late 1980s (Mammen 2016). We also reconstruct a strong decline of the total Red Kite population in Germany by nearly $40 \%$ from the early 1990s to the early 2000s (Fig. 4.5). Because most of the German Red Kite population winters on the Iberian peninsula, this could to a large extent explain the recorded $50 \%$ decrease of the species' wintering population in Spain during same time period (Viñuela et al. 1999; Cardiel 2006). Since the German breeding population of the Red Kite declined approximately by $20 \%$ during this time period (Mammen 2016), only the consideration of simultaneous cryptic declines in juvenile and non-breeding individuals based on demographic data reveals the full magnitude of the decrease during this time period. Additionally, we show that the age of first reproduction in a Red Kite population is most likely density-dependent and that incorporating this into model projections yields more accurate results.

\section{Density-dependent age of first reproduction}

The existing data on Red Kite age of first reproduction clearly suggest such a density-dependence (Tab. 4.1) - as already proposed by Walz (2005), but has largely been overlooked in previous simulation studies. Also, the first results from telemetry studies tagging juvenile Red Kites under a high density situation in Switzerland indicate a strongly increased recruitment age and considerable floating behaviour: a large proportion of individuals has not yet settled in a breeding territory at ages up to the sixth calendar year (Scherler 2020). Despite extensive scientific evidence that age of first reproduction frequently responds to changes in population size, both in long- and short-lived species, this process is often not considered in PVA assessments or other demographic simulations (cf. Ferrer et al. 2004; Morandini et al. 2019). Yet, variation in age of first reproduction can have a substantial impact on the structure and temporal development of animal populations. We show here that for raptors this not only applies to small populations, where changes in age of first reproduction affect productivity and thus extinction risk (Morandini et al. 2019), but that also the dynamics of larger populations can be affected via effects on non-breeding floaters. The existing knowledge about density feedbacks on age of first reproduction in a variety of animal species highlights the generality 
of this process, which means it should also be considered more often to improve the robustness of demographic simulations and projection models (Chaudhary and Oli 2020).

\section{Population dynamics and conservation status}

In the case of the German Red Kite population, our model allows for the first time to investigate the likely long-term changes in the total population, including a separate consideration of juveniles and non-breeding individuals. This model framework allows a more comprehensive assessment of the conservation status for the species and highlights changes in population size that go unnoticed if only the breeding part of the population is being considered. As such, our results have far-reaching implications for the conservation status of the Red Kite in Germany, because they suggest a drastic long-term decrease in the number of juveniles and non-breeding individuals in the population. The demographic drivers of this process are, on the one hand, the observed substantial declines in juvenile survival rates and breeding productivity (Mammen et al. 2017; Katzenberger et al. 2019a), which are both at least partly connected to decreased food availability during the breeding season (Pfeiffer 2000; Nachtigall et al. 2010). Declining survival rates are surely also impacted by direct mortality - how different causes contribute to this quantitatively is however currently unclear (Katzenberger et al. 2019a). On the other hand, a density-dependent shift towards a younger age of first breeding has likely eroded the non-breeding part of the Red Kite population over time (Walz 2005). This continuous shrinkage of floaters is however not visible when judged only by the stabilised trend of the breeding population. This also indicates that the capacity to buffer further negative effects, that exists to some degree in a healthy raptor population (Hunt 1998; Ferrer et al. 2004), could be largely eroded at least in parts of the German Red Kite population. In a healthy raptor population, the ratio of breeding to non-breeding individuals can be expected as nearly 1:1 (also known as "Moffat's equilibrium"; Newton 1988; Hunt 1998); a situation that our model suggests occurred only in the 1980s for the Red Kite in Germany. This floater-to-breeder ratio can help to assess the health of a raptor population (Penteriani et al. 2011), while an increased proportion of immature birds recruiting as breeders can act as a warning sign of further population declines (Ferrer et al. 2003). However, these metrics need to be combined with other information to reliably assess population health and to predict the risk of decline (Monzón and Friedenberg 2018). Another important consideration is that breeding attempts by younger, inexperienced individuals tend to produce less offspring in the Red Kite (Evans et al. 1999; Pfeiffer 2009), which could further affect the productivity of the population. 
Because formerly marginal breeding populations of the Red Kite in Europe are increasing, e.g. in the UK, in Switzerland and in Sweden, the global conservation status of the species has recently been down-listed from "Near Threatened" to "Least Concern" by BirdLife International (BirdLife International 2020). This assessment is however most likely only based on nest counts and the number of breeding pairs in the different European countries of the species' range - which potentially overlooks demographic changes in population structure and the non-breeding parts of the Red Kite populations. It was acknowledged in the reclassification process, that the documented long-term decline of Red Kite survival in Germany (Katzenberger et al. 2019a), could limit the recovery of the European population (BirdLife International 2020). However, as we show here, and as also demonstrated by Sergio et al. (2020), a focus on breeding individuals alone fails to account for substantial decreases in the juvenile and non-breeding age classes of the Red Kite. If this more comprehensive view is taken, and cryptic population declines inferred from demographic data are considered, the major part of the European Red Kite population in Germany is still decimated well below its numbers from thirty years ago. Since the major threats in the breeding and wintering areas of the species also persist (BirdLife International 2020), we argue that the European conservation assessment of the Red Kite should also consider this new information. Generally, our example shows that conservation status assessments for long-lived bird species, with potentially large non-breeding proportions and known floating behaviour, could benefit from including further demographic data and modelling procedures to allow a more comprehensive view on total population size (Penteriani et al. 2011; Tanferna et al. 2013; Lee et al. 2017; Piper et al. 2020).

\section{Future research needs}

The density-dependence function that we used here to reconstruct Red Kite population dynamics is based on case studies and empirical data. Yet, the exact functional form of the relationship between age of first reproduction and population density in the Red Kite is currently unknown. By including different assumptions about the form of the relationship (exponent 1-8) in our model scenarios, we could show that density most likely has a non-linear effect on age of first breeding. However, this needs further empirical study, to improve demographic simulations and model projections for Red Kite population studies. Especially the satellite telemetry of juvenile Red Kites, which allows to determine the exact location and age of first breeding for an individual, promises further insights here. Generally, a better understanding of individual life-history effects on reproduction and survival but also of sex-specific strategies would be needed to further improve the demographic models for the Red Kite. For example, breeding performance improves in early-life and senesces with age differently for male and female white-tailed eagles Haliaeetus albicilla (Murgatroyd et al. 2018), while 
reproduction of black sparrowhawks Accipiter melanoleucus shows no increase in early-life but senescence with age for both sexes (Sumasgutner et al. 2019). For the Red Kite it is currently unclear if, or how, breeding performance declines with increasing age. Also, sex-specific strategies in age of first reproduction have received little attention for raptors but they could markedly affect demographic models (Millsap et al. 2019). If such individual life-history effects explain much of the variation in population dynamics, the effect of density-dependent variation in age of first reproduction could be smaller than suggested here.

Our reconstruction of the Red Kite population in Germany also assumes the dynamics of a single, nation-wide population. Of course, the national Red Kite population consists in reality of a number of local or regional subpopulations, with differing densities, vital rates and trends. As neither the likely exchange and interplay between these subpopulations, nor their vital rates, are currently known, especially not the by far most important parameter adult survival (Sergio et al. 2019a), we can only reconstruct a hypothetical large-scale population at the moment. The major data source for estimating local survival rates is of course individual marking, but with feasible additional efforts also field surveys of breeding territories can elucidate these key demographic data by non-invasive means (Brune et al. 2019) or even from unmarked individuals (Roth and Amrhein 2010; Oppel et al. 2016). Future studies should also aim for a better understanding of emigration and immigration in local Red Kite populations, which can be achieved by combining different data sources in an integrated population model (Schaub and Abadi 2011; Plard et al. 2019).

If we consider the simplification to a nation-wide population, the uncertainty about individual lifehistory effects, as well as the use of time-aggregated survival estimates, our model cannot be expected to fully reproduce the annual variation in population size of the Red Kite in Germany. Rather, the results should be seen as a long-term reconstruction of key features of the species' population dynamics. In comparison to annual changes from index data (Fig. 4.4), which are imputed to the national scale but likely subject to observation error and site-level effects as well, some temporal mismatch and differences in the magnitude of annual changes need to be expected. We therefore focus our results on the relative improvement in prediction error related to the assumption on age of first reproduction when forecasting a time-series over several decades.

Finally, when using density-dependent models, the assumed capacity has an influence on the resulting projections. It is currently not clear how to measure a realistic landscape capacity on the local scale; 
one approach to get an objective estimate of the potential for Red Kite breeding territories in a landscape could be to apply habitat suitability models, taking into account breeding and feeding habitats, in conjunction with population surveys to account for social attraction and philopatry (Heuck et al. 2013; Katzenberger 2019).

\section{Conclusions}

We could show, based on a review of existing population studies and our simulations, that the age of first reproduction for the Red Kite most likely responds non-linearly to population density. Such a density feedback, seen in a variety of animal populations, should be considered more often in demographic simulations and PVA studies to further improve the robustness of model projections. For the Red Kite and other raptors, the existing evidence strongly supports a substantial effect of variation in age of first reproduction on population productivity, but also on the proportion of non-breeding floaters in the total population. This means that judging the conservation status of long-lived raptor populations only by changes in the number of breeding individuals, is prone to overlooking substantial changes in the dynamics of floaters and of total population size. For a better understanding of the population dynamics of the Red Kite and other raptors, we need more empirical research on the age of first reproduction in relation to population density, but also more demographic data on the dispersal and survival of individuals.

\section{Data accessibility}

Our results can be fully replicated with the VORTEX software, the input data given in Tab. S4.1 and the cited references. Upon publication acceptance, the model results will also be uploaded to a publicly accessible repository (e.g. figshare).

\section{Acknowledgements}

J.K. gratefully acknowledges funding from the Federal Agency for Nature Conservation (BfN), with funds from the Ministry for the Environment, Nature Conservation and Nuclear Safety (FKZ 3511685(10). We thank the 'Förderverein für Ökologie und Monitoring von Greifvogel- und Eulenarten' for reporting the results from the MEROS project. For helpful comments on previous drafts of this manuscript we are grateful to J. Kamp, S. Fischer, C. Sudfeldt and P. Scherler. The constructive comments from F. Sergio as well as four anonymous reviewers greatly helped to further improve the manuscript. 


\subsection{Supporting information}

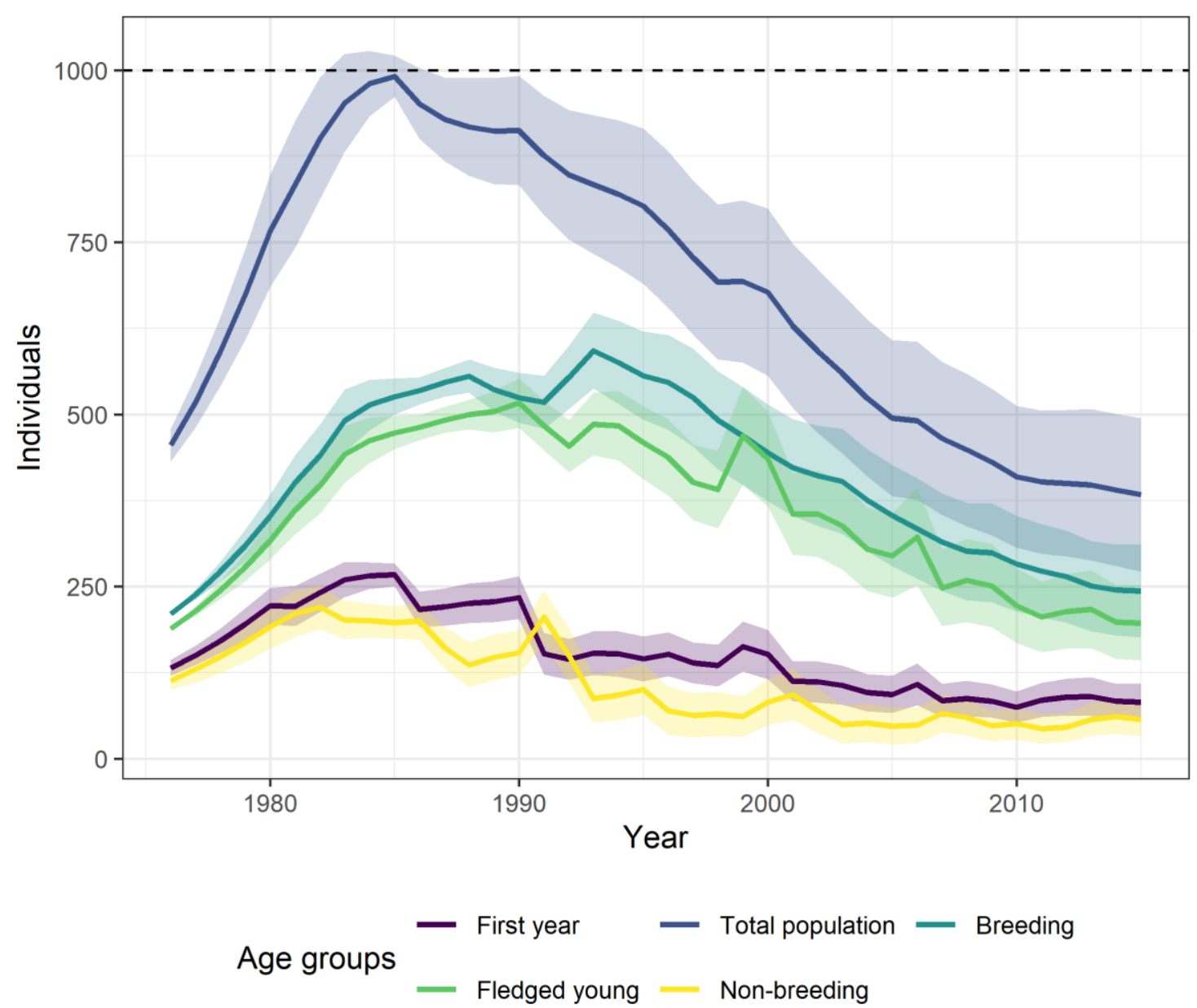

Fig. S4.1: Mean number of Red Kites in different age groups from 1000 simulations with the model scenario ' $3 y^{\prime}$, assuming a fixed age of first reproduction with 3 years. Shading shows one standard deviation around the mean; the dashed horizontal line shows the assumed capacity 
Tab. S4.1: Values used to parameterise the VORTEX population model. Functions are initialised with the equals sign, TIMESERIES is an existing VORTEX function to read the input values as an annual timeseries.

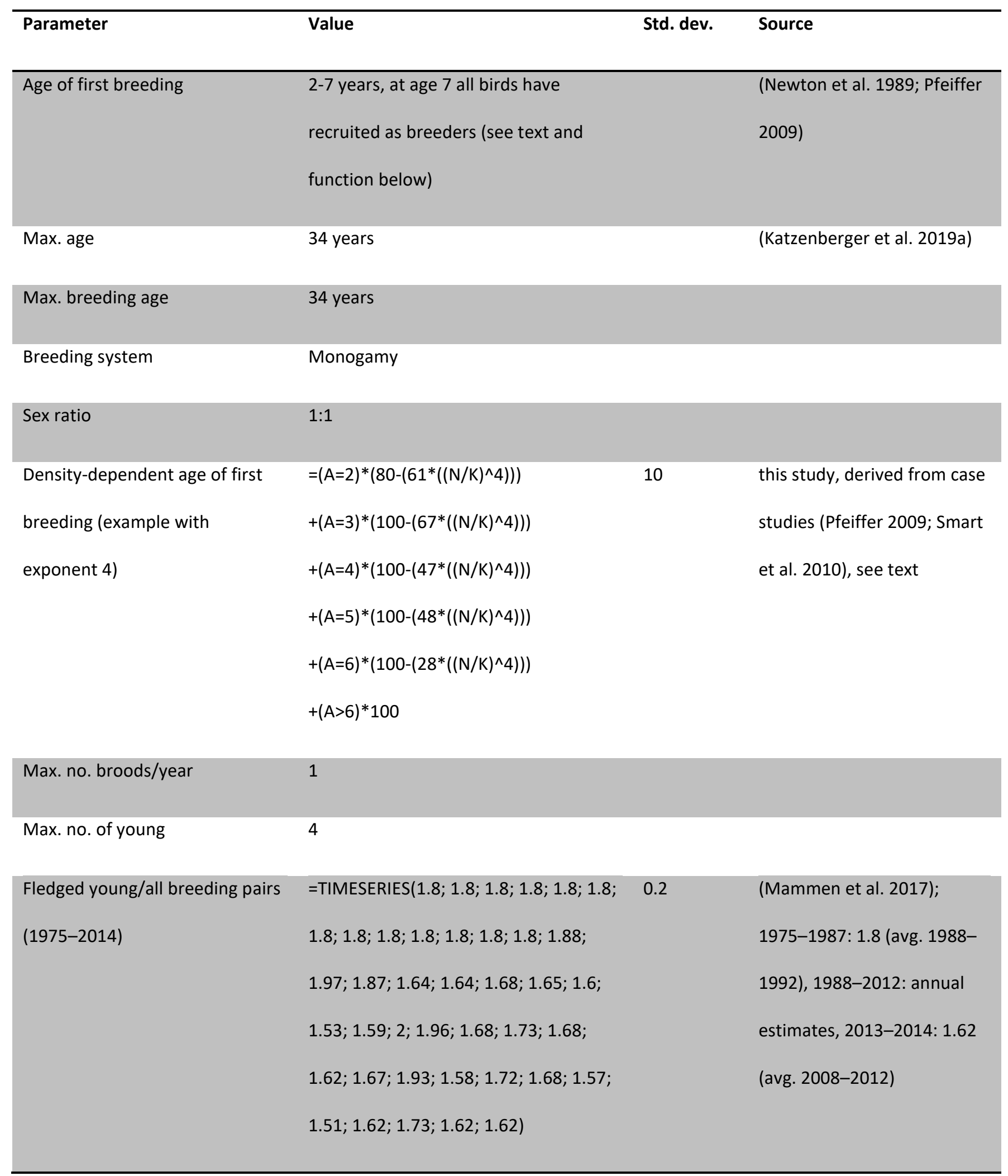




\begin{tabular}{|c|c|c|c|}
\hline Mortality first year (5-year & $=$ TIMESERIES(30.2; 30.2; 30.2; 30.2; & 6 & (Katzenberger et al. 2019a) \\
\hline periods from 1975-2014 in \%) & $\begin{array}{l}\text { 30.2; 38.4; 38.4; 38.4; 38.4; 38.4; 54.4; } \\
\text { 54.4; 54.4; 54.4; 54.4; 68.3; 68.3; 68.3; } \\
68.3 ; 68.3 ; 65.3 ; 65.3 ; 65.3 ; 65.3 ; 65.3 ; \\
68.5 ; 68.5 ; 68.5 ; 68.5 ; 68.5 ; 66.2 ; 66.2 ; \\
66.2 ; 66.2 ; 66.2 ; 58.3 ; 58.3 ; 58.3 ; 58.3 ; \\
58.3)\end{array}$ & & \\
\hline $\begin{array}{l}\text { Mortality second year (5-year } \\
\text { periods from 1975-2014 in \%) }\end{array}$ & $\begin{array}{l}=\text { TIMESERIES(27; 27; 27; 27; 27; 22.5; } \\
22.5 ; 22.5 ; 22.5 ; 22.5 ; 28.9 ; 28.9 ; 28.9 ; \\
28.9 ; 28.9 ; 27.1 ; 27.1 ; 27.1 ; 27.1 ; 27.1 ; \\
\text { 36.8; 36.8; 36.8; 36.8; 36.8; 30.8; 30.8; } \\
\text { 30.8; 30.8; 30.8; 26.6; 26.6; 26.6; 26.6; } \\
26.6 ; 30.6 ; 30.6 ; 30.6 ; 30.6 ; 30.6)\end{array}$ & 5 & (Katzenberger et al. 2019a) \\
\hline $\begin{array}{l}\text { Mortality third year and older } \\
\text { (5-year periods from 1975-2014 } \\
\text { in \%) }\end{array}$ & $\begin{array}{l}=\text { TIMESERIES(16.1; 16.1; } 16.1 ; 16.1 ; \\
\text { 16.1; 18.7; } 18.7 ; 18.7 ; 18.7 ; 18.7 ; 23.6 ; \\
23.6 ; 23.6 ; 23.6 ; 23.6 ; 18 ; 18 ; 18 ; 18 ; \\
\text { 18; 20.2; 20.2; } 20.2 ; 20.2 ; 20.2 ; 21.9 ; \\
21.9 ; 21.9 ; 21.9 ; 21.9 ; 21.4 ; 21.4 ; 21.4 ; \\
21.4 ; 21.4 ; 20.8 ; 20.8 ; 20.8 ; 20.8 ; 20.8)\end{array}$ & 2.5 & (Katzenberger et al. 2019a) \\
\hline Starting population size $(\mathrm{N})$ & 400 & & \\
\hline Capacity (K) & 1000 & & \\
\hline
\end{tabular}




\section{Chapter 5: Synopis}

\subsection{Perspective on the ecology and conservation of the Red Kite}

Considering both the existing knowledge and the chapters of this thesis, the Red Kite should be viewed as a highly social and adaptable species, with a peculiar demography and which is profoundly linked to humans in many ways. In the recent decade, the European population development of the Red Kite seems to have entered into a new phase, with population increases in formerly marginal breeding areas (BirdLife International 2020). Which processes might be causing these recent developments is yet unclear, but certainly behavioural changes in the Red Kite population as well as recent improvements in the main wintering areas could contribute to an explanation. From a behavioural perspective, an increasing tendency to overwinter in the traditional breeding areas (Aebischer 2009; Karthäuser et al. 2019b), could have improved the survival rates in some areas (decreasing threats of migration). On the other hand, a re-conquering of the rural landscape in close proximity to humans (Nicolai et al. 2017; Martínez-Abraín et al. 2019), could have enhanced the proportion of breeding individuals and reproductive success and productivity in the Red Kite population (successful breeding by fearless individuals in formerly unused habitat near humans). Also, it seems the major threat from direct and indirect poisoning for Red Kites in Spain (Cardiel and Viñuela 2009; Luque-Larena et al. 2018; Mateo-Tomás et al. 2020) was decreased to some extent in the last ten years - both by curtailing illegal use of poison baits (de la Bodega et al. 2020) as well as by reducing secondary poisoning through limiting agricultural rodenticide application in some regions (J. Viñuela, pers. comm.). These hypotheses are however entirely untested and need to be investigated further on relevant spatial scales and with suitable data.

Key aspects of this thesis are the study of demography, distribution and population dynamics disciplines which are usually looking backwards in time to describe and analyse developments in the past, especially for such a long-lived study species like the Red Kite. Yet, important aims of these efforts are always an increased understanding of central demographic rates, inference on crucial influencing variables and generally a scientific basis for informing future decisions and developments. The key scientific tools for making informed predictions and for projecting possible outcomes based on current knowledge are statistical and mechanistic models (Clark and Gelfand 2006), which essentially need sound empirical data and expert knowledge to give useful results (Chaudhary and Oli 2020).

A central aspect of the population biology of the Red Kite, that is scientifically well established but still often underappreciated in applied management and conservation assessments, is the extreme longevity of the species and the major importance of adult survival for its demography (Tenan et al. 
2012; Sergio et al. 2019a; Bird et al. 2020). The fact that population growth rate of the Red Kite reacts proportionally 10-20 times more strongly to variation in adult survival than to productivity (Sergio et al. 2019a) and the finding that as much as 27 breeding pairs are necessary to generate a single prime age breeding individual (Sergio et al. 2020) nicely illustrate this central paradigm. In this context, it becomes abundantly clear that preventing mortality of adult Red Kites is the centrepiece of the species' conservation and that for a better understanding of changes in population size current data on survival rates are indispensable.

The age-specific survival rates calculated in chapter 2 based on ring-recoveries from Germany are a step forward in this direction; the declining trend in adult survival throughout the last decades documented with this analysis makes it clear that the causes of Red Kite mortality need to be addressed further to ensure long-term viability of the species. However, to inform on the regionally differing population trends of the species in Germany in the last years (Grüneberg and Karthäuser 2019), future studies on survival rates need to incorporate more recent data and should focus on a regional spatial scale. The drastic decrease in Red Kite juvenile survival that was also found in chapter 2 has less direct influence on population growth rate, but it erodes the non-breeding part of the population over time - as shown in chapter 4 and also in the recent work by Sergio et al. (2020). The causes of the change in Red Kite juvenile survival need further study, but two major, non-exclusive hypotheses on causal mechanisms for the decline over several decades are: (i) long-term negative effects of poisoning and (ii) a decrease in body condition related to ongoing declines in food availability.

Poisoning has affected the European Red Kite population for decades (Berny and Gaillet 2008; Cardiel and Viñuela 2009) and still threatens survival by direct as well as indirect effects (Mateo-Tomás et al. 2020; Badry et al. 2021). That younger individuals are especially vulnerable to poisoning suggests previous work from the UK and from Spain (Smart et al. 2010; Tavecchia et al. 2012; Sergio et al. 2020). The study from Sanz-Aguilar et al. (2015) however reports a higher susceptibility of adult individuals to poisoning; generally the authors conclude from their comparison of island vs. mainland populations, that survival in the first year could be especially dependent on conditions in the wintering areas for migratory Red Kite populations (Sanz-Aguilar et al. 2015).

The loss of food-availability in the agricultural landscape is considered another major threat for the Red Kite (Knott et al. 2009); in Germany this issue is mostly discussed as a cause for decreasing breeding success and nestling productivity (Mammen et al. 2014). But also after fledging from the parental nest, this threat could negatively impact the survival probability of juveniles hatching under low resource availability - a process known from other long-lived bird species (Van De Pol et al. 2006; Payo-Payo et al. 2016). Indeed, the work by Pfeiffer (2000) documents a long-term decrease in body- 
weight of Red Kite nestlings in Germany, which strongly suggests subsequent negative effects on fitness and survival in early life. A positive effect of food availability on the body condition of the chicks is also supported by feeding experiments in Switzerland, but the results also indicate that lower nestling body condition can be compensated to some degree by fledging later from the nest (Scherler 2020).

Additionally, density-dependence in the breeding and/or wintering habitats could affect survival in early-life through resource availability. Declines in juvenile survival would be expected for long-lived species under increasing density (Eberhardt 2002; Nicoll et al. 2003), but the prevalence of low juvenile survival during periods of population decline in Spain and in Germany (Sergio et al. 2020, chapter 2, chapter 4) implies that competition is not the driver of the observed long-term declines in Red Kite juvenile survival.

Despite warranting further research on causal mechanisms, the recent evidence from Germany (chapter 2) and Spain (Sergio et al. 2020), documenting low levels of juvenile survival for the Red Kite, highlights a previously overlooked key aspect in the conservation management of the species: the immature and the non-breeding part of the population. Although the survival of immature individuals and of non-breeding floaters has a relatively small direct impact on the population growth rate, high mortality in the pre-adult age classes destabilises the demographic system and also limits the effectiveness of conservation management aiming at increases in breeding success and productivity (Sergio et al. 2020). Also, the erosion of the non-breeding individuals in the population minimises the buffering capacity usually inherent in a healthy raptor population and threatens its future viability - a process that is entirely overlooked if the conservation status is judged only by the number of breeding pairs and additional demographic data is not considered or not available (chapter 4). For Red Kite populations showing low juvenile and immature survival and a decreasing reproduction, like in southern Spain but also in Germany, it can thus be concluded that only by the combined improvement of pre-adult survival and of adult reproduction the population can be substantially stabilised in its foundation (Sergio et al. 2020).

The Red Kite is rightfully an emblem of bird conservation in Germany, due to the disproportionally high responsibility for the species, given by the simple fact that no other country in the world is home to nearly as many breeding pairs (BirdLife International 2019). Whereas a general responsibility for society follows inevitably from this fact (Bairlein 2020), there is also a major legal responsibility, or even liability, assigned to the authorities on the federal and national level to ensure a good conservation status for the Red Kite in Germany (EU birds directive 2009/147/EG, 30.11.2009). To fullfill this responsibility, it is not only necessary to monitor the number of breeding individuals in the country, but also to gain an understanding of the species' population dynamics by studying its 
demography and especially Red Kite mortality and survival rates - as previously remarked by Aebischer (2009), Bezzel (2010) and Bairlein (2020) and also shown in this thesis.

The ideal breeding habitat for the Red Kite is often described as diverse and extensively used agricultural landscapes, a requirement shared with many other species in decline due to intensified use and loss of farmland habitats everywhere in Europe (Pe'er et al. 2014; PECBMS 2020). The analyses in chapter 3 support this view as an optimal breeding habitat for the Red Kite, but they also point out that the species is clearly not limited to such landscapes but can also cope to some extent with higher levels of intensification and under certain circumstances also benefits from human presence. Nevertheless, biodiversity-rich farmlands are key for the long-term viability of the Red Kite, to assure food availability and successful reproduction.

Increasing the food availability for raptors like the Red Kite, by implementing agricultural measures that improve abundance and accessibility of prey objects especially during the breeding season, can have an 'umbrella-function' and benefits for wider biodiversity in farmland systems (Karthäuser et al. 2019a). This means that the central role of the Red Kite in bird conservation in Germany can also be used to promote wider biodiversity improvements and its charismatic nature and its visibility in the rural landscape contribute to make it a suitable flagship species (Sergio et al. 2008) - which is able to generate public interest and support for its conservation.

Due to the strong association with the agricultural landscape, the Red Kite is also considered a farmland bird indicator species for Germany and its population trends, together with other selected species, are used to represent the state of biodiversity in this habitat (Achtziger et al. 2004). However, because the population growth rate of the Red Kite is so sensitive to adult mortality, which is rather disconnected from farmland habitats, and because threats during migration and in the wintering areas also play a major role for the species, this direct indicator function is questionable. Red Kites are also very adaptable in terms of foraging and can heavily use anthropogenic food sources which are not directly linked to farmland (Bischofberger et al. 2019). Furthermore, both the apparent strong influence of social factors on the probability of occurrence (chapter 3 ) as well as the demographic population structure with delayed recruitment and floating behaviour (chapter 4) could cause substantial time lags between changes in the agricultural landscape and the breeding population size of the Red Kite. In total, it seems unlikely that the population trends of the Red Kite are a good indicator for the short-term state of biodiversity in the agricultural landscape and other species should be considered for building a robust farmland bird indicator. 


\subsection{Important avenues for further research in Germany}

The work in this thesis highlights several important questions for further research on the Red Kite in Germany:

\section{Are there regional differences in the survival rates of the Red Kite in Germany?}

In addition to the existing bird ringing data regularly used to study survival rates, other data can also contribute to an increased understanding of spatial differences in Red Kite survival probability. Clearly, other forms of individual marking, e.g. with wing tags or satellite transmitters, also give information on annual survival rates. Especially the data already generated by the increasing use of telemetry in the last decades could already help to get a better picture on regionally differing survival rates of the species. Furthermore, a yet unexplored potential for a better understanding of regionally differing survival rates lies in the widespread territory monitoring of raptors. If territory surveys in the field are combined with feather collections, the resulting information can be analysed with genetic markers and thereby also provide individualbased data - almost like a non-invasive mark-recapture study (Brune et al. 2019). Additionally, repeated visits to territories and nest sites during the breeding season and observations of unmarked animals can on their own already provide estimates of occupancy states and colonisation patterns for single territories - known to produce similar results compared to individual-based marking (Roth and Amrhein 2010; Oppel et al. 2016; Kéry and Royle 2020). This is a highly promising avenue to gain further demographic data on the Red Kite and other raptor species, which can be realised without much additional cost and effort - simply by an improved data collection. Currently, each single visit and the observations made at a specific territory, as well as the local sampling effort, are not explicit documented in many monitoring schemes. Rather, only the final outcome for each territory and its reproductive state are frequently submitted in different monitoring schemes. Based on such aggregated data it is however not possible to further analyse the results using occupancy-modelling. A major step forward in this direction is currently happening in Germany by implementing observer-friendly digital bird monitoring tools (Kunz et al. 2020), and the possibility to easily collect territory-based observations from single visits in field surveys will likely also improve in the near future.

\section{Which factors explain annual variation in Red Kite survival over the last decades?}

Based on the ring-recovery analyses in chapter 2 , it is now possible to study long-term variation in the survival rates of the Red Kite population. By correlating age-specific annual survival probabilities with potential drivers in the breeding and wintering ranges like food availability, 
weather/climate patterns, inter- and intraspecific competition or human land-use and mortality factors, we could increase our understanding how strongly different drivers shaped Red Kite survival over the long term. However, due to the migratory behaviour of the species and the variety of human and environmental drivers acting on survival, individual-based studies will most likely be needed in addition to such population-level analyses to adequately consider the full complexity of the species' life cycle.

\section{What are the causes of mortality in different age classes of the Red Kite?}

Until now the study of Red Kite mortality is mostly restricted to the opportunistic recovery of dead individuals in the field; a detailed investigation for all potential causes of death is usually not possible in such cases. This means that most likely certain causes of death go unnoticed or are at least underrepresented in the available data. Thus, for many recoveries the cause of death is simply unknown (chapter 2 ). The widespread use of satellite telemetry now allows to follow the fate of selected individuals in real-time - this means that also the cause of death can rapidly be investigated at the last transmitted location of an individual (Murgatroyd et al. 2019; Sergio et al. 2019b). Regardless of the method used to study survival, it is of vital importance to separate the cause of death between different age classes, because mortality for adult, breeding Red Kites has a much stronger impact on the population growth rate (Sergio et al. 2019a). As detailed in section

5.1, addressing frequent causes of mortality in pre-adult age classes is however also essential to improve the long-term viability of Red Kite populations (Sergio et al. 2020).

\section{How does age of first breeding vary in the Red Kite population according to density?}

The information currently available clearly suggests that age of first breeding shows substantial variation for the Red Kite according to population density and that this can act as an important buffering mechanism on the population level (chapter 4). With the increasing use of satellite telemetry, it also becomes possible to gather more specific data on age of first breeding for individuals tagged as nestlings and its relationship with local population density. Existing studies show short settlement distances to the place of birth by Red Kites (Nachtigall 2008; Pfeiffer 2009; Scherler 2020), which likely promotes a floating strategy for sexually mature individuals that have not yet acquired a breeding territory (Sergio et al. 2020). Using telemetry to collect data on natal dispersal (age and distance to origin at first reproduction), together with information on local breeding density (for source as well as settlement regions), will improve the understanding of this 
process and enables more accurate demographic models to aid the management of local populations.

\section{Is the proportion of Red Kites breeding near human settlements increasing over time?}

The Red Kite is clearly a species that can co-exist with human presence, or even benefit from it, as documented by historical as well as present observations on breeding and feeding ecology (Ortlieb 1989; Orros and Fellowes 2015; Bischofberger et al. 2019; Carter 2019; Katzenberger 2019; Cereghetti et al. 2019). The century-long persecution of predators also drove the Red Kite to near-extinction in the early $20^{\text {th }}$ century and this is a likely explanation for widespread avoidance-behaviour against humans in the Red Kite population, which then showed a substantial increase under declining persecution in the 1970s and 1980s (Aebischer 2009). With ceasing direct human persecution and increases in Red Kite population size, the species has already reclaimed formerly used breeding habitat near human settlements in Germany (Ortlieb 1992; Nicolai et al. 2017). It seems plausible that such a process of behavioural adaption to human presence starts slowly, with a few especially fearless individuals, and then intensifies and speeds up under beneficial foraging conditions and successful breeding attempts near humans. Such a non-linear process of refuge abandonment is increasingly recognised in various examples of European scavengers and apex predators (Martínez-Abraín et al. 2019; Martínez-Abraín et al. 2020) and may well also explain in part the recent changes in Red Kite population trends observed in Europe (BirdLife International 2020). The breeding distribution of the Red Kite, as well as breeding success and productivity, in relation to human influences therefore deserves more attention; comparing current data to field surveys from the 1970s/80s could potentially already highlight substantial behavioural changes in nest-site selection and habitat-specific breeding success.

\section{Do conditions from the past impact current Red Kite populations?}

The results from chapter 3 in this thesis strongly support what has already been recognized by previous research: the occurrence of the Red Kite in Germany can only partly be explained by current environmental factors; most likely the present distribution pattern is also affected by social, behavioural and historical aspects (Hothorn et al. 2011; Heuck et al. 2013). It would therefore be valuable to investigate if conditions from the past still affect current Red Kite populations via 'land-use legacies' (Foster et al. 2003; Perring et al. 2016). Relevant land-use change for the species could encompass a wide spectrum from agricultural cultivation, landscape complexity and livestock farming to pesticide-application, urbanisation or rural infrastructure 
development. Although the variety of potential influences can likely not fully be represented with satellite images, such remotely-sensed data provide a window into the past and can also help to explain present trends in biodiversity (Jung et al. 2020). 


\section{References}

Achtziger R, Stickroth H, Zieschank R (2004) Nachhaltigkeitsindikator für die Artenvielfalt - ein Indikator für den Zustand von Natur und Landschaft in Deutschland. Angew Landschaftsökologie 63:1-137

Aebischer A (2009) Der Rotmilan. Ein faszinierender Greifvogel. Haupt Verlag, Bern, Stuttgart, Wien

Aebischer A, Sergio F (2020) Red Kite. In: Keller V, Herrando S, Vorí̌̌ek P, et al. (eds) European Breeding Bird Atlas 2. Distribution, Abundance and Change. Lynx Edicions, Barcelona

Allouche O, Tsoar A, Kadmon R (2006) Assessing the accuracy of species distribution models: prevalence, kappa and the true skill statistic (TSS). J Appl Ecol 43:1223-1232. doi: 10.1111/j.1365-2664.2006.01214.x

Anderson DR, Burnham KP, White GC (1985) Problems in estimating age-specific survival rates from recovery data of birds ringed as young. J Anim Ecol 54:89-98. doi: 10.2307/4622

Anderson SC (2020) sdmTMB: Fit Spatio-temporal Species Distribution Models with "TMB." In: v. 0.0.4.9. https://github.com/pbs-assess/sdmTMB

Anderson SC, Ward EJ (2018) Black swans in space: modelling spatiotemporal processes with extremes. Ecology 100:1-9. doi: 10.1002/ecy.2403

Antor RJ, Margalida A, Frey H, et al (2007) First breeding age in captive and wild Bearded Vultures Gypaetus barbatus. Acta Ornithol 42:114-118. doi: 10.3161/068.042.0106

Badry A, Schenke D, Treu G, Krone O (2021) Linking landscape composition and biological factors with exposure levels of rodenticides and agrochemicals in avian apex predators from Germany. Environ Res 193:110602. doi: 10.1016/j.envres.2020.110602

Baillie S (2001) The contribution of ringing to the conservation and management of bird populations: A review. Ardea 89:167-184

Bairlein F (2020) "Verantwortungsart Rotmilan." In: Deutsche Wildtier Stiftung (ed) Schutz der Verantwortungsart Rotmilan - Ergebnisse des Verbundprojekts Rotmilan - Land zum Leben. Tagungsband Abschlussveranstaltung 22.10.2019 in Berlin. Hamburg, pp 29-33

Bairlein F, Dierschke J, Dierschke V, et al (2014) Atlas des Vogelzugs: Ringfunde deutscher Brut-und Gastvögel. Aula-Verlag

Balmori A (2019) Endangered bird mortality by gunshots: still a current problem. Biodivers Conserv 28:2555-2564. doi: 10.1007/s10531-019-01778-9

Barbosa AM, Brown JA, Jimenez-Valverde A, Real R (2016) modEvA: Model Evaluation and Analysis v. 1.3.2. https://cran.r-project.org/package=modEvA

Beitz H, Schmidt HH, Hörnicke E, Schmidt H (1991) Erste Ergebnisse der Analyse zur Anwendung von Pflanzenschutzmitteln und ihren ökologisch-chemischen und toxikologischen Auswirkungen in der ehemaligen DDR. Mitteilungen aus der Biol Bundesanstalt für Land- und Forstwirtschaft Berlin-Dahlem 274:1-123

Bellebaum J, Korner-Nievergelt F, Dürr T, Mammen U (2013) Wind turbine fatalities approach a level of concern in a raptor population. J Nat Conserv 21:394-400. doi: 10.1016/j.jnc.2013.06.001

Berny P, Gaillet J-R (2008) Acute poisoning of Red Kites (Milvus milvus) in France: Data from the Sagir Network. J Wildl Dis 44:417-426. doi: 10.7589/0090-3558-44.2.417 
Bezzel E (2010) Das Jahrtausend danach - Zukunft des Rotmilans (Milvus milvus) in der Kulturlandschaft. Vogel und Umwelt 18:5-17

BfN (2017) Agrar-Report 2017 - Bundesamt für Naturschutz. Bonn - Bad Godesberg

BfN (2008) Bundesamt für Naturschutz: Biogeografische Regionen und naturräumliche Haupteinheiten

Deutschlands. https://www.bfn.de/fileadmin/MDB/documents/themen/natura2000/Naturraeume_Deutschla nds.pdf

BGR (2019) Bundesanstalt für Geowissenschaften und Rohstoffe: Fachinformationssystem Bodenkunde. https://produktcenter.bgr.de

Bird JP, Martin R, Akçakaya HR, et al (2020) Generation lengths of the world's birds and their implications for extinction risk. Conserv Biol cobi.13486. doi: 10.1111/cobi.13486

BirdLife International (2019) Red Kite Milvus milvus. IUCN Red List Threat Species. doi: https://dx.doi.org/10.2305/IUCN.UK.2019-3.RLTS.T22695072A155600973.en

BirdLife International (2020) Red Kite (Milvus milvus) - reclassify from Near Threatened to Least Concern. In: BirdLife's Glob. Threat. Bird Forums https//globally-threatened-birdforums.birdlife.org/2020/03/red-kite-milvus-milvus-reclassify-from-near-threatened-to-leastconcern/. https://globally-threatened-bird-forums.birdlife.org/2020/03/red-kite-milvus-milvusreclassify-from-near-threatened-to-least-concern/

BirdLife International (2015) Species factsheet: Milvus milvus. http://datazone.birdlife.org/species/factsheet/red-kite-milvus-milvus. Accessed 1 Mar 2016

Bischofberger I, Kamrad MJ, Wasmund N, et al (2019) Werden junge Rotmilane Milvus milvus satt? Nahrungsmengen und Nahrungszusammensetzung in drei Regionen Deutschlands. Vogelwelt 139:87-99

Bivand R, Wong DWS (2018) Comparing implementations of global and local indicators of spatial association. TEST 27:716-748. doi: 10.1007/s11749-018-0599-x

Blanco G, Bautista LM (2020) Avian Scavengers as Bioindicators of Antibiotic Resistance Due to Livestock Farming Intensification. Int J Environ Res Public Health 17:3620. doi: 10.3390/ijerph17103620

Blank BF, Jacob J, Petri A, Esther A (2011) Topography and soil properties contribute to regional outbreak risk variability of common voles (Microtus arvalis). Wildl Res 38:541-550. doi: 10.1071/WR10192

Bonenfant C, Gaillard J, Coulson T, et al (2009) Empirical evidence of density-dependence in populations of large herbivores. Adv Ecol Res 41:313-357. doi: 10.1016/S0065-2504(09)00405$\mathrm{X}$

Borowik T, Jędrzejewska B (2018) Europe-wide consistency in density-dependence of red deer (Cervus elaphus) fertility. Mamm Biol 89:95-99. doi: 10.1016/j.mambio.2017.10.005

Brooks S, Gelman A (1998) Alternative methods for monitoring convergence of iterative simulations. J Comput Graph Stat 7:434-455

Brownie C, Anderson DR, Burnham KP, Robson DS (1985) Statistical inference from band recovery data. US Fish and Wildlife Service Resource Publication, 156

Brune J, Krüger O, Hippauf E, et al (2019) Eine nichtinvasive Methode für Populationsstudien beim Rotmilan Milvus milvus: Molekulargenetische Individualerkennung anhand von Mauserfedern. 
Vogelwelt 139:129-140

Burgas D, Byholm P, Parkkima T (2014) Raptors as surrogates of biodiversity along a landscape gradient. J Appl Ecol 51:786-794. doi: 10.1111/1365-2664.12229

Busch M, Katzenberger J, Trautmann S, et al (2020) Drivers of population change in common farmland birds in Germany. Bird Conserv Int 30:335-354. doi: 10.1017/S0959270919000480

Busch M, Trautmann S, Gerlach B (2017) Overlap between breeding season distribution and wind farm risks: a spatial approach. Vogelwelt 137:169-180

Cardiel I (2006) El milano real en España. II Censo Nacional (2004). SEO/BirdLife, Madrid

Cardiel I, Viñuela J (2009) The Red Kite Milvus milvus in Spain: distribution, recent population trends and current threats. Informationsd Naturschutz Niedersachsen 3:181-183

Carrete M, Donázar JA, Margalida A (2006) Density-dependent productivity depression in Pyrenean Bearded Vultures: Implications for conservation. Ecol Appl 16:1674-1682. doi: 10.1890/10510761(2006)016[1674:DPDIPB]2.0.CO;2

Carter I (2019) The Red Kite reintroduction: 30 years on. Br Birds 112:422-426

Carter I, Grice P (2000) Studies of re-established Red Kites in England. Br Birds 93:304-322

Ceccolini G, Cenerini A, Baini M, et al (2013) Reintroduzione del nibbio reale Milvus milvus in Toscana meridionale. In: Mezzavilla F, Scarton F (eds) Atti II Convegno Italiano Rapaci Diurni e Notturni. Associazione faunisti Veneti, pp 11-20

Cereghetti E, Scherler P, Fattebert J, Grüebler MU (2019) Quantification of anthropogenic food subsidies to an avian facultative scavenger in urban and rural habitats. Landsc Urban Plan 190:103606. doi: 10.1016/j.landurbplan.2019.103606

Chaudhary V, Oli MK (2020) A critical appraisal of population viability analysis. Conserv Biol 34:26-40. doi: $10.1111 /$ cobi.13414

Chollet J-Y, Razin M, Joncour G, et al (2015) VIGILANCE POISON: Illegal poisoning and lead intoxication are the main factors affecting avian scavenger survival in the Pyrenees (France). Ecotoxicol Environ Saf 118:71-82. doi: 10.1016/j.ecoenv.2015.04.003

Clark JS, Gelfand AE (2006) A future for models and data in environmental science. Trends Ecol Evol 21:375-380. doi: 10.1016/j.tree.2006.03.016

Clobert J, Lebreton JD, Marzolin G (1990) The estimation of local immature survival rate and of agespecific proportions of breeders in bird populations. In: Blondel J, Gosler A, Lebreton J, McCleery R (eds) Population Biology of Passerine Birds. Springer, Berlin, Heidelberg, pp 199-213

Coeurdassier M, Poirson C, Paul JP, et al (2012) The diet of migrant Red Kites Milvus milvus during a Water Vole Arvicola terrestris outbreak in eastern France and the associated risk of secondary poisoning by the rodenticide bromadiolone. Ibis 154:136-146. doi: 10.1111/j.1474919X.2011.01193.x

Cooper NW, Murphy MT, Redmond L, Dolan AC (2009) Density-dependent age at first reproduction in the eastern kingbird. Oikos 118:413-419. doi: 10.1111/j.1600-0706.2008.16997.x

Cox C (1991) Pesticides and Birds: From DDT to Today's Poisons. J Pestic Reform 11:2-6

Crespo-Luengo G, Hernández-Lambraño RE, Barbero-Bermejo I, Sánchez-Agudo JÁ (2020) Analysis of Spatio-Temporal Patterns of Red Kite Milvus milvus Electrocution. Ardeola 67:247. doi: 10.13157/arla.67.2.2020.ra2 
Croxall JP, Rothery P, Pickering SPC, Prince PA (1990) Reproductive performance, recruitment and survival of Wandering Albatrosses Diomedea exulans at Bird Island, South Georgia. J Anim Ecol 59:775. doi: 10.2307/4895

de la Bodega D, Cano C, Mínguez E (2020) El veneno en España. Evolución del envenenamiento de fauna silvestre (1992-2017). SEO/BirdLife, WWF, Madrid

Destatis (2019) Statistische Ämter des Bundes und der Länder: Atlas Agrarstatistik. https://www.atlasagrarstatistik.nrw.de/

Deutsche Wildtier Stiftung (ed) (2020) Schutz der Verantwortungsart Rotmilan - Ergebnisse des Verbundprojekts Rotmilan - Land zum Leben. Tagungsband Abschlussveranstaltung 22.10.2019 Berlin

Dormann CF, McPherson J, Araújo M, et al (2007) Methods to account for spatial autocorrelation in the analysis of species distributional data: a review. Ecography (Cop) 30:609-628. doi: 10.1111/j.2007.0906-7590.05171.x

Dürr T (2009) Zur Gefährdung des Rotmilans Milvus milvus durch Windenergieanlagen in Deutschland. Informationsd Naturschutz Niedersachsen 29:185-191

DWD (2019) Deutscher Wetterdienst: CDC-Climate Date Center. ftp://ftp-cdc.dwd.de/pub/CDC/

Eberhardt LL (2002) A paradigm for population analysis of long-lived vertebrates. Ecology 83:28412854. doi: 10.1890/0012-9658(2002)083[2841:APFPAO]2.0.CO;2

Elliott KH, Elliott JE, Wilson LK, et al (2011) Density-dependence in the survival and reproduction of bald eagles: Linkages to chum salmon. J Wildl Manage 75:1688-1699. doi: 10.1002/jwmg.233

Ergon T, Ergon R, Begon M, et al (2011) Delayed density-dependent onset of spring reproduction in a fluctuating population of field voles. Oikos 120:934-940. doi: 10.1111/j.1600-0706.2010.18983.x

Evans IM, Summers RW, O'Toole L, et al (1999) Evaluating the success of translocating Red Kites Milvus milvus to the UK. Bird Study 46:129-144. doi: 10.1080/00063659909461125

Fay R, Barbraud C, Delord K, Weimerskirch H (2017) Contrasting effects of climate and population density over time and life stages in a long-lived seabird. Funct Ecol 31:1275-1284. doi: $10.1111 / 1365-2435.12831$

Ferrer M, Otalora F, García-Ruiz JM (2004) Density-dependent age of first reproduction as a buffer affecting persistence of small populations. Ecol Appl 14:616-624. doi: 10.1890/02-5361

Ferrer M, Penteriani V, Balbontín J, Pandolfi M (2003) The proportion of immature breeders as a reliable early warning signal of population decline: evidence from the Spanish imperial eagle in Doñana. Biol Conserv 114:463-466. doi: 10.1016/S0006-3207(03)00085-5

Fielding AH, Bell JF (1997) A review of methods for the assessment of prediction errors in conservation presence/absence models. Environ Conserv 24:38-49

Foken W (2000) Beringungs- und Fundzahlen der Vogelwarte Helgoland aus dem Zeitraum 1909-1998. Inst für Vogelforsch "Vogelwarte Helgoland" Jahresbericht 4:23-26

Foster D, Swanson F, Aber J, et al (2003) The importance of land-use legacies to ecology and conservation. Bioscience 53:77-88. doi: 10.1641/0006-3568(2003)053[0077:TIOLUL]2.0.CO;2

Furness RW (2015) Density dependence in seabirds: Great Skuas Stercorarius skua start to breed at a younger age when conditions are better. Ringing Migr 30:43-50. doi: 10.1080/03078698.2015.1059631 
Gamelon M, Grøtan V, Engen S, et al (2016) Density dependence in an age-structured population of great tits: Identifying the critical age classes. Ecology 97:2479-2490. doi: 10.1002/ecy.1442

Ganz K, Jenni L, Madry MM, et al (2018) Acute and Chronic Lead Exposure in Four Avian Scavenger Species in Switzerland. Arch Environ Contam Toxicol. doi: 10.1007/s00244-018-0561-7

Gedeon K, Grüneberg C, Mitschke A, et al (2014) Atlas Deutscher Brutvogelarten. Atlas of German breeding birds. Stiftung Vogelmonitoring Deutschland \& Dachverband Deutscher Avifaunisten, Münster

George K (1995) Neue Bedingungen für die Vogelwelt der Agrarlandschaft in Ostdeutschland nach der Wiedervereinigung. Ornithol Jahresbericht Museum Heineanum 13:1-25

Gerlach B, Dröschmeister R, Langgemach T, et al (2019) Vögel in Deutschland - Übersichten zur Bestandssituation. DDA, BfN, LAG VSW, Münster

Gilroy JJ, Virzi T, Boulton RL, Lockwood JL (2012) A new approach to the "apparent survival" problem: estimating true survival rates from mark-recapture studies. Ecology 93:1509-1516. doi: 10.1890/12-0124.1

Gottschalk E, Wasmund N, Sauer B, Bayoh R (2015) Nahrungsmangel beim Rotmilan Milvus milvus? Was können zusätzliche Mahdflächen zur Nahrungsverfügbarkeit beitragen? Abhandlungen und Berichte aus dem Museum Heineanum 10:17-32

Grün G, Sadek H, Clausing P (1982) Bewertung der akuten Toxizität von Pflanzenschutzmitteln für Vögel in Beziehung zu möglichen Nebenwirkungen im Freiland. Nachrichtenblatt für den Pflanzenschutzd der DDR 36:127-130

Grüneberg C, Karthäuser J (2019) Verbreitung und Bestand des Rotmilans Milvus milvus in Deutschland - Ergebnisse der bundesweiten Kartierung 2010-2014. Vogelwelt 139:101-116

Grünkorn T, Blew J, Coppack T, et al (2016) Ermittlung der Kollisionsraten von (Greif)Vögeln und Schaffung planungsbezogener Grundlagen für die Prognose und Bewertung des Kollisionsrisikos durch Windenergieanlagen (PROGRESS). Schlussbericht zum durch das Bundesministerium für Wirtschaft und Energie geförderten Verbundvorhaben

Hallmann CA, Sorg M, Jongejans E, et al (2017) More than 75 percent decline over 27 years in total flying insect biomass in protected areas. PLoS One 12:e0185809. doi: 10.1371/journal.pone.0185809

Heinisch E, Kettrup A, Wenzel-Klein S (1994) Schadstoffatlas Osteuropa: Ökologisch-chemische und ökotoxikologische Fallstudien über organische Spurenstoffe und Schwermetalle in OstMitteleuropa. ecomed, Landsberg am Lech

Heuck C, Brandl R, Albrecht J, Gottschalk TK (2013) The potential distribution of the Red Kite in Germany. J Ornithol 154:911-921. doi: 10.1007/s10336-013-0955-2

Heuck C, Herrmann C, Levers C, et al (2019) Wind turbines in high quality habitat cause disproportionate increases in collision mortality of the white-tailed eagle. Biol Conserv 236:4451. doi: 10.1016/j.biocon.2019.05.018

Hirschfeld A (2011) Distribution and possible impacts of illegal persecution on the Red Kite (Milvus milvus) population in Germany. Berichte zum Vogelschutz 47/48:183-191

Hirschfeld A, Gevers D, Heyd A (2017) Illegale Greifvogelverfolgung in Deutschland 2005 - 2015: Verbreitung, Ausmaß, betroffene Arten und Strafverfolgung. Berichte zum Vogelschutz 53/54:43-62 
Hoffmann M, Gelpke C, Böhmer C, et al (2017) Zum Bruterfolg des Rotmilans (Milvus milvus) in Hessen. Vogel und Umwelt 22:25-32

Hothorn T, Müller J, Schröder B, et al (2011) Decomposing environmental, spatial, and spatiotemporal components of species distributions. Ecol Monogr 81:329-347. doi: 10.1890/10-0602.1

Hötker H, Thomsen K-M, Köster H (2005) Auswirkungen regenerativer Energiegewinnung auf die biologische Vielfalt am Beispiel der Vögel und der Fledermäuse. BfN-Skripten 142:1-83

Hoy SR, Petty SJ, Millon A, et al (2017) Density-dependent increase in superpredation linked to food limitation in a recovering population of northern goshawks Accipiter gentilis. J Avian Biol 48:1205-1215. doi: 10.1111/jav.01387

Hunt WG (1998) Raptor floaters at Moffat's equilibrium. Oikos 82:191-197. doi: 10.2307/3546929

IÖR (2019) Leibniz-Institut für ökologische Raumentwicklung: Monitor der Siedlungs- und Freiraumentwicklung. In: (C) GeoBasis-DE/BKG. www.ioer-monitor.de

Isbell F, Reich PB, Tilman D, et al (2013) Nutrient enrichment, biodiversity loss, and consequent declines in ecosystem productivity. Proc Natl Acad Sci 110:11911-11916. doi: 10.1073/pnas.1310880110

Jacob J, Broll A, Esther A (2018) Rückstände von als Rodentizid ausgebrachten Antikoagulanzien in wildlebenden Biota. Umweltbundesamt Texte 04/2018

Jacob J, Buckle A (2017) Use of Anticoagulant Rodenticides in Different Applications Around the World. In: van den Brink N, Elliott J, Shore R, Rattner B (eds) Anticoagulant Rodenticides and Wildlife. Springer, Cham, pp 11-43

Joest R (2018) Wie wirksam sind Vertragsnaturschutzmaßnahmen für Feldvögel? Untersuchungen an Feldlerchenfenstern, extensivierten Getreideäckern und Ackerbrachen in der Hellwegbörde (NRW). Vogelwelt 138:109-121

Jorgenson JT, Festa-Bianchet M, Lucherini M, Wishart WD (1993) Effects of body size, population density, and maternal characteristics on age at first reproduction in bighorn ewes. Can J Zool 71:2509-2517. doi: 10.1139/z93-344

Jung M, Scharlemann JPW, Rowhani P (2020) Landscape-wide changes in land use and land cover correlate with, but rarely explain local biodiversity change. Landsc Ecol 35:2255-2273. doi: 10.1007/s10980-020-01109-2

Karthäuser J, Katzenberger J, Sudfeldt C (2019a) Evaluation von Maßnahmen zur Verbesserung des Nahrungsangebotes für den Rotmilan Milvus milvus in intensiv genutzten Agrarlandschaften. Vogelwelt 139:71-86

Karthäuser J, König C, Wahl J (2019b) Wie viele Rotmilane überwintern in Deutschland? Der Falke $66: 18-19$

Katzenberger J (2019) Verbreitungsbestimmende Faktoren und Habitateignung für den Rotmilan Milvus milvus in Deutschland. Vogelwelt 139:117-128

Katzenberger J, Gottschalk E (2019) Abhängigkeit des Erstbrutalters von der Populationsdichte: Eine Integration in Populationsmodelle für den Rotmilan Milvus milvus. Vogelwelt 139:171-180

Katzenberger J, Gottschalk E, Balkenhol N, Waltert M (2019a) Long-term decline of juvenile survival in German Red Kites. J Ornithol 160:337-349. doi: 10.1007/s10336-018-1619-z

Katzenberger J, Karthäuser J, Serfling J (2019b) Greifvogelschutz und Ökologie: Rotmilan-Forschung in 


\section{Deutschland. Der Falke 66:28-33}

Kellner K (2016) jagsUI: A Wrapper Around "rjags" to Streamline "JAGS" Analyses. https://cran.rproject.org/package=jagsUI

Kéry M, Royle JA (2020) Modeling Species Distribution and Range Dynamics, and Population Dynamics Using Dynamic Occupancy Models. In: Applied Hierarchical Modeling in Ecology: Analysis of Distribution, Abundance and Species Richness in R and BUGS. Elsevier, pp 207-297

Kéry M, Schaub M (2012) Bayesian Population Analysis using WinBUGS. Academic Press

Knott J, Newbery P, Barov B (2009) Action plan for the red kite Milvus milvus in the European Union. Brussels

Kolbe M, Nicolai B, Winkelmann R, Steinborn E (2019) Totfundstatistik und Verlustursachen beim Rotmilan Milvus milvus in Sachsen-Anhalt. Vogelwelt 139:141-153

Krüger O (2005) Age at first breeding and fitness in goshawk Accipiter gentilis. J Anim Ecol 74:266273. doi: 10.1111/j.1365-2656.2005.00920.x

Kunz F, Dröschmeister R, Trautmann S, Wahl J (2020) Monitoring Häufiger Brutvögel: Erfolgreicher Start ins digitale Zeitalter. Der Falke 67:31-35

Lacy R, Pollak J (2018) VORTEX: A Stochastic Simulation of the Extinction Process. In: Version 10.3.650. http://www.vortex10.org/

Langgemach T, Dürr T (2018) Informationen über Einflüsse der Windenergienutzung auf Vögel. In: Landesamt für Umwelt, Gesundh. und Verbraucherschutz Brand. Staatl. Vogelschutzwarte. https://Ifu.brandenburg.de/cms/media.php/lbm1.a.3310.de/vsw_dokwind_voegel.pdf

Langgemach T, Krone O, Sömmer P, et al (2010) Verlustursachen bei Rotmilan (Milvus milvus) und Schwarzmilan (Milvus migrans) im Land Brandenburg. Vogel und Umwelt 18:85-101

Langvatn R, Albon SD, Burkey T, Clutton-Brock TH (1996) Climate, plant phenology and variation in age of first reproduction in a temperate herbivore. J Anim Ecol 65:653. doi: 10.2307/5744

Latimer AM, Banerjee S, Sang H, et al (2009) Hierarchical models facilitate spatial analysis of large data sets: A case study on invasive plant species in the northeastern United States. Ecol Lett 12:144154. doi: $10.1111 / \mathrm{j} .1461-0248.2008 .01270 . x$

Lee AM, Reid JM, Beissinger SR (2017) Modelling effects of nonbreeders on population growth estimates. J Anim Ecol 86:75-87. doi: 10.1111/1365-2656.12592

López-Perea JJ, Camarero PR, Sánchez-Barbudo IS, Mateo R (2019) Urbanization and cattle density are determinants in the exposure to anticoagulant rodenticides of non-target wildlife. Environ Pollut 244:801-808. doi: 10.1016/j.envpol.2018.10.101

Lourenço R, del Mar Delgado M, Campioni L, et al (2018) Why do top predators engage in superpredation? From an empirical scenario to a theoretical framework. Oikos 127:1563-1574. doi: 10.1111/oik.05118

Luque-Larena JJ, Mougeot F, Arroyo B, Lambin X (2018) “ Got rats ?" Global environmental costs of thirst for milk include acute biodiversity impacts linked to dairy feed production. Glob Chang Biol 1-3. doi: $10.1111 /$ gcb.14170

Mammen U (2016) Anwendungsmöglichkeiten einer Datenbank zur Langzeitdynamik von Greifvögeln und Eulen. Beiträge zur Jagd- und Wildforsch 41:203-210

Mammen U, Nicolai B, Böhner J, et al (2014) Artenhilfsprogramm Rotmilan des Landes Sachsen- 
Anhalt. Berichte des Landesamtes für Umweltschutz Sachsen-Anhalt 5:1-163

Mammen U, Stark I, Stubbe M (2017) Reproduktionsparameter der Greifvögel und Eulen Deutschlands von 1988 bis 2012. In: Populationsökologie Greifvogel- und Eulenarten 7. pp 9-28

Martínez-Abraín A, Jiménez J, Jiménez I, et al (2020) Ecological consequences of human depopulation of rural areas on wildlife: A unifying perspective. Biol Conserv 252:108860. doi: 10.1016/j.biocon.2020.108860

Martínez-Abraín A, Jiménez J, Oro D (2019) Pax Romana: 'refuge abandonment' and spread of fearless behavior in a reconciling world. Anim Conserv 22:3-13. doi: 10.1111/acv.12429

Mateo-Tomás P, Olea PP (2011) The importance of social information in breeding site selection increases with population size in the Eurasian Griffon Vulture Gyps fulvus. Ibis 153:832-845. doi: 10.1111/j.1474-919X.2011.01154.x

Mateo-Tomás P, Olea PP, Mínguez E, et al (2020) Direct evidence of poison-driven widespread population decline in a wild vertebrate. Proc Natl Acad Sci 201922355 . doi: 10.1073/pnas.1922355117

Melero Y, Robinson E, Lambin X (2015) Density- and age-dependent reproduction partially compensates culling efforts of invasive non-native American mink. Biol Invasions 17:2645-2657. doi: 10.1007/s10530-015-0902-7

Meyer CB, Meyer JS, Francisco AB, et al (2016) Can ingestion of lead shot and poisons change population trends of three European birds: Grey partridge, common buzzard, and red kite? PLoS One 11:1-28. doi: 10.1371/journal.pone.0147189

Millsap BA (2018) Demography and metapopulation dynamics of an urban Cooper's Hawk subpopulation. Condor 120:63-80. doi: 10.1650/condor-17-124.1

Millsap BA, Madden K, Murphy RK, et al (2019) Demographic consequences of sexual differences in age at first breeding in Cooper's Hawks (Accipiter cooperii). Auk 136:1-20. doi: 10.1093/auk/ukz032

Molenaar FM, Jaffe JE, Carter I, et al (2017) Poisoning of reintroduced red kites (Milvus milvus) in England. Eur J Wildl Res 63:94. doi: 10.1007/s10344-017-1152-z

Montaz J, Jacquot M, Coeurdassier M (2014) Scavenging of rodent carcasses following simulated mortality due to field applications of anticoagulant rodenticide. Ecotoxicology 23:1671-1680. doi: 10.1007/s10646-014-1306-7

Monzón JD, Friedenberg NA (2018) Metrics of population status for long-lived territorial birds: A case study of golden eagle demography. Biol Conserv 220:280-289. doi: 10.1016/j.biocon.2018.02.023

Morandini V, Dietz S, Newton I, Ferrer M (2019) The role of age of first breeding in modeling raptor reintroductions. Ecol Evol 9:2978-2985. doi: 10.1002/ece3.4979

Murgatroyd M, Redpath SM, Murphy SG, et al (2019) Patterns of satellite tagged hen harrier disappearances suggest widespread illegal killing on British grouse moors. Nat Commun 10:1094. doi: 10.1038/s41467-019-09044-w

Murgatroyd M, Roos S, Evans R, et al (2018) Sex-specific patterns of reproductive senescence in a longlived reintroduced raptor. J Anim Ecol 87:1587-1599. doi: 10.1111/1365-2656.12880

Nachtigall W (2008) Der Rotmilan (Milvus milvus, L. 1758) in Sachsen und Südbrandenburg Untersuchungen zu Verbreitung und Ökologie. Dissertation, Martin-Luther-Universität Halle- 


\section{Wittenberg}

Nachtigall W, Stubbe M, Herrmann S (2010) Aktionsraum und Habitatnutzung des Rotmilans (Milvus milvus) während der Brutzeit-eine telemetrische Studie im Nordharzvorland. Vogel und Umwelt 18:25-61. doi: 10.1046/j.1439-0361.2003.03005.x

Nagel H, Nicolai B, Mammen U, et al (2019) Verantwortungsart Rotmilan Ermittlung von Dichtezentren des Greifvogels in Sachsen-Anhalt. Naturschutz und Landschaftsplan 51:14-19

Neubert MG, Caswell H (2000) Density-dependent vital rates and their population dynamic consequences. J Math Biol 41:103-121. doi: 10.1007/s002850000031

Newton I (2013) Pesticides and Birds. Br Birds 106:189-205

Newton I (1988) Population regulation in peregrines: An overview. In: Cade TJ, Enderson JH, Thelander CG, White CM (eds) Peregrine Falcon Populations: Their Management and Recovery. The Peregrine Fund, Inc., Boise, ID, pp 761-770

Newton I, Davis PE, Davis JE (1989) Age of first breeding, dispersal and survival of Red Kites Milvus milvus in Wales. Ibis 131:16-21. doi: 10.1111/j.1474-919X.1989.tb02738.x

Newton I, Mcgrady MJ, Oli MK (2016) A review of survival estimates for raptors and owls. Ibis 158:227248. doi: 10.1111/ibi.12355

Nicolai B, König H (1990) Der Bestand des Rotmilans in der DDR - Ergebnisse der Brutvogelkartierung. Abhandlungen und Berichte aus dem Museum Heineanum 1:1-12

Nicolai B, Kostrzewa A (2001) Rotmilan (Milvus milvus). In: Kostrzewa A, Speer G (eds) Greifvögel in Deutschland - Bestand, Situation, Schutz, 2. Auflage. Wiebelsheim, pp 20-24

Nicolai B, Mammen U, Kolbe M (2017) Long-term changes in population and habitat selection of Red Kite Milvus milvus of the region with the highest population density. Vogelwelt 137:194-197

Nicoll MAC, Jones CG, Norris K (2003) Declining survival rates in a reintroduced population of the Mauritius kestrel: Evidence for non-linear density dependence and environmental stochasticity. J Anim Ecol 72:917-926. doi: 10.1046/j.1365-2656.2003.00768.x

Ntampakis D, Carter I (2005) Red Kites and rodenticides - A feeding experiment. Br Birds 98:411-416

Oli MK, Dobson FS (1999) Population cycles in small mammals: The role of age at sexual maturity. Oikos 86:557. doi: $10.2307 / 3546660$

Oppel S, Dobrev V, Arkumarev V, et al (2016) Assessing the effectiveness of intensive conservation actions: Does guarding and feeding increase productivity and survival of Egyptian Vultures in the Balkans? Biol Conserv 198:157-164. doi: 10.1016/j.biocon.2016.04.002

Orros ME, Fellowes MDE (2015) Widespread supplementary feeding in domestic gardens explains the return of reintroduced Red Kites Milvus milvus to an urban area. Ibis 157:230-238. doi: 10.1111/ibi.12237

Ortega E, Mañosa S, Margalida A, et al (2009) A demographic description of the recovery of the Vulnerable Spanish imperial eagle Aquila adalberti. Oryx 43:113-121. doi: $10.1017 /$ S0030605307991048

Ortlieb R (1989) Der Rotmilan, 3rd edn. Neue Brehm-Bücherei, Wittenberg

Ortlieb R (1992) Rotmilanbruten in der Nähe menschlicher Siedlungen. Der Falke 39:162-164

Payo-Payo A, Genovart M, Bertolero A, et al (2016) Consecutive cohort effects driven by density- 
dependence and climate influence early-life survival in a long-lived bird. Proc R Soc B Biol Sci 283:20153042. doi: 10.1098/rspb.2015.3042

Pe'er G, Dicks L V., Visconti P, et al (2014) EU agricultural reform fails on biodiversity. Science (80- ) 344:1090-1092. doi: 10.1126/science.1253425

Pe'er G, Matsinos YG, Johst K, et al (2013) A protocol for better design, application, and communication of population viability analyses. Conserv Biol 27:644-656. doi: 10.1111/cobi.12076

PECBMS (2020) European wild bird indicators, 2020 update. https://pecbms.info

Penteriani V, Ferrer M, Delgado MM (2011) Floater strategies and dynamics in birds, and their importance in conservation biology: Towards an understanding of nonbreeders in avian populations. Anim Conserv 14:233-241. doi: 10.1111/j.1469-1795.2010.00433.x

Penteriani V, Otalora F, Ferrer M (2006) Floater dynamics can explain positive patterns of densitydependent fecundity in animal populations. Am Nat 168:697-703. doi: 10.1086/507995

Perring MP, De Frenne P, Baeten L, et al (2016) Global environmental change effects on ecosystems: the importance of land-use legacies. Glob Chang Biol 22:1361-1371. doi: 10.1111/gcb.13146

Pfeiffer T (2009) Untersuchungen zur Altersstruktur von Brutvögeln beim Rotmilan Milvus milvus. In: Populationsökologie Greifvogel- und Eulenarten 6. pp 197-210

Pfeiffer T (2000) Über den Ernährungszustand juveniler Rotmilane (Milvus milvus) in der Umgebung von Weimar und daraus abzuleitende Schutzvorschläge. Landschaftspfl und Naturschutz Thüringen 37:1-10

Pfeiffer T, Meyburg BU (2009) Satellitentelemetrische Untersuchungen zum Zug- und Überwinterungsverhalten Thüringischer Rotmilane Milvus milvus. Vogelwarte 47:171-187

Piper WH, Grear J, Hoover B, et al (2020) Plunging floater survival causes cryptic population decline in the Common Loon. Condor 122:1-10. doi: 10.1093/condor/duaa044

Plard F, Fay R, Kéry $M$, et al (2019) Integrated population models: powerful methods to embed individual processes in population dynamics models. Ecology 100:e02715. doi: 10.1002/ecy.2715

Plummer M (2003) JAGS: A program for analysis of Bayesian graphical models using Gibbs sampling. Proc 3rd Int Work Distrib Stat Comput (DSC 2003) 20-22. doi: 10.1.1.13.3406

Potiek A, Krüger O (2016) Modellierung der Auswirkungen der Mortalität auf Populationsebene. In: Grünkorn T, Blew J, Coppack T, et al. (eds) Ermittlung der Kollisionsraten von (Greif)Vögeln und Schaffung planungsbezogener Grundlagen für die Prognose und Bewertung des Kollisionsrisikos durch Windenergieanlagen (PROGRESS). pp 187-215

Pradel R, Johnson AR, Viallefont A, et al (1997) Local recruitment in the Greater Flamingo: A new approach using capture-mark-recapture data. Ecology 78:1431-1445. doi: 10.1890/00129658(1997)078[1431:LRITGF]2.0.CO;2

QGIS Development Team (2019) QGIS Geographic Information System. http://qgis.osgeo.org

R Core Team (2018) R: A language and environment for statistical computing. R Foundation for Statistical Computing, Vienna, Austria

Reed JM, Mills LS, Dunning Jr. JB, et al (2002) Emerging issues in population viability analysis. Conserv Biol 16:7-19

Riedel B, Riedel M, Wieland H, Grün G (1988) Vogeltoxikologische Bewertung des Einsatzes von 
Delicia-Chlorphacinon-Ködern in landwirtschaftlichen Kulturen. Nachrichtenblatt für den Pflanzenschutzd der DDR 42:48-51

Robin X, Turck N, Hainard A, et al (2011) pROC: an open-source package for R and S+ to analyze and compare ROC curves. BMC Bioinformatics 12:77. doi: 10.1186/1471-2105-12-77

Roth T, Amrhein V (2010) Estimating individual survival using territory occupancy data on unmarked animals. J Appl Ecol 47:386-392. doi: 10.1111/j.1365-2664.2010.01786.x

Roth T, Weber D (2007) Top predators as indicators for species richness? Prey species are just as useful. J Appl Ecol 45:987-991. doi: 10.1111/j.1365-2664.2007.01435.x

Sansom A, Etheridge B, Smart J, Roos S (2016) Population modelling of North Scotland red kites in relation to the cumulative impacts of wildlife crime and wind farm mortality. Scottish Nat Herit Comm Rep No 904

Sanz-Aguilar A, De Pablo F, Donázar JA (2015) Age-dependent survival of island vs. mainland populations of two avian scavengers: delving into migration costs. Oecologia 179:405-414. doi: $10.1007 / \mathrm{s} 00442-015-3355-x$

Schaub M (2012) Spatial distribution of wind turbines is crucial for the survival of red kite populations. Biol Conserv 155:111-118. doi: 10.1016/j.biocon.2012.06.021

Schaub M, Abadi F (2011) Integrated population models: a novel analysis framework for deeper insights into population dynamics. J Ornithol 152:227-237. doi: 10.1007/s10336-010-0632-7

Schaub M, Pradel R (2004) Assessing the relative importance of different sources of mortality from recoveries of marked animals. Ecology 85:930-938

Scherler P (2020) Drivers of Departure and Prospecting in Dispersing Juvenile Red Kites (Milvus milvus). Dissertation, Universtiy of Zürich

Schielzeth H (2010) Simple means to improve the interpretability of regression coefficients. Methods Ecol Evol 1:103-113. doi: 10.1111/j.2041-210X.2010.00012.x

Schmidt K (2003) Ergebnisse der Meldungen für Pflanzenschutzmittel und Wirkstoffe nach $\$ 19$ des Pflanzenschutzgesetzes für die Jahre 1999, 2000 und 2001 im Vergleich zu 1998. Nachrichtenblatt des Dtsch Pflanzenschutzdienstes 55:121-133

Schönfeld M (1984) Migration, Sterblichkeit, Lebenserwartung und Geschlechtsreife mitteleuropäischer Rotmilane, Milvus milvus (L.), im Vergleich zum Schwarzmilan, Milvus migrans (Boddaert). Hercynia 3:241-257

Sellmann J (1991) Prognose des Auftretes der Feldmaus Microtus arvalis (Pallas, 1779). In: Populationsökologie von Kleinsäugerarten Wiss. Beitr. Univ. Halle 1990/34. pp 183-196

Senzaki M, Yamaura Y, Nakamura F (2015) The usefulness of top predators as biodiversity surrogates indicated by the relationship between the reproductive outputs of raptors and other bird species. Biol Conserv. doi: 10.1016/j.biocon.2015.07.027

Sergio F, Blas J, Hiraldo F (2009) Predictors of floater status in a long-lived bird: a cross-sectional and longitudinal test of hypotheses. J Anim Ecol 78:109-118. doi: 10.1111/j.1365-2656.2008.01484.x

Sergio F, Caro T, Brown D, et al (2008) Top predators as conservation tools: Ecological rationale, assumptions, and efficacy. Annu Rev Ecol Evol Syst 39:1-19. doi: 10.1146/annurev.ecolsys.39.110707.173545

Sergio F, Newton I, Marchesi L, Pedrini P (2006) Ecologically justified charisma: Preservation of top 
predators delivers biodiversity conservation. J Appl Ecol 43:1049-1055. doi: 10.1111/j.13652664.2006.01218.x

Sergio F, Tanferna A, Chicano J, et al (2019a) Protected areas under pressure: decline, redistribution, local eradication and projected extinction of a threatened predator in Doñana National Park. Endanger Species Res 38:189-204. doi: 10.3354/esr00946

Sergio F, Tavecchia G, Blas J, et al (2020) Demographic modeling to fine-tune conservation targets: importance of pre-adults for the decline of an endangered raptor. Ecol Appl DOI: 10.1002/eap.2266. doi: 10.1002/eap.2266

Sergio F, Tavecchia G, Tanferna A, et al (2019b) When and where mortality occurs throughout the annual cycle changes with age in a migratory bird: individual vs population implications. Sci Rep 9:17352. doi: 10.1038/s41598-019-54026-z

Smart J, Amar A, Sim IMW, et al (2010) Illegal killing slows population recovery of a re-introduced raptor of high conservation concern - The red kite Milvus milvus. Biol Conserv 143:1278-1286. doi: 10.1016/j.biocon.2010.03.002

Somodi I, Lepesi N, Botta-Dukát Z (2017) Prevalence dependence in model goodness measures with special emphasis on true skill statistics. Ecol Evol 7:863-872. doi: 10.1002/ece3.2654

Stearns S (1992) The Evolution of Life Histories. Oxford University Press, Oxford

Stubbe M (1982) Brutdichte und Altersstruktur einer Rotmilan-Population - Milvus milvus (L. 1758) im nördlichen Harzvorland der DDR im Vergleich zum Mäusebussard Buteo buteo (L. 1758). Arch für Naturschutz und Landschaftsforsch 22:205-214

Sumasgutner P, Koeslag A, Amar A (2019) Senescence in the city: exploring ageing patterns of a longlived raptor across an urban gradient. J Avian Biol 50:jav.02247. doi: 10.1111/jav.02247

Tanferna A, López-Jiménez L, Blas J, et al (2013) Habitat selection by Black kite breeders and floaters: Implications for conservation management of raptor floaters. Biol Conserv 160:1-9. doi: 10.1016/j.biocon.2012.12.031

Tavecchia G, Adrover J, Navarro AM, Pradel R (2012) Modelling mortality causes in longitudinal data in the presence of tag loss: Application to raptor poisoning and electrocution. J Appl Ecol 49:297305. doi: 10.1111/j.1365-2664.2011.02074.x

Tavecchia G, Pradel R, Genovart M, Oro D (2007) Density-dependent parameters and demographic equilibrium in open populations. Oikos 116:1481-1492. doi: 10.1111/j.0030-1299.2007.15791.x

Tenan S, Adrover J, Muñoz Navarro A, et al (2012) Demographic consequences of poison-related mortality in a threatened bird of prey. PLoS One 7:1-11. doi: 10.1371/journal.pone.0049187

Trites AW, York AE (1993) Unexpected changes in reproductive rates and mean age at first birth during the decline of the Pribilof northern fur seal (Callorhinus ursinus). Can J Fish Aquat Sci 50:858864. doi: $10.1139 / f 93-098$

Van De Pol M, Bruinzeel LW, Heg D, et al (2006) A silver spoon for a golden future: Long-term effects of natal origin on fitness prospects of oystercatchers (Haematopus ostralegus). J Anim Ecol 75:616-626. doi: 10.1111/j.1365-2656.2006.01079.x

Viechtbauer W (2010) Conducting meta-analyses in R with the metafor package. J Stat Softw 36:1-48

Viñuela J, Martí R, Ruiz. A (1999) El milano real en España. SEO/BirdLife, Madrid

Wallmann J, Bender A, Bode C, et al (2017) Abgabemengenerfassung antimikrobiell wirksamer Stoffe 
in Deutschland 2016. Dtsch Tierärzteblatt 65:1650-1659

Walz J (2014) Bemerkenswerte Bestandszunahme von Rot- und Schwarzmilan (Milvus milvus, M. migrans) in den Oberen Gäuen westlich Böblingen. Ornithol Jahreshefte für Baden-württemb 30:19-27

Walz J (2005) Rot- und Schwarzmilan. Flexible Jäger mit Hang zur Geselligkeit. Aula-Verlag, Wiebelsheim

Wayland M, Wilson LK, Elliott JE, et al (2003) Mortality, morbidity, and lead poisoning of eagles in western Canada, 1986-1998. J Raptor Res 37:8-18

Wellmann L (2013) Verbreitung, Bestand und Gefährdungssituation des Rotmilans Milvus milvus in Niedersachsen und Bremen 2008-2012. Vogelkundliche Berichte aus Niedersachsen 43:209-240

Wenz K, Ziebarth N (2017) Düngerüberschüsse aus der Landwirtschaft. In: Der kritische Agrarbericht 2017. ABL Verlag, Hamm, pp 199-203

Wieland H, Schellenberg G (1984) Empfehlungen zur Überwachung und Bekämpfung der Feldmaus (Microtus arvalis Pall.) in Feldkulturen. Nachrichtenblatt für den Pflanzenschutzd der DDR 38:254-256 


\section{Declaration}

I am the first author of the manuscripts included as chapter two, three and four of this thesis in which I took part in all aspects of study design and statistical analysis and also wrote the majority of the manuscripts.

I, Jakob Katzenberger, hereby declare that I am the author of this dissertation entitled 'Habitat use and population viability of the Red Kite (Milvus milvus) in Germany'. All references and data sources that were used in this dissertation have been appropriately acknowledged. Furthermore, I declare that this work has not been submitted elsewhere in any form as part of another dissertation procedure.

Göttingen, 03.02.2021

(Jakob Katzenberger) 